\title{
A Direct Steam Heat Option for Hydrothermal Treatment of Municipal Solid Waste
}

C.B. Thorsness

April 12, 1995

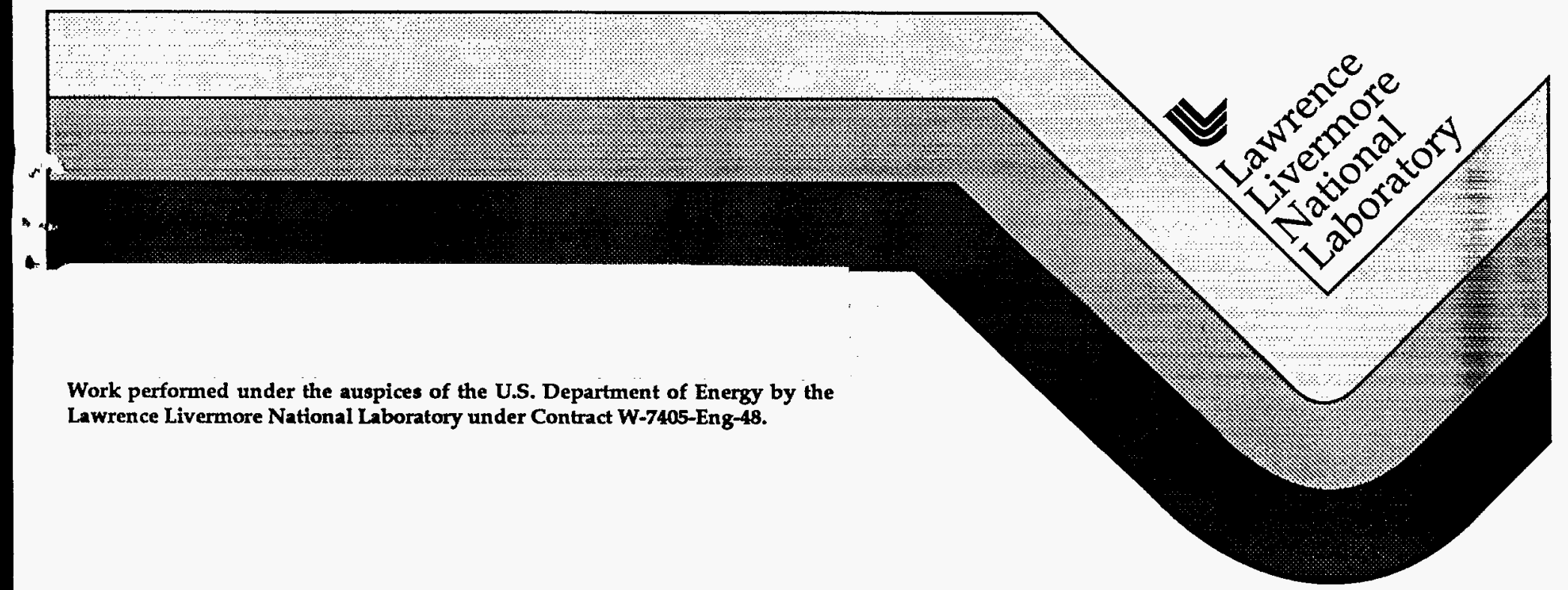




\section{DISCLAIMER}

This document was prepared as an acccount of work sponsored by an agency of the United States Government. Neither the United States Government nor the University of California nor any of their employees, makes any warranty, express or implied, or assumes any legal liability or responsibility for the accuracy, completeness, or usefulness of any information, apparatus, product, or process disclosed, or represents that its use would not infringe privately own rights. Reference herein to any specific commercial products, process, or service by trade name, trademark, manufacturer, or otherwise, does not necessarily constitute or imply its endorsement, recommendation, or favoring by the United States Government or the University of California. The views and opinions of authors expressed herein do not necessarily state or reflect those of the United States Government or the University of California, and shall not be used for advertising or product endorsement purposes.

This report has been reproduced directly from the best avallable copy.

Available to DOE and DOE contractors from the Office of Scientific and Technical Information P.O. Box 62 , Oak Ridge, TN 37831

Prices available from (615) 576-8401, FTS 626-8401

Available to the public from the

National Technical Information Service

U.S. Department of Commerce 5285 Port Royal Rd. Springfield, VA 22161 


\section{DISCLAIMER}

Portions of this document may be illegible in electronic image products. Images are produced from the best available original document. 


\section{TABLE OF CONTENTS}

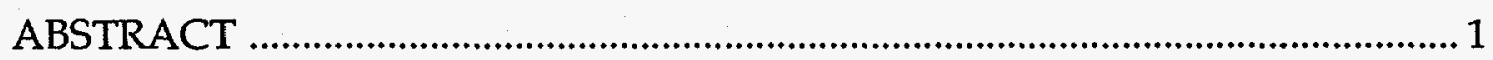

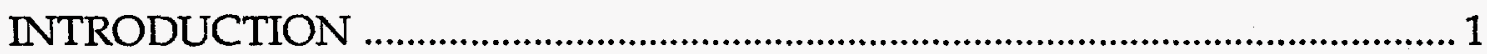

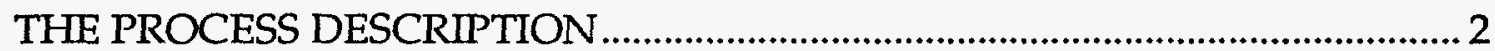

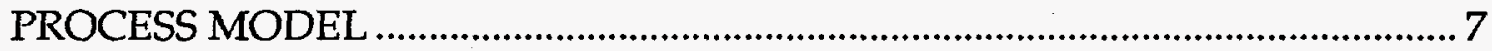

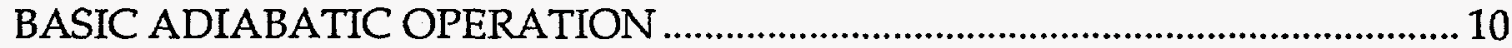

Computed Results for No Preheat Beds ............................................................. 10

Computed Results for One Preheat Bed ......................................................... 14

Computed Results for Two Preheat Beds ............................................................ 17

Computed Results for Three Preheat Beds......................................................... 22

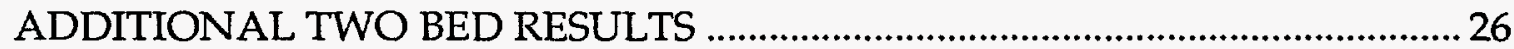

MSW Water Content ......................................................................................... 26

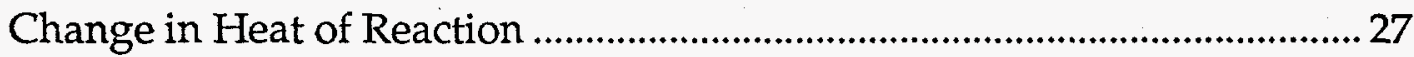

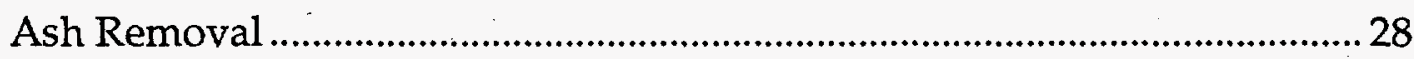

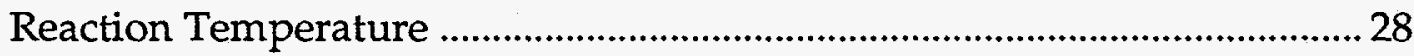

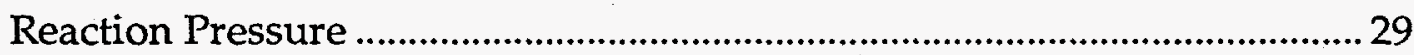

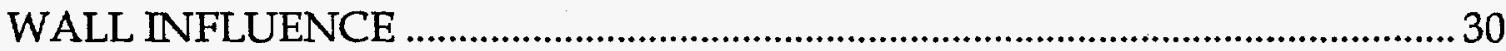

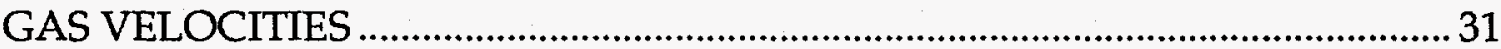

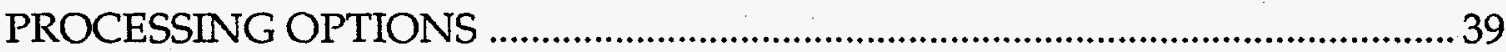

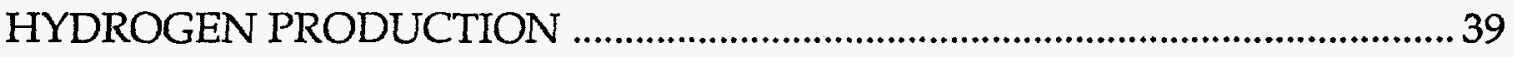

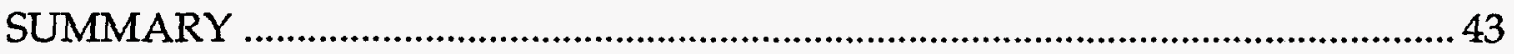

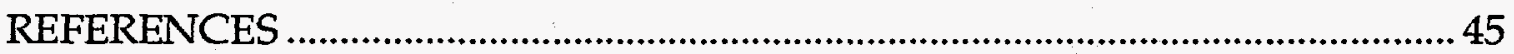

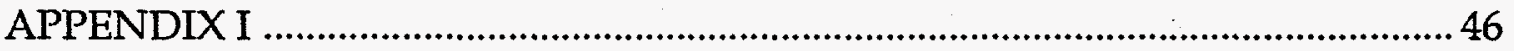




\begin{abstract}
A conceptual process for producing a gasifiable slurry from raw municipal solid waste (MSW) using direct steam heating is outlined. The process is based on the hydrothermal decomposition of the organic matter in the MSW, which requires the MSW to be heated to $300-350 \mathrm{C}$ in the presence of water. A process model is developed and it is shown, based on preliminary estimates of the hydrothermal reaction stoichiometry, that a process using multiple pressure vessels, which allows recovery of waste heat, results in a process capable of producing a product slurry having a $40 \mathrm{wt} . \%$ solids content with no waste water emissions. Results for a variety of process options and process parameters are presented. It is shown that the addition of auxiliary feedstock to the gasifier, along with the MSW derived slurry, results in more efficient gasification. It is estimated that $2.6 \mathrm{kmol} / \mathrm{s}$ of hydrogen can be produced from $30 \mathrm{~kg} / \mathrm{s}$ (2600 tonne/day) of MSW and $16 \mathrm{~kg} / \mathrm{s}$ of heavy oil. Without the additional feedstock, heavy oil in this case, only $0.49 \mathrm{kmol} / \mathrm{s}$ of hydrogen would be produced.
\end{abstract}

\title{
INTRODUCTION
}

Hydrogen can be produced from municipal solid waste (MSW) by high temperature gasification and subsequent processing of the syngas. In order to introduce MSW into a gasification reactor, the raw MSW must be processed. In a previous report ${ }^{1}$ a conceptual process model was developed for hydrothermally processing MSW to form a water solid slurry suitable for feeding a high pressure oxygen blown gasifier. This hydrothermal process involves heating the raw slurry to temperatures of 300-350 C at pressures sufficient to maintain the water phase. At these temperatures the organic matter (biomass) in MSW begins to breakdown in a process very much paralleling the formation of coal in natural settings. The cell structure present in the biomass derived constituents is destroyed and the oxygen content is reduced by the evolution of carbon dioxide and water. The breakdown of the cell structure and the coalifaction of the organic matter allow pumpable slurries to be formed which have much higher fuel content than those which can be produced from raw MSW.

In the previous work, a processing scheme for the hydrothermal treatment of MSW slurries which used a large heat exchanger to heat the MSW slurry to reaction temperatures was employed. The heat exchanger allowed heat to be transferred between the hot reacted slurry and the cold raw slurry. In this way only modest amounts of energy are required to heat the raw slurry to the desired reaction temperature. In order for this scheme to work, the raw slurry must have a low enough effective viscosity to allow it to be successfully heated in the heat exchanger. This means a raw solid loading of between 5-15 wt. \%. This loading is far less than what is needed for an economically viable gasification process. Consequently, the reacted slurry in this scheme must be concentrated prior to its introduction into the gasifier. 
The relatively low solid concentration of the incoming slurry means that a very large heat exchanger is required. In addition, it may be that fouling would be a real problem in prolonged operation of such a unit. For these reasons and others the option of heating the MSW to the required temperature using direct heating with high pressure steam needs to be considered. This report describes a model and selected computed results relating to the use of direct steam heating of MSW to form slurry feedstocks suitable for gasification.

\section{THE PROCESS DESCRIPTION}

The simplest means of utilizing direct steam heating of MSW would involve a batch process scheme. The shredded and classified raw MSW would be loaded into a pressure vessel. The vessel would be sealed and steam would be introduced to heat and pressurize the vessel. After maintaining the system at reaction temperature for the desired length of time the pressure would be gradually reduced, turning part of the water to steMOLECULAR REACTION MODELLING OFontents. After reaching atmospheric pressure, the reactor would be unloaded and the hydrothermally altered MSW slurry would be ready to be fed to the gasification unit.

Schematically this process is shown in Figure 1. The raw MSW is shredded and classified and then loaded into a reactor vessel. (The ASH referred to in the figure is a name given to all inorganic constituents in the process modeling work described here.) The batch operation is depicted in the figure as if it were continuous. The various stages of operation of the reactor vessel are labeled stage 1-3. Stage 1 (not labeled in the figure) is the atmospheric loading of the classified MSW into the vessel. Stage 2 is the steam heating of the MSW feed with high pressure steam and stage 3 is the pressure letdown/cooling phase. The gas and steam from stage 2 and stage 3 operations are sent to a condenser. The water collected in the condenser is shown being fed back into the process during the stage 3 operation. This water could also be mixed after the cool down process. There is some very small advantage to adding it to the hot mix since the sensible heat very slightly reduces the amount of steam produced during the pressure letdown and thus slightly reduces the condenser load. However, this effect is extremely small and results with the condensate added after the cooldown lead to essentially the same results.

The process scheme shown assumes that all the water entering the process will be present in the product slurry. One of the primary purposes of the modeling reported here is to determine the final water content of the product slurry using this assumption. In theory, the final product slurry water content could be adjusted by addition or removal of water. However, if water removal is necessary then the processing would have to deal with a waste water stream. Consequently, it will be assumed in most of the following that all water entering the process leaves with the final product slurry. 


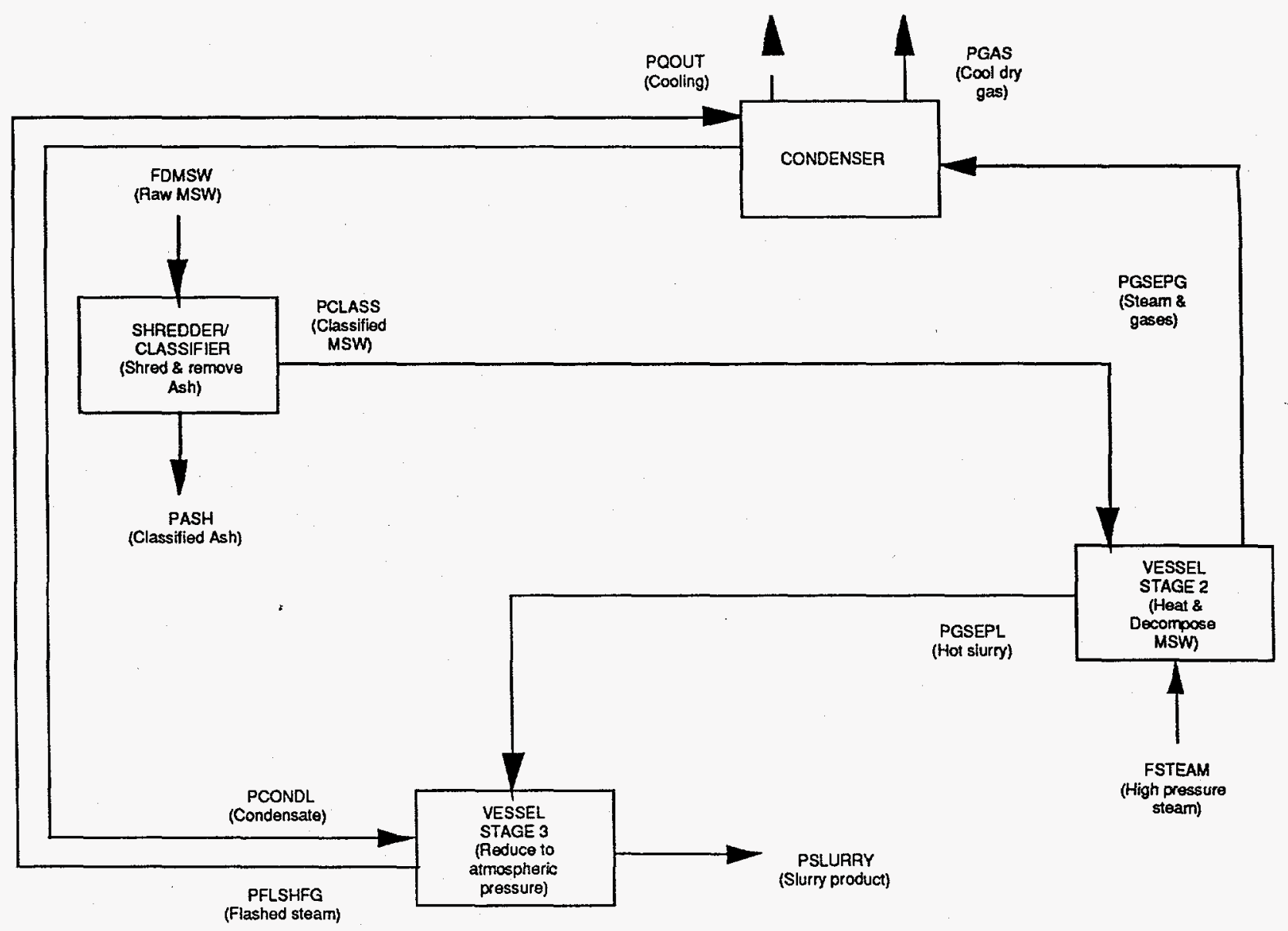

Figure 1. Hydrothermal conceptual process using high pressure direct steam heating.

The scheme represented in Fig. 1 is the simplest process for using steam to heat the raw MSW. However, it is not the most thermally efficient because the hot steam and gases which emerge from the reactor are simply sent to the condenser. Clearly, a more energy efficient process would involve recovering some of this waste heat. In Fig. 2 a process is shown which does that. An extra reactor vessel stage has been added so that energy in the gases exiting the reactor in stage 3 can be used to partially preheat the incoming raw MSW. The reactor vessel in the preheat mode is held at a pressure lower than that of the active reactor, stage 3 , so that gas can flow with no need for compression. Since the preheat bed must be available at the same time the steam heat phase, stage 3 , is active it is clear that more than one pressure vessel would be needed. In this case a minimum of two vessels must be present. 


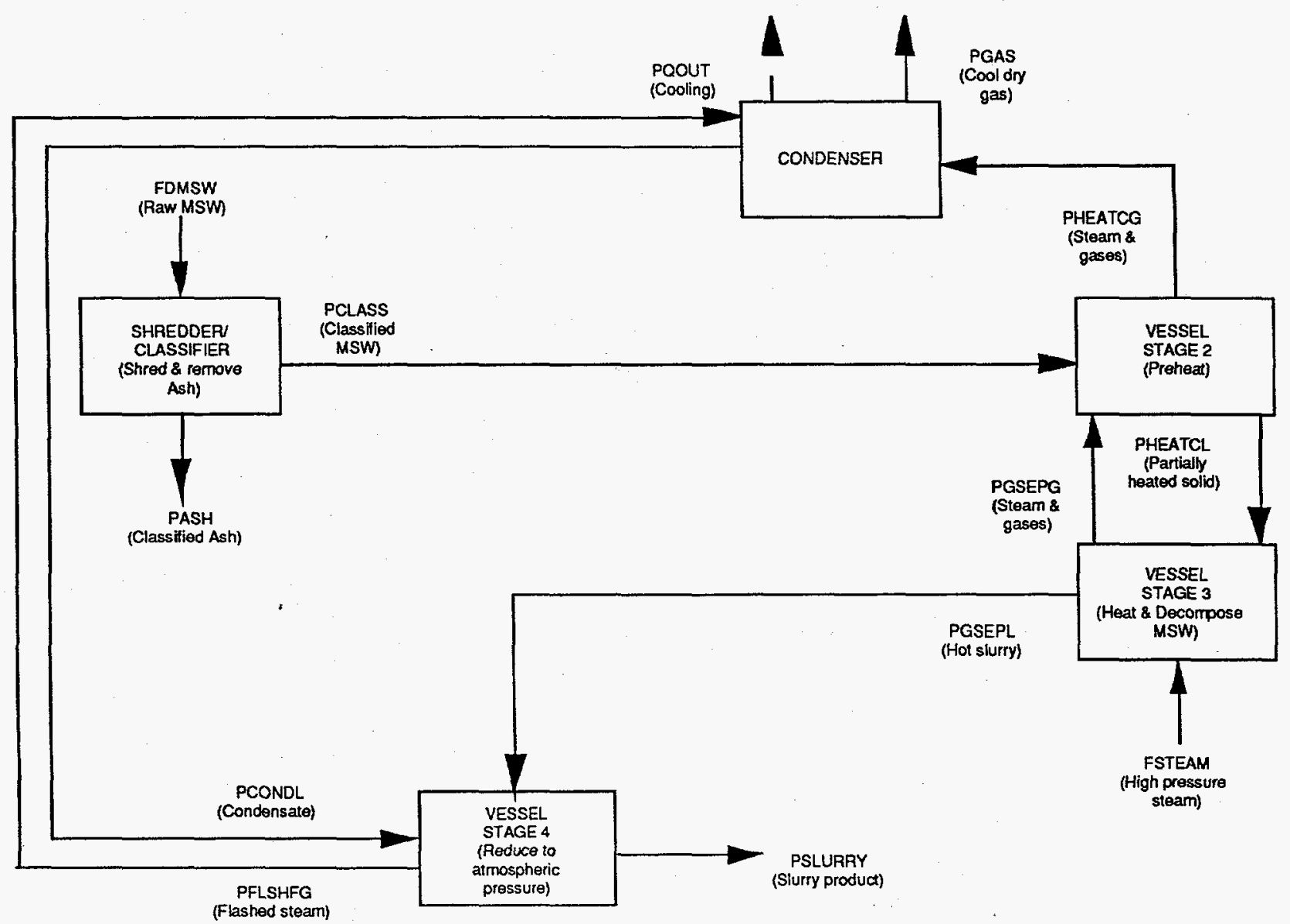

Figure 2 Direct steam heat process using one preheat bed.

To implement such a process several vessels would probably be connected together so that extra vessels would not sit idle waiting for a companion vessel to be prepared to allow the preheat operation to proceed. In Fig. 3 a time sequence for operation with one preheat bed is shown. Four vessels are shown, one each for the four major stages of operation, loading, preheating, heating/reacting and pressure letdown. Assuming times for each operation are similar, all four vessels would be participating in one of the operations at all times and a load of product slurry would be produced every $\Delta t$ time internal. This interval would be set by the slowest operation which would probably be stage 3 , the final heating and reaction operation. It is in this stage that the highest temperatures are obtained and as a consequence most of the reaction occurs. A residence time of 15 to 30 minutes at the peak temperature would probably be required. Therefore, the stage 3 operation would have to last at least that long. 


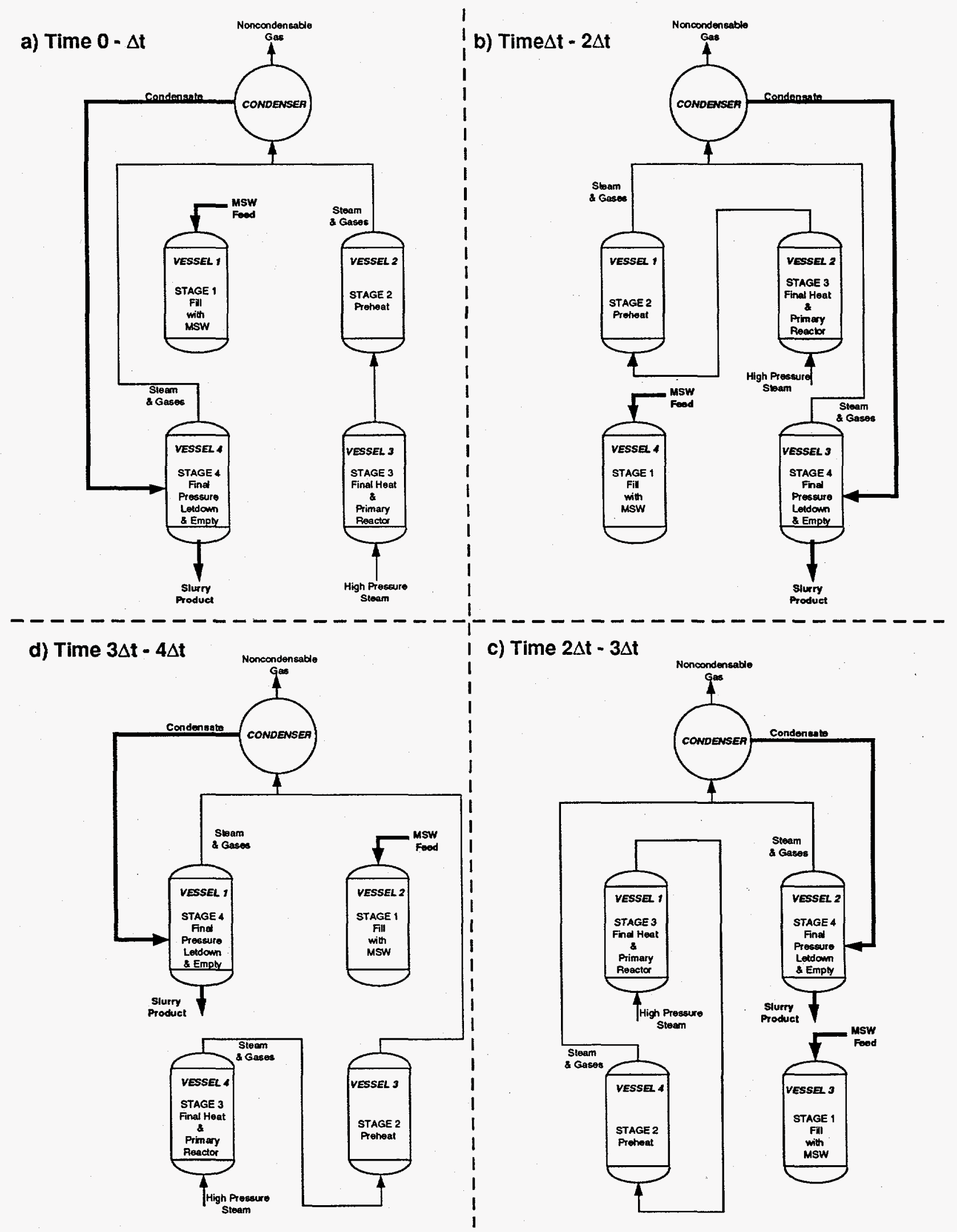

Figure 3. Process schematic for single preheat vessel case showing operation in each of four configurations (a-d). The sequence is repeated after $4 \Delta \mathrm{t}$ time units. 
In the above, one preheat bed was shown. This bed makes use of the hot gas exiting the final heat and reaction stage of the operation. However, no use is made of the steam evolved in the pressure letdown phase. To help recover more of the waste heat, additional preheat beds can be added. In Figs. 4 and 5 schematics of systems in which two and three preheat beds are used are shown. As more preheat stages, and companion pressure letdown stages, are added, heat recovery is increased and the operation behaves more like a countercurrent heat exchange system and is thus more energy efficient. On the other hand, the number of vessels required increases. Each additional preheat bed is used to recover heat from lower and lower pressure steam.

The pressures of the intermediate beds can be adjusted, within limits, to optimize heat recovery. The high pressure limit is set by the bed into which the high pressure steam is introduced. The final pressure in this vessel must be sufficient to maintain a liquid phase at the desired operating temperature. The lower pressure limit is set by the pressure of the final stage. This pressure needs to be near atmospheric to allow handling of the product slurry in low pressure temporary storage vessels.

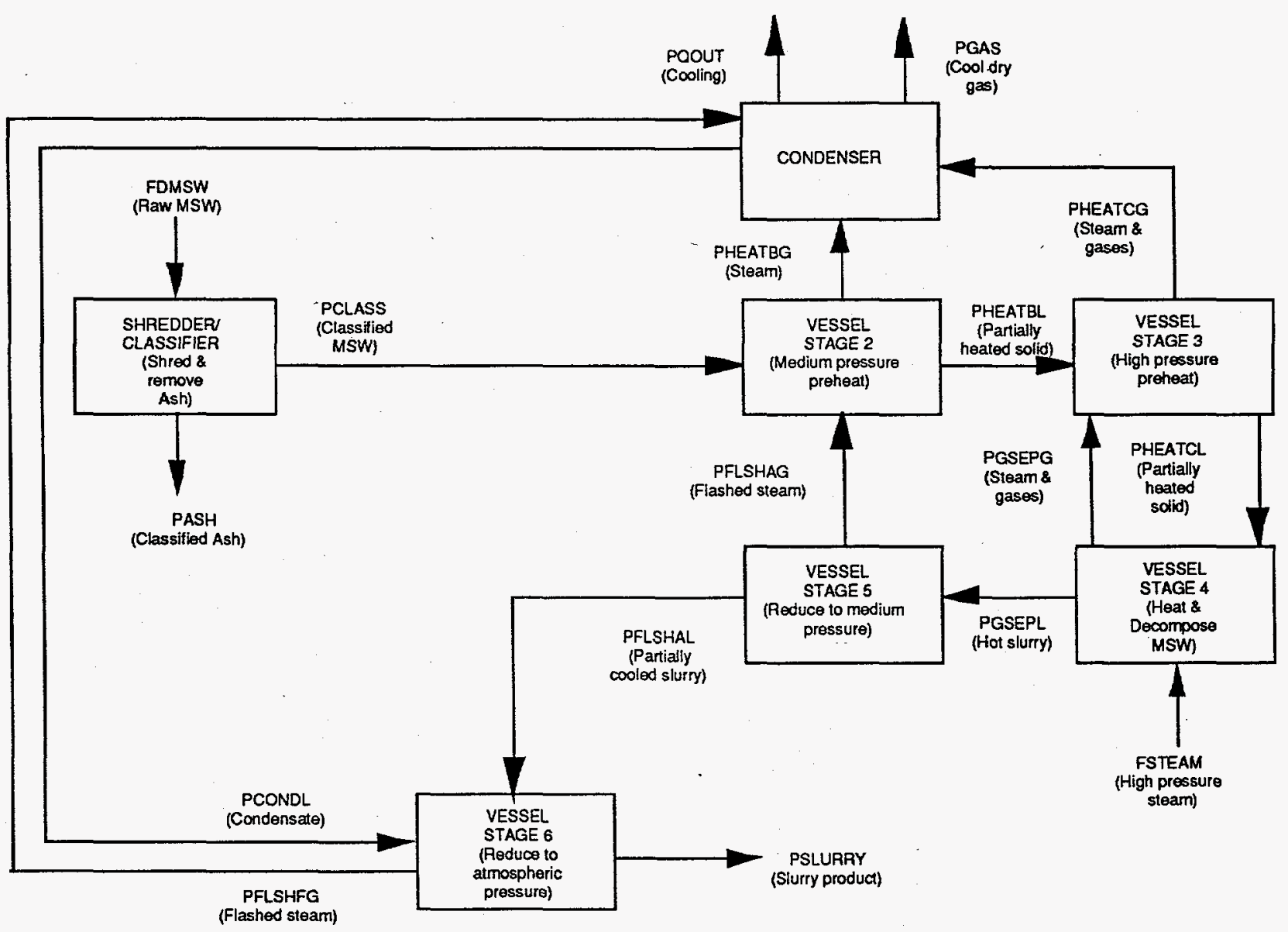

Figure 4 Direct steam heat process using two preheat bed. 


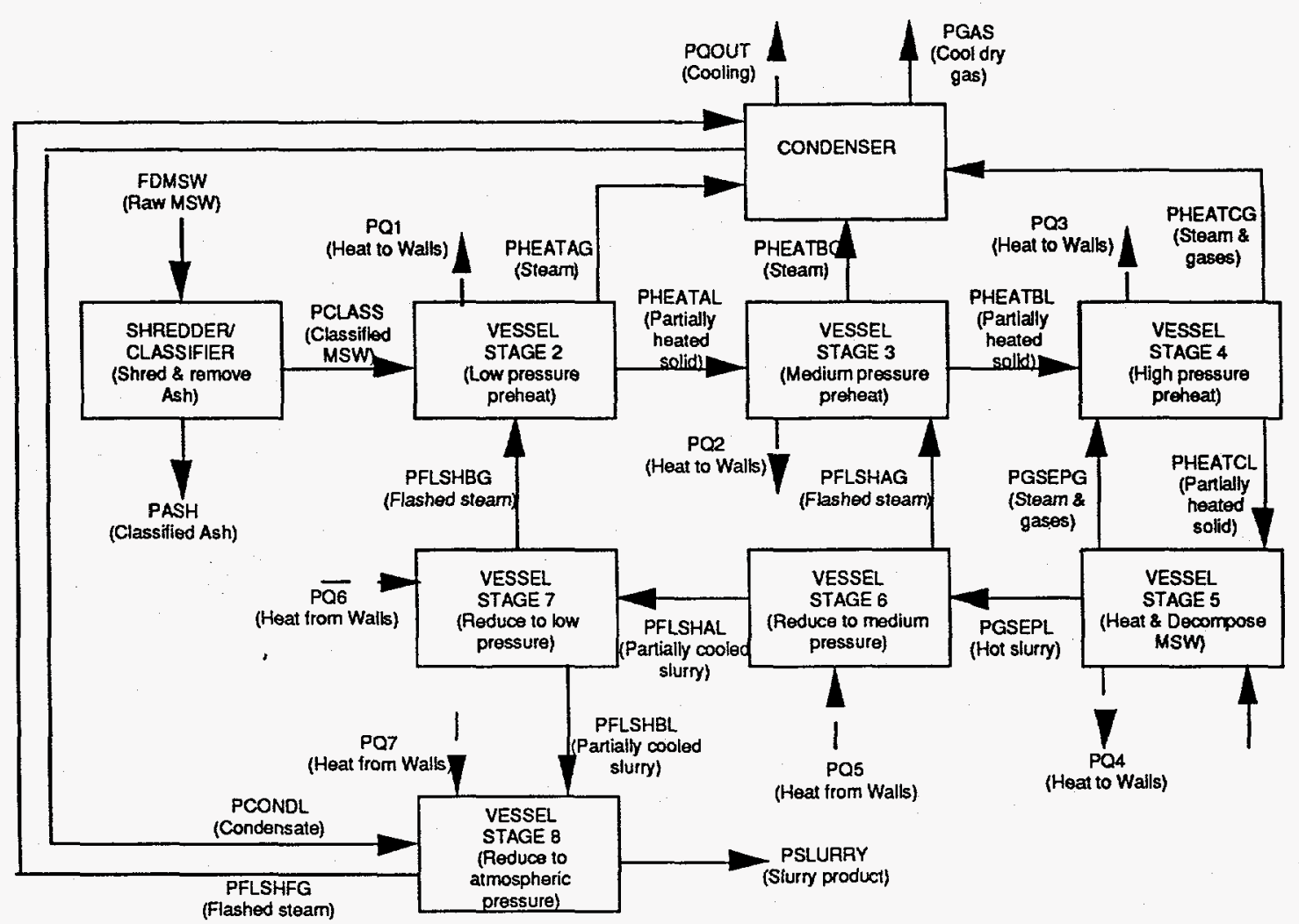

Figure 5 Direct steam heat process using three preheat beds.

As the number of preheat stages increases the number of reactor vessels needed increases. If the same sort of quasi-continuous operation is used as outlined previously for the one preheat bed case (i.e. one in which vessels do not sit idle) then the two preheat bed case would require six total vessels, and the three preheat bed case eight vessels. As the number of vessels increase, the additional expense and complexity would eventually offset the energy savings. This point is addressed in a later section.

\section{PROCESS MODEL}

The ASPEN PLUS simulator has been used to simulate the conceptual processes shown in the previous section. ASPEN PLUS is primarily a steady-state simulator. However, for purposes of material and energy balance calculations the batch process can be viewed as a continuous process using the streams indicated in the figures. ASPEN PLUS modules can be used which incorporate the correct overall change in stream properties from inlet to outlet. In this way steam requirements and slurry concentrations important to the process can be calculated.

Since the intent of the model development is to allow realistic estimates of the performance of the MSW-to-Hydrogen process to be computed, it is important that both material and energy constraints be incorporated into the simulation. The ASPEN PLUS simulator performs the required computations routinely as long as the chemical species 
of interest are well characterized. Many of the species needed in the simulation, like oxygen, water and hydrogen, are well defined and standard methods of computing the required thermodynamic properties are available within the ASPEN PLUS simulation environment. However, several of the important species, including MSW, are ill defined from the process simulation standpoint because they are a mixture of a large number of different constituents, and because the basic constituents themselves have no defined atomic composition or thermodynamic properties. Fortunately, ASPEN PLUS provides a means to deal with such ill defined species through the use of what the simulator calls nonconventional solids. However, to make use of these nonconventional solids, compositional and thermodynamic properties must be defined in a way which allows ASPEN PLUS to perform the required process calculations.

In previous work a method to define a set of nonconventional components has been outlined ${ }^{1}$ and the same scheme will be employed here. The raw input MSW is assumed to be composed of an organic composite material characteristic of biomass derived constituents, a plastic component, an ash component (inorganic constituents) and moisture or water. All but the water components are treated as nonconventional solids. At this point in the modeling process it has been assumed that the organic component undergoes chemical change in the process while the ash and plastic passes through chemically unchanged. In reality, the ash component would be modified, but the nature of this change would not strongly influence the overall material and energy balance of the hydrogen production process and are currently not considered. Information to date also indicates that most of the plastic will probably not be chemically altered in the hydrothermal process at the temperatures currently under consideration.

In addition to the nonconventional solids used to specify the incoming MSW, one other nonconventional solid is defined. This solid is used to represent the solid product of the hydrothermal decomposition of the organic composite material in the MSW. Each of the nonconventional solids has been given a component name for use in the simulation. These names are:

ORG - The composite organic material of the incoming MSW

PLS - The plastic component of the MSW

ASH - The ash, inorganic, component of the MSW

GORG - The solid organic product of the hydrothermal decomposition of MSW These names will be used throughout the report to designate these materials.

The decomposition of ORG (biomass related component of MSW) in the current model is handled by assuming the overall reaction can be adequately described by the following

$$
\begin{aligned}
\mathrm{CH}_{\mathrm{A}} \mathrm{O}_{\mathrm{B}}(\mathrm{ORG}) \Rightarrow & \mathrm{CH}_{\mathrm{a}} \mathrm{O}_{\mathrm{b}}(\mathrm{GORG})+\alpha \mathrm{CO}_{2}+\beta \mathrm{CO}+ \\
& \delta \mathrm{H}_{2}+\phi \mathrm{H}_{2} \mathrm{O}+\gamma \mathrm{CH}_{4}
\end{aligned}
$$

In this overall reaction methane is used to approximate all hydrocarbon type gases produced. For simplicity, the $\mathrm{N}, \mathrm{S}$ and $\mathrm{Cl}$ have been omitted from the simplified reaction description. Currently these species are all carried along with the GORG component. 
The same MSW composition and decomposition stoichiometry as employed in the previous work ${ }^{1}$ are used here. The assumed values are given in Tables 1 and 2 . In the process modeling results it is assumed that the PLS component does not change in the hydrothermal treatment units and that the ORG component decomposes according to the stoichiometry given in Table 2. The energetics of the assumed ORG decomposition are given in the second part of the table. Notice for this choice of parameters the heat of reaction for the decomposition at $25 \mathrm{C}$ is small and all the heating value of the MSW is available in the solid product.

Table 1. Assumed raw MSW component composition.

\begin{tabular}{|cc|}
\hline Component & Weight \% \\
\hline H2O & 25.0 \\
ORG & 48.6 \\
PLS & 8.3 \\
ASH & 18.1 \\
\hline
\end{tabular}

Table 2. Stoichiometry and energetics used in defining MSW related components.

\begin{tabular}{|c|c|c|c|c|c|c|c|c|c|c|c|}
\hline & Feed & Feed & $\begin{array}{l}\text { Solid } \\
\text { Product }\end{array}$ & $\begin{array}{l}\text { Solid } \\
\text { Product }\end{array}$ & \multicolumn{4}{|c|}{ Dry Gas Mole \% } & $\begin{array}{l}\text { Solid } \\
\text { Product } \\
\text { /Feed }\end{array}$ & $\begin{array}{l}\mathrm{H} 2 \mathrm{O} \\
\text { Product } \\
\text { /Feed }\end{array}$ & $\begin{array}{c}\text { Dry Gas } \\
\text { Product } \\
\text { /Feed }\end{array}$ \\
\hline & $\mathrm{H} / \mathrm{C}$ & $\mathrm{O} / \mathrm{C}$ & $\mathrm{H} / \mathrm{C}$ & $\mathrm{O} / \mathrm{C}$ & $\mathrm{CO} 2$ & $\infty$ & $\mathrm{H} 2$ & $\overline{\mathrm{CH} 4}$ & $(\mathrm{~kg} / \mathrm{kg})(\mathrm{k}$ & $/ \mathrm{kg})$ & (kg/kg) \\
\hline$\widehat{C P G}$ & 1.49 & 0.66 & 1 & 0.33 & 80 & 4 & 7 & 9 & 0.72 & 0.19 & 0.09 \\
\hline PLS & 1.71 & 0.24 & 1.71 & 0.24 & 0 & 0 & 0 & 0 & 1 & 0 & 0 \\
\hline $\mathrm{BRG}+\mathrm{PLS}$ & 1.52 & 0.60 & 1.10 & 0.32 & 80 & 4 & 7 & 9 & 0.76 & 0.16 & 0.08 \\
\hline
\end{tabular}

\begin{tabular}{|c|c|c|c|c|}
\hline & $\begin{array}{l}\text { Feed } \\
\text { Heating } \\
\text { Value }\end{array}$ & $\begin{array}{l}\text { Solid } \\
\text { Product } \\
\text { Heating } \\
\text { Value }\end{array}$ & $\begin{array}{c}\text { Heat } \\
\text { Reaction }\end{array}$ & $\begin{array}{c}\text { Solid } \\
\text { Product } \\
\text { / Feed } \\
\text { Heating } \\
\text { Value }\end{array}$ \\
\hline & $(\mathrm{MJ} / \mathrm{kg})$ & $(\mathrm{MJ} / \mathrm{kg})$ & $(\mathrm{MJ} / \mathrm{kg})$ & \\
\hline$\overline{C A G}$ & 17.9 & 24.7 & 0.26 & 1.0 \\
\hline PLS & 30.6 & 30.6 & 0 & 1.0 \\
\hline $\mathrm{bRG}+\mathrm{PLS}$ & 19.8 & 25.6 & 0.22 & 1.0 \\
\hline
\end{tabular}

The required atomic composition and thermodynamic properties for conventional species used in the model are taken from ASPEN PLUS property models. The ASPEN PLUS property model set SYSOP8A has been employed. This model computes Henry's Law constants for each of the gas components in the water phase. These estimates are based on idealized models. If the amount of gas separation must be known more precisely better means of computation would probably be required, particularly for carbon dioxide which has the potential to interact with dissolved bases. In previous work ${ }^{1}$ the ASPEN PLUS estimates for the nonpolar species considered appear to be within $10-25 \%$ of measured values in pure water and those for carbon dioxide within $40 \%$. 


\section{BASIC ADIABATIC OPERATION}

In this section results computed from the ASPEN PLUS model formulated to simulate the 0,1,2 and 3 preheat bed options of the hydrothermal processing of MSW using direct steam heating are presented. In the computed results it is assumed that the raw MSW feed rate is $30 \mathrm{~kg} / \mathrm{s}$ (2600 tonne/day, 1470 tonne/day dry-ash-free) and $50 \%$ of the incoming ash component is separated from the stream in the shredding/classification operation before entering the hydrothermal treatment vessel. Unless noted otherwise, the reaction stage is assumed to reach $300 \mathrm{C}$ and $10 \mathrm{MPa}$.

\section{Computed Results for No Preheat Beds}

Computed results for the ASPEN PLUS model of the no preheat bed configuration are listed in Table 3. The schematic process flow is that given in Fig. 2, and the stream names are defined in that figure. The material streams are depicted in the figure as solid lines and the energy flow streams with a dashed line. For this case an average flow of $21.2 \mathrm{~kg} / \mathrm{s}$ of steam is required to raise the incoming MSW to the desired $300 \mathrm{C}$ and compensate for the reaction endotherm. Steam evolution equal to approximately half the injected steam rate is required to cool the slurry from the $300 \mathrm{C}$ reaction temperature to $100 \mathrm{C}$ during the pressure letdown/cooling stage.

Because of the production of noncondensable gases in the decomposition reaction, it is probably necessary to have some gas flow out of the reactor vessel during the active steam heating phase. This gas flow would actually occur during the latter stages of the steam heating process. The actual amount of flow required would depend on the amount of noncondensable gas formed, the exact void volume in the vessel, the maximum operating pressure of the vessel, and the desired temperature. In general the vessel maximum vessel pressure would be chosen as low as possible to allow the desired temperature to be achieved. The highest temperature which can be reached in the vessel would be the boiling point of water at the vessel pressure. This is only true if the gas phase is all steam. As the gas phase concentration on noncondensable gas increases then the maximum temperature which can be reached, maintaining a water phase, would decrease in accordance with the reduction of partial pressure of water vapor in the gas.

Since the model used here treats the process as a continuous one, it is natural to have the amount of gas flow out of the reactor vessel carry with it the same amount of noncondensable gas that is produced from the decomposition reaction. This assumption leads to computed flows which represent a system in which capacitance of the vessels plays no role. Results based on this assumption should yield reasonable estimates since in a real system the capacitance of the vessels to contain gas would probably not be large, the vessel would be nearly filled with solid and water. A more important consideration is probably the timing of the gas release and the amount of gas which dissolves into the liquid phase. In the calculations, some estimate is made for this latter effect, although the exact solubility, particularly of carbon dioxide, is probably influenced by the chemical properties of the various other species dissolved in the water 
phase. The variation of gas release with time is not easily accounted for in this continuous model of the process and has not been incorporated.

In this case the calculations indicate that flow of $6.24 \mathrm{kmol} / \mathrm{s}$ must exit the reactor vessel to sweep out the produced noncondensable gas. The gas exiting the reactor is approximately 11 mole \% noncondensable and 89 mole \% steam. This exit flow rate is, of course, a function of the steam flow rate used. In the model, this steam flow rate is not a parameter but is fixed by the rate of MSW feed to the process, which is a selectable parameter.

The product slurry produced by the process, based on recombining the condensate with the final product, has a solid content of $33 \mathrm{wt} . \%$. If the condensate is not recombined with the final product then the product slurry would have a solid content of $52 \mathrm{wt} . \%$. It is interesting that these levels correspond very closely with desired values of 35-55 wt.\% water for an acceptable slurry product.

The use of the term solid content needs some clarification. In the above, and much of the remainder of the report, the term weight percent solids is used. This term is meant to represent all the nonwater portion of the slurry. In the model described here all the solid and liquid products of decomposition are represented by the nonconventional species GORG, and in the model GORG is treated like a solid. In reality, however, the products of decomposition would involve some liquid and some soluble components. These components are included here in what is referred to as solid.

Table 3 Computed results for no preheat bed case.

\begin{tabular}{|c|c|c|c|c|c|c|c|c|c|c|}
\hline Stream & FDMSW & FSTEAM & PASH & PSLURRY & PGAS & PCLASS & PGSEPG & PGSEPL & PFLSHFG & PCONDL \\
\hline Total Flow $(\mathrm{kg} / \mathrm{s})$ & 30 & 21.2 & 2.72 & 47.2 & 1.34 & 27.3 & 6.24 & 42.3 & 12 & 16.9 \\
\hline Pressure (MPa) & 0.1 & $\$ 1.2$ & 0.1 & 0.1 & 0.1 & 0.1 & 10.0 & 10.0 & 0.1 & 0.1 \\
\hline Temperature $(\mathrm{C})$ & 25 & 320 & 25 & 100 & 40 & 25 & 300 & 300 & 100 & 40 \\
\hline \multicolumn{11}{|l|}{ Conventional } \\
\hline Flow $(\mathrm{kg} / \mathrm{s})$ & 7.5 & 21.2 & & 31.4 & 1.34 & 7.5 & 6.24 & 26.6 & 12 & 16.9 \\
\hline Vapor fraction & 0 & 1 & & 0 & 1 & 0 & 1 & 0 & 1 & 0 \\
\hline Flow $(\mathrm{kmol} / \mathrm{s})$ & 0.416 & 7.18 & & 7.75 & 0.037 & 0.416 & 0.309 & 7.47 & 0.664 & 0.936 \\
\hline $\mathrm{H} 2(\mathrm{~mol} \%)$ & 0 & 0 & & 0 & 6.5 & 0 & 0.76 & 0 & 0 & 0 \\
\hline $\mathrm{Co}(\mathrm{mol} \%)$ & 0 & 0 & & 0 & 3.7 & 0 & 0.44 & 0 & 0 & 0 \\
\hline $\mathrm{CO} 2$ (mol \%) & 0 & 0 & & 0 & 74.0 & 0 & 8.72 & 0.02 & 0.08 & 0.03 \\
\hline $\mathrm{H} 2 \mathrm{O}(\mathrm{mol} \%)$ & 100 & 100 & & 100 & 7.5 & 100 & 89.08 & 99.97 & 99.9 & 99.96 \\
\hline $\mathrm{CH} 4(\mathrm{~mol} \mathrm{\%})$ & 0 & 0 & & 0 & 8.3 & 0 & 0.99 & 0 & 0 & 0 \\
\hline \multicolumn{11}{|l|}{ Nonconventional } \\
\hline Flow $(\mathrm{kg} / \mathrm{s})$ & 22.5 & & 2.72 & 15.74 & & 19.8 & & 75.7 & & \\
\hline ASH(wr \%) & 24.1 & & 100 & 17.2 & & 13.7 & & 77.2 & & \\
\hline ORG (w\%) & 64.8 & & 0 & 0 & & 73.7 & & 0 & & \\
\hline GORG (wt \%) & 0 & & 0 & 66.9 & & 0 & & 66.9 & & \\
\hline PLS (wt \%) & 11.1 & & 0 & 15.8 & & 12.6 & & 15.8 & & \\
\hline Stream & PQOUT & & & & & & & & & \\
\hline Energy flow (MW & 43.6 & & & & & & & & & \\
\hline
\end{tabular}

As mentioned above the desired reaction temperature, the system pressure, and the steam flowing in and out of the reactor stage are interrelated. For any given reaction temperature there is a minimum pressure of operation which will maintain a water phase in the reactor. This pressure is the vapor pressure of water at the desired reaction temperature. However, the reactor can be operated at higher pressures. As the pressure is increased the need to reduce the level of noncondensable gases in the reactor decreases and therefore the gas flow out should be reduced. 
A series of runs were done in which the pressure of the reactor stage was varied. Other parameters of the problem were held constant. The one exception was the temperature of the steam which was increased slightly to maintain the vapor phase in the injection stream as the system pressure increased. In all cases the reactor temperature was set at $300 \mathrm{C}$.

Table 4 gives selected results of these calculations. The results do show the flow rate out of the reactor decreasing as the pressure increases, as does the required steam injection rate. The mole percent of steam in the gas exiting the reactor drops as the pressure increases for reasons outlined above.

The lowest pressure used in the calculations, $9 \mathrm{MPa}$, is only about $0.4 \mathrm{MPa}$ above the vapor pressure of water at $300 \mathrm{C}$. This is actually more like $0.5 \mathrm{MPa}$ above the water vapor pressure used in the model calculations because of the property option set used. The ASPEN PLUS property option set SYSOP8A was used in the calculations because it was capable of estimating the Henry's law constant for noncondensable components. The estimated water vapor pressure curve for this option set differs slightly from measured steam values (see Appendix I).

As the pressure increases the total amount of condensate decreases because of the lower required steam injection rate. As a consequence, the final slurry product, which includes condensate, has a higher solids content as the pressure is increased. This change along with the change in steam flow rate is plotted as a function of system pressure in Fig. 6. There is a higher benefit for changes in pressure at the low pressure end. As the pressure gets farther from the water vapor pressure the benefits of increasing pressure on lower steam flow and increased solids concentration decline rapidly. This is a simple result of material balance considerations and reflect the manner in which the gas flow rate exiting the reactor responds to a change in pressure. This relation is shown graphically in Fig 7 .

Table 4. Computed results for the no preheat bed case as a function of maximum system pressure.

\begin{tabular}{|ccccccccc|}
\hline $\begin{array}{c}\text { System } \\
\text { Pressure } \\
(\mathrm{MPa})\end{array}$ & $\begin{array}{c}\text { FSTEAM } \\
\text { Temperature } \\
(\mathrm{C})\end{array}$ & $\begin{array}{c}\text { FSTEAM } \\
\text { Rate } \\
(\mathrm{kmol} / \mathrm{s})\end{array}$ & $\begin{array}{c}\text { FSTEAM } \\
\text { Rate } \\
(\mathrm{kg} / \mathrm{s})\end{array}$ & $\begin{array}{c}\text { PSLURRY } \\
\text { Solids } \\
(\mathrm{wt} . \%)\end{array}$ & $\begin{array}{c}\text { PQOUT } \\
(\mathrm{MW})\end{array}$ & $\begin{array}{c}\text { PGSEPG } \\
\text { H2O } \\
(\mathrm{mol} \%)\end{array}$ & $\begin{array}{c}\text { PGSEPG } \\
\text { Rate } \\
(\mathrm{kmol} / \mathrm{s})\end{array}$ & $\begin{array}{c}\text { PGSEPG } \\
\text { Rate } \\
(\mathrm{kg} / \mathrm{s})\end{array}$ \\
\hline 9 & 320 & 1.71 & 30.8 & 27.8 & 67.1 & 95.9 & 0.832 & 15.65 \\
9.5 & 320 & 1.31 & 23.6 & 31.8 & 49.5 & 92.3 & 0.440 & 8.60 \\
10 & 320 & 1.18 & 21.2 & 33.4 & 43.6 & 89.7 & 0.309 & 6.24 \\
11 & 320 & 1.07 & 19.3 & 34.8 & 38.9 & 83.6 & 0.204 & 4.34 \\
12 & 340 & 1.03 & 18.5 & 35.5 & 36.8 & 79.0 & 0.159 & 3.52 \\
13 & 340 & 1.00 & 18.0 & 35.8 & 35.6 & 75.2 & 0.134 & 3.07 \\
14 & 340 & 0.98 & 17.7 & 36.1 & 34.8 & 72.0 & 0.118 & 2.78 \\
\hline
\end{tabular}




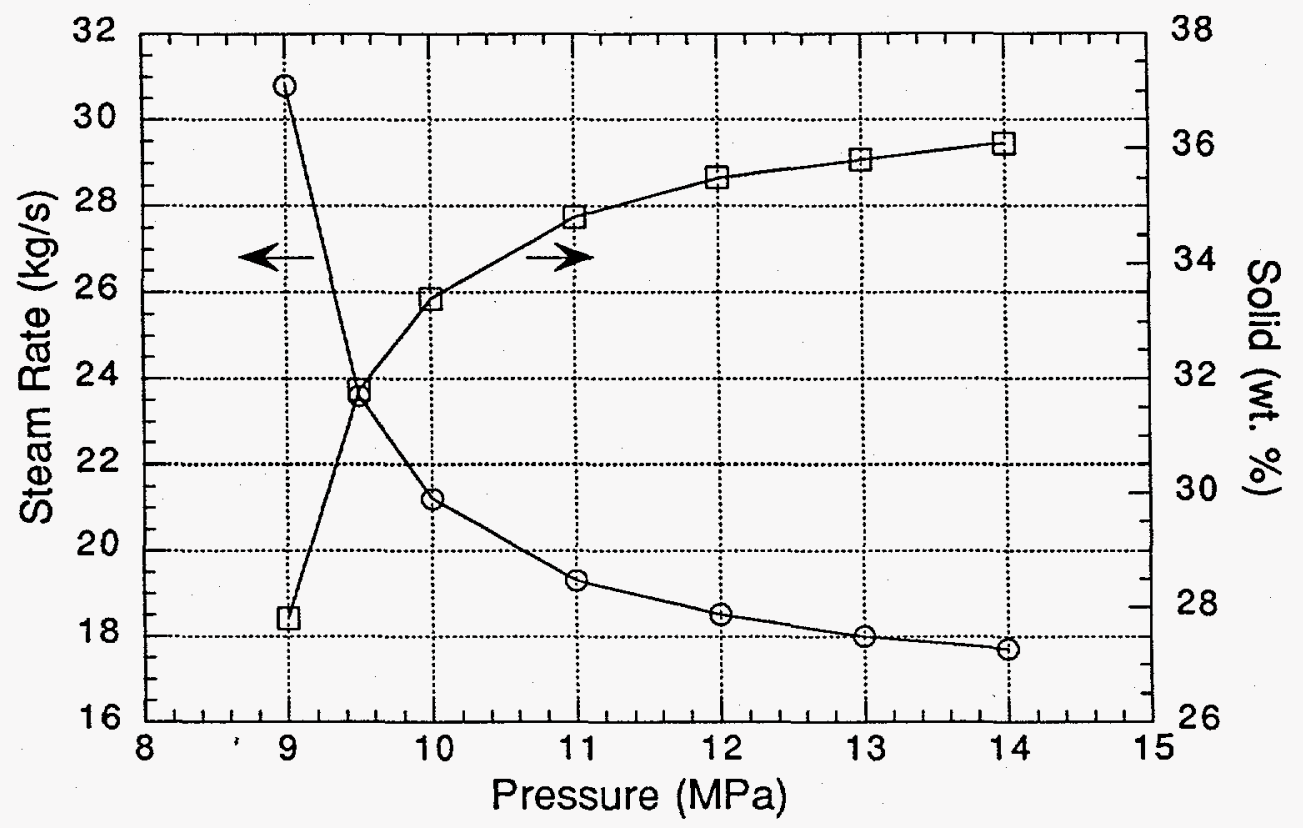

Figure 6. Computed steam injection rate and product slurry solids content as a function of operating pressure for a system with no preheat beds.

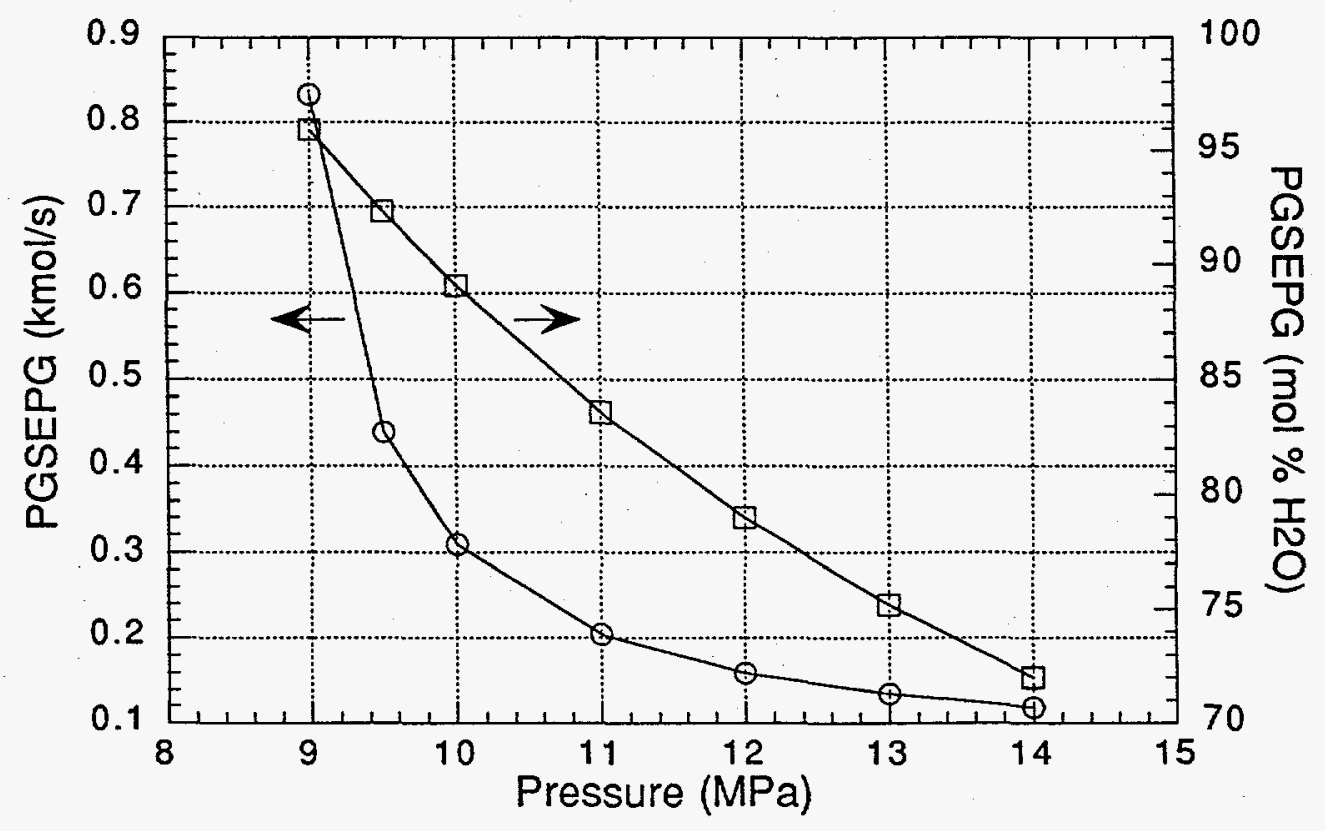

Figure 7. Computed reactor gas rate and steam content as a function of operating pressure for a system with no preheat beds.

In Fig. 8 the decline in the required cooling as a function pressure is plotted. Again the shape of the curve is dictated by the shape of the curve representing the reactor exit gas flow rate. 


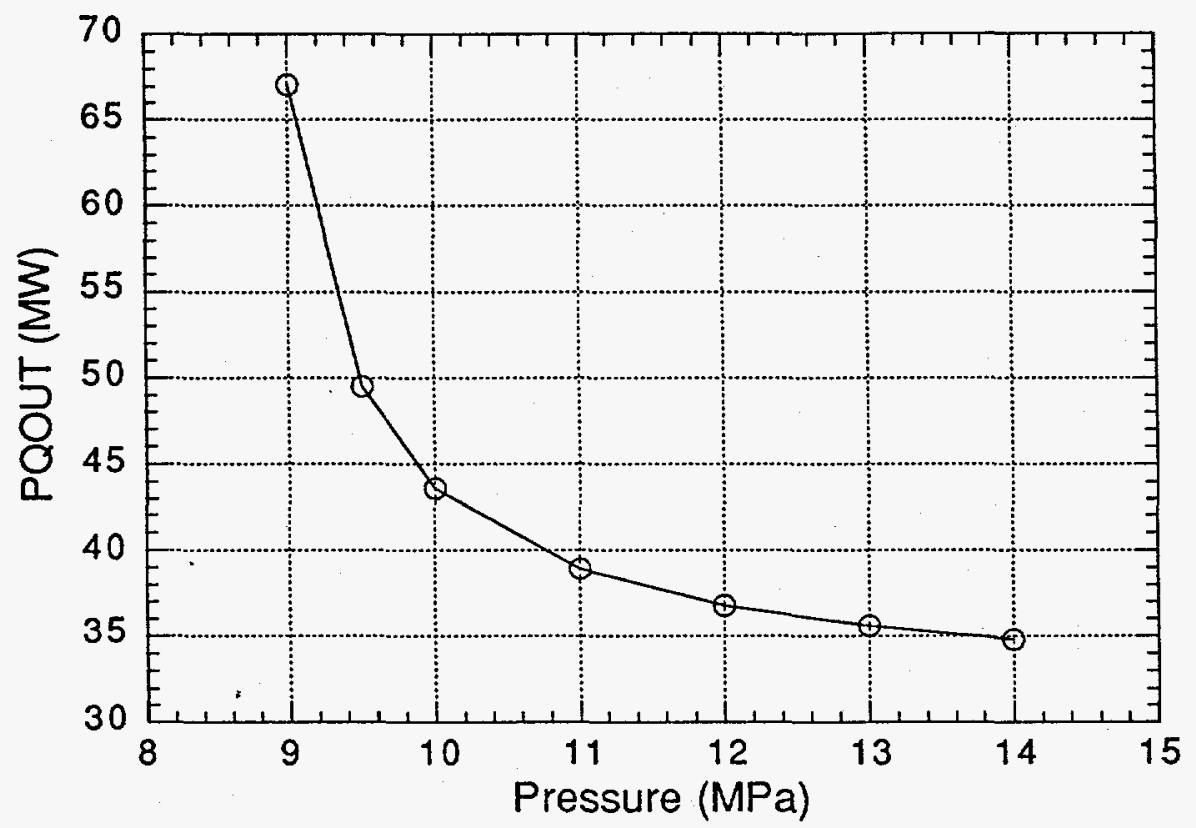

Figure 8. Computed cooling requirements, PQOUT, as a function of operating pressure for a system with no preheat beds.

\section{Computed Results for One Preheat Bed}

As pointed out previously, employing a preheat bed in the process should improve performance from an energy utilization standpoint. In this section results are presented for a system using one preheat bed. The process is shown schematically in Fig. 2. The preheat bed is added to the system to capture heat energy in the gas stream exiting the primary reaction stage.

In the one preheat bed process an additional parameter is added to the system, the maximum pressure at which the preheat bed is to operate. For the conceptual process to make sense this pressure must always be less than the reaction stage pressure so that the gas will flow from the reaction stage to the preheat stage.

A series of the model runs were done in which the pressure difference between the reaction stage and preheat stage was varied. In these runs the maximum pressure of the reaction stage was held constant a $10 \mathrm{MPa}$. Selected results of these calculations are given in Table 5. As would be expected, the process is more efficient the closer the preheat bed pressure is to the reaction stage pressure; the steam flow rate is lower, the slurry solids content is higher, and the cooling requirements are less. This is a direct consequence of the increasing preheat bed temperature as the preheat bed pressure increases. The high pressure and higher temperature bed more efficiently recovers the energy from the gas exiting the reaction stage bed. 
In Fig. 9 the slurry product solid concentration and preheat bed temperature are plotted as a function of the pressure difference between beds. The plot shows that the process performance as measured by slurry solids content, is not a strong function of pressure difference until this difference becomes a substantial fraction of the maximum reactor vessel pressure. This means that exact pressure difference needed to drive the flow through the preheat bed should have very little influence on the operating efficiency.

Table 5. Computed results for the one preheat bed case as a function of the pressure difference between the reaction vessel and the preheat bed. The reactor vessel pressure is held constant at $10 \mathrm{MPa}$.

\begin{tabular}{|ccccccc|}
\hline $\begin{array}{c}\text { Pressure } \\
\text { Difference } \\
\text { (MPa) }\end{array}$ & $\begin{array}{c}\text { FSTEAM } \\
\text { Rate } \\
(\mathrm{kg} / \mathrm{s})\end{array}$ & $\begin{array}{c}\text { PSLURRY } \\
\text { Solids } \\
(\text { wt. \%) }\end{array}$ & $\begin{array}{c}\text { PQOUT } \\
(\mathrm{MW})\end{array}$ & $\begin{array}{c}\text { PHEATG } \\
\text { Temperature } \\
(\mathrm{C})\end{array}$ & $\begin{array}{c}\text { PHEATG } \\
\text { Rate } \\
(\mathrm{kmol} / \mathrm{s})\end{array}$ & $\begin{array}{c}\text { PHEATG } \\
\text { H2O } \\
(\mathrm{mol} \%)\end{array}$ \\
\hline 0.2 & 16.4 & 37.2 & 31.6 & 196 & 0.042 & 20.2 \\
3 & 16.4 & 37.2 & 31.7 & 192 & 0.044 & 23.7 \\
6 & 16.5 & 37.1 & 32.0 & 187 & 0.050 & 32.9 \\
8 & 16.8 & 36.8 & 32.7 & 178 & 0.067 & 49.8 \\
9 & 17.4 & 36.4 & 34.0 & 163 & 0.101 & 66.8 \\
9.8 & 18.8 & 35.2 & 37.7 & 115 & 0.203 & 83.4 \\
\hline
\end{tabular}

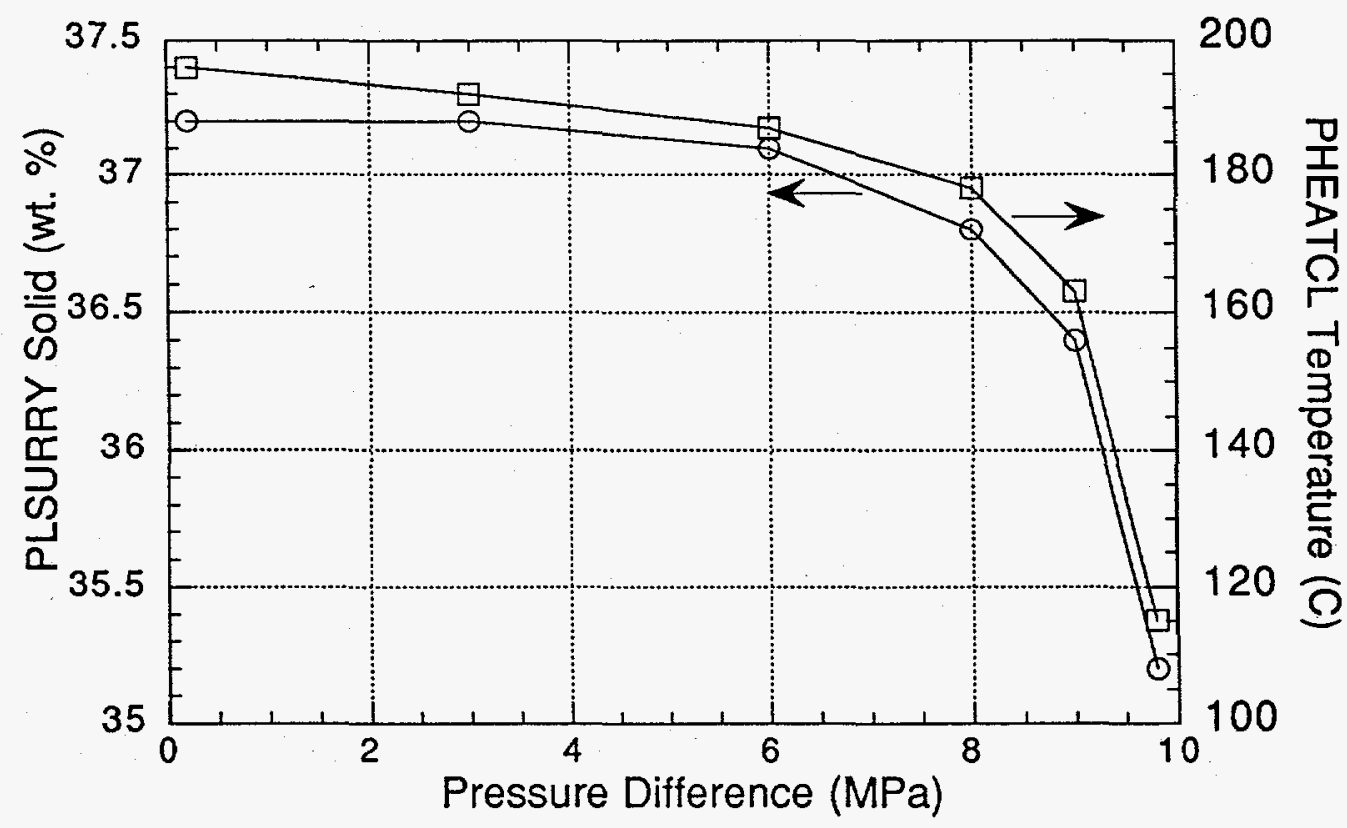

Figure 9 Computed product slurry solid content and the temperature of the preheat bed as a function of the preheat bed temperature for a system with one preheat bed.

A complete set of computed results are given in Fig. 10 for the case in which the preheat bed is at a pressure of only $0.2 \mathrm{MPa}$ lower than the reaction stage. In these results, as others, the pressure of the gas exiting a unit is assumed to be the same as the pressure of the unit it is exiting. For this case a solids concentration in the slurry product of 37.2 wt.\% is computed, this is about $4 \mathrm{wt} . \%$ higher than for the $10 \mathrm{MPa}$ no preheat bed case. The cooling requirement improvement is even better, with the one heat bed case, requiring more than $25 \%$ less cooling. The required steam flow is more than $20 \%$ less than the no heat bed case. 


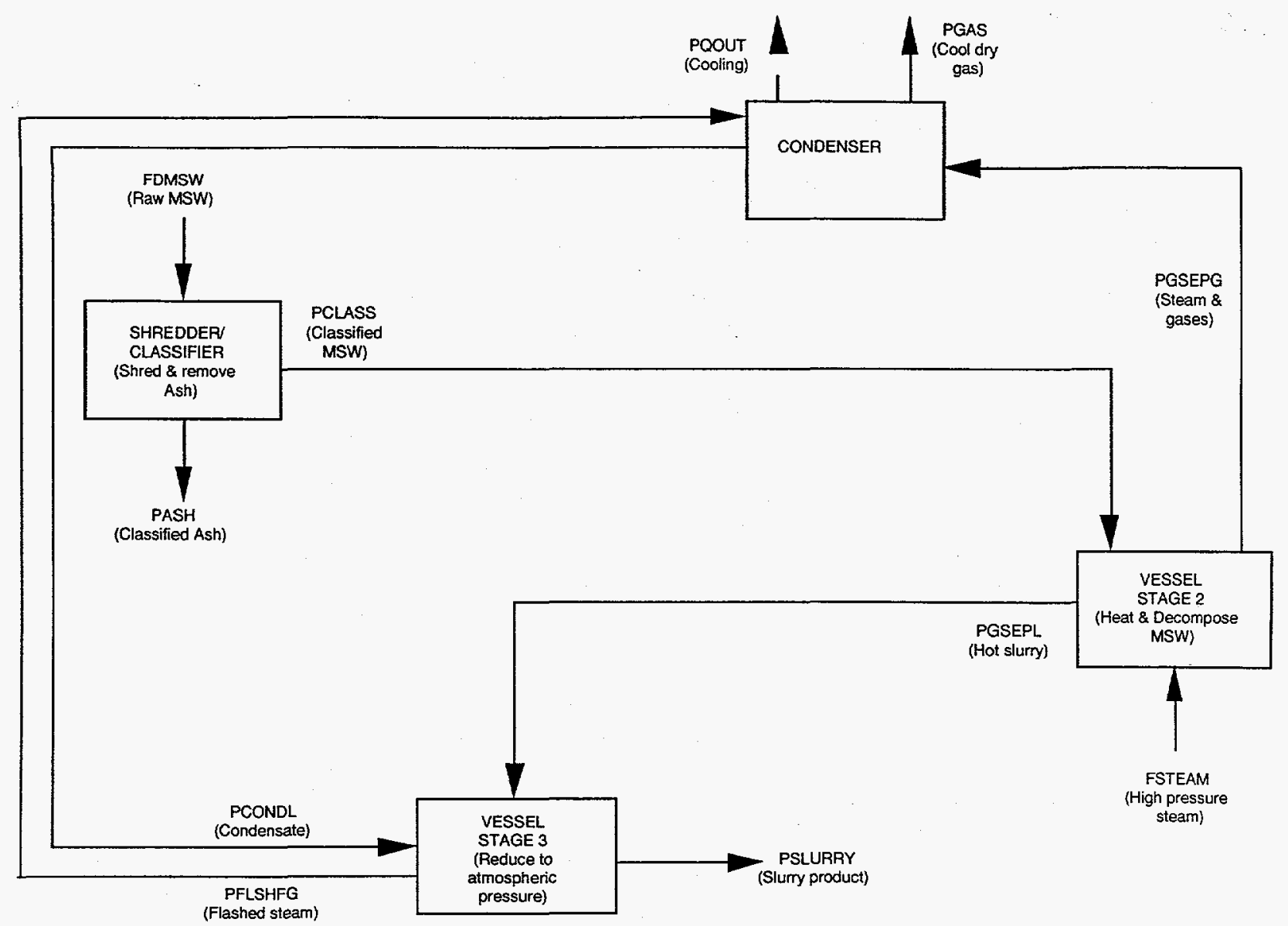

\begin{tabular}{|c|c|c|c|c|c|c|c|c|}
\hline Stream & FDMSW & FSTEAM & PASH & PSLURRY & PGAS & PCLASS & PHEATCG & PHEA \\
\hline Total Flow (kg/s) & 30 & 16.3 & 2.72 & 42.3 & 1.34 & 27.3 & 1.43 & 32 \\
\hline Pressure (MPa) & 0.1 & 11.2 & 0.1 & 0.1 & 0.1 & 0.1 & 9.8 & 9. \\
\hline Temperature (C) & 25 & 320 & 25 & 100 & 40 & 25 & 197 & 19 \\
\hline \multicolumn{9}{|l|}{ Conventional } \\
\hline Flow (kg/s) & 7.5 & 16.3 & & 26.6 & 1.34 & 7.5 & 1.43 & 12 \\
\hline Vapor fraction & 0 & 1 & & 0 & 1 & 0 & 1 & \\
\hline Flow (kmol/s) & 0.416 & 0.91 & & 1.47 & 0.037 & 0.416 & 0.042 & 0.1 \\
\hline $\mathrm{H} 2(\mathrm{~mol} \%)$ & 0 & 0 & & 0 & 6.5 & 0 & 5.6 & 0.8 \\
\hline $\mathrm{CO}(\mathrm{mol} \%)$ & 0 & 0 & & 0 & 3.7 & 0 & 3.2 & \\
\hline $\mathrm{CO} 2(\mathrm{~mol} \%)$ & 0 & 0 & & 0 & 74.0 & 0 & 63.8 & 0.3 \\
\hline $\mathrm{H} 2 \mathrm{O}(\mathrm{mol} \%)$ & 100 & 100 & & 100 & 7.5 & 100 & 20.2 & 99 \\
\hline $\mathrm{CH} 4$ (mol \%) & 0 & 0 & & 0 & 8.3 & 0 & 7.2 & 0.0 \\
\hline \multicolumn{9}{|l|}{ Nonconventional } \\
\hline Flow $(\mathrm{kg} / \mathrm{s})$ & 22.5 & & 2.72 & 15.74 & & 19.8 & & 19 \\
\hline ASH (wt \%) & 24.1 & & 100 & 17.2 & & 13.7 & & 13 \\
\hline ORG (wt \%) & 64.8 & & 0 & 0 & & 73.7 & & 73 \\
\hline GORG (wt \%) & 0 & & 0 & 66.9 & & 0 & & \\
\hline PLS (wt \%) & 11.1 & & 0 & 15.8 & & 12.6 & & 12 \\
\hline Stream & PQOUT & & & & & & & \\
\hline Energy flow (MW) & 31.6 & & & & & & & \\
\hline
\end{tabular}

Figure 10. Computed results for one preheat bed. 


\begin{tabular}{|c|c|c|c|c|}
\hline $\mathrm{CL}$ & PGSEPG & PGSEPL & PFLSHFG & PCONDL \\
\hline & 6.76 & 42.2 & 12.4 & 12.5 \\
\hline & 10.0 & 10.0 & 0.1 & 0.1 \\
\hline & 300 & 300 & 100 & 40 \\
\hline & & & & \\
\hline & 6.76 & 26.5 & 12.4 & 12.5 \\
\hline & 1 & 0 & 1 & 0 \\
\hline & 0.334 & 1.47 & 0.689 & 0.694 \\
\hline & 0.73 & 0 & 0 & 0 \\
\hline & 0.41 & 0 & 0 & 0 \\
\hline & 8.84 & 0.02 & 0.07 & 0.03 \\
\hline & 89.08 & 99.97 & 99.92 & 99.96 \\
\hline & 0.93 & 0 & 0 & 0 \\
\hline & & & & \\
\hline & & 15.7 & & \\
\hline & & 17.2 & & \\
\hline & & 0 & & \\
\hline & & 66.9 & & \\
\hline & & 15.8 & & \\
\hline & & & & \\
\hline & & & & \\
\hline & & & & \\
\hline
\end{tabular}




\section{Computed Results for Two Preheat Beds}

As described earlier, a second preheat stage can be added to the process. This stage is accompanied by an additional pressure letdown stage, see Fig. 4 . For a fixed operating pressure and temperature for the reaction stage, stage 4 , this two bed preheat process has three additional process parameters. These are the pressure differences between stages feeding the preheat beds and the preheat beds themselves, and the pressure for the intermediate pressure reduction, stage 5 .

To determine the optimum pressure for the intermediate pressure letdown, stage 5, a series of runs were done. The pressure of the reaction stage was again held constant at $10 \mathrm{MPa}$ and a pressure difference of $0.2 \mathrm{MPa}$ was assumed to exist between preheat beds and their corresponding feed gas beds. Selected results of these calculations are listed in Tables $6 \mathrm{a} \& \mathrm{~b}$. In these tables the PFLSHAG pressure is the pressure of stage 5 , the intermediate pressure letdown.

Table 6a. Computed results for the two preheat bed case as a function of the pressure difference between the reaction vessel and the preheat bed. The reactor vessel pressure is held constant at $10 \mathrm{MPa}$.

\begin{tabular}{|cccccccc|}
\hline $\begin{array}{c}\text { PFLSHAG } \\
\begin{array}{c}\text { Pressure } \\
(\mathrm{MPa})\end{array}\end{array}$ & $\begin{array}{c}\text { FSTEAM } \\
\text { Rate } \\
(\mathrm{kg} / \mathrm{s})\end{array}$ & $\begin{array}{c}\text { PSLURRY } \\
\text { Solids } \\
(\text { wt. } \%)\end{array}$ & $\begin{array}{c}\text { POOT } \\
(\mathrm{MW})\end{array}$ & $\begin{array}{c}\text { PHEATCG } \\
\text { Rate } \\
(\mathrm{kg} / \mathrm{s})\end{array}$ & $\begin{array}{c}\text { PHEATCL } \\
\text { Temperature } \\
(\mathrm{C})\end{array}$ & $\begin{array}{c}\text { PHEATBG } \\
\text { Rate } \\
(\mathrm{kg} / \mathrm{s})\end{array}$ & $\begin{array}{c}\text { PHEATBL } \\
\text { Temperature } \\
(\mathrm{C})\end{array}$ \\
\hline 0.4 & 14.2 & 39.2 & 26.2 & 1.7 & 234 & 9.3 & 120 \\
0.8 & 13.1 & 40.3 & 23.6 & 1.9 & 250 & 6.4 & 159 \\
1.5 & 12.1 & 41.4 & 21.0 & 2.2 & 265 & 3.4 & 192 \\
2.5 & 11.2 & 42.4 & 18.8 & 2.6 & 276 & 0.3 & 219 \\
2.6 & 11.1 & 42.5 & 18.7 & 2.6 & 276 & 0.1 & 220 \\
2.7 & 11.1 & 42.5 & 18.7 & 2.6 & 276 & 0.0 & 219 \\
3 & 11.4 & 42.1 & 19.3 & 2.5 & 273 & 0.0 & 217 \\
4 & 12.2 & 41.2 & 21.4 & 2.1 & 262 & 0.0 & 186 \\
5 & 13.1 & 40.3 & 23.6 & 1.9 & 250 & 0.0 & 157 \\
6 & 14.0 & 39.4 & 25.8 & 1.7 & 237 & 0.0 & 126 \\
7 & 14.9 & 38.5 & 28.1 & 1.6 & 222 & 0.0 & 91 \\
8 & 15.8 & 37.7 & 30.2 & 1.5 & 206 & 0.0 & 52 \\
9 & 16.2 & 37.3 & 31.3 & 1.4 & 197 & 0.0 & 28 \\
\hline
\end{tabular}


Table 6b. Computed results for the two preheat bed case as a function of the pressure difference between the reaction vessel and the preheat bed. The reactor vessel pressure is held constant at $10 \mathrm{MPa}$.

\begin{tabular}{|ccccccc|}
\hline $\begin{array}{c}\text { PFLSHAG } \\
\text { Pressure } \\
(\mathrm{MPa})\end{array}$ & $\begin{array}{c}\text { PGSEPG } \\
\begin{array}{c}\text { Rate } \\
(\mathrm{kg} / \mathrm{s})\end{array}\end{array}$ & $\begin{array}{c}\text { PGSEPG } \\
\text { Temperature } \\
(\mathrm{C})\end{array}$ & $\begin{array}{c}\text { PFLSHAG } \\
\text { Rate } \\
(\mathrm{kg} / \mathrm{s})\end{array}$ & $\begin{array}{c}\text { PFLSHAG } \\
\text { Temperature } \\
(\mathrm{C})\end{array}$ & $\begin{array}{c}\text { PFLSHFG } \\
\text { Rate } \\
(\mathrm{kg} / \mathrm{s})\end{array}$ & $\begin{array}{c}\text { PCONDL } \\
\text { Rate } \\
(\mathrm{kg} / \mathrm{s})\end{array}$ \\
\hline 0.4 & 6.6 & 300 & 11.7 & 144 & 0.6 & 10.2 \\
0.8 & 6.5 & 300 & 10.3 & 171 & 2.1 & 9.0 \\
1.5 & 6.4 & 300 & 8.6 & 199 & 3.8 & 8.0 \\
2.5 & 6.4 & 300 & 6.9 & 224 & 5.6 & 7.3 \\
2.6 & 6.4 & 300 & 6.7 & 226 & 5.8 & 7.2 \\
2.7 & 6.4 & 300 & 6.6 & 229 & 5.9 & 7.3 \\
3 & 6.4 & 300 & 6.1 & 234 & 6.3 & 7.5 \\
4 & 6.4 & 300 & 4.8 & 251 & 7.6 & 8.4 \\
5 & 6.5 & 300 & 3.7 & 265 & 8.7 & 9.3 \\
6 & 6.6 & 300 & 2.6 & 276 & 9.8 & 10.2 \\
7 & 6.6 & 300 & 1.6 & 286 & 10.9 & 11.1 \\
8 & 6.7 & 300 & 0.6 & 295 & 11.8 & 12.0 \\
9 & 6.8 & 300 & 0.1 & 299 & 12.3 & 12.4 \\
\hline
\end{tabular}

The computed results, see Fig. 11, indicate that an optimum exists for the stage 5 pressure. It is $2.6 \mathrm{MPa}$. At this pressure the slurry solids concentration is a maximum, and the steam flow rate and cooling requirement are a minimum. The reason for the optimum becomes clear when considering the results plotted in Fig 12. As the stage 5 pressure is increased, the amount of gas, stream PHEATBG, exiting the first preheat bed, stage 2, decreases rapidly. As $2.6 \mathrm{MPa}$ is approached this flow goes to zero. This means that the bed has absorbed all the heat energy from the intermediate pressure letdown bed and the stage 2 bed temperature is at a maximum. As the pressure is further increased, the amount of steam reaching the bed from the stage 5 letdown decreases, stream PFLSHAG, while the steam produced, stream PFLSHAG, from the final letdown, stage 6 , increases to compensate. This shifting of steam between the stages causes a decrease in the steam which can be captured and thus a loss of efficiency. It is true that the steam, PHEATCG, exiting the second preheat bed, stage 3 , continues to decline as the pressure increases, see Fig. 13, but this change is less than the shift of steam production from stage 5 to stage 6 . 


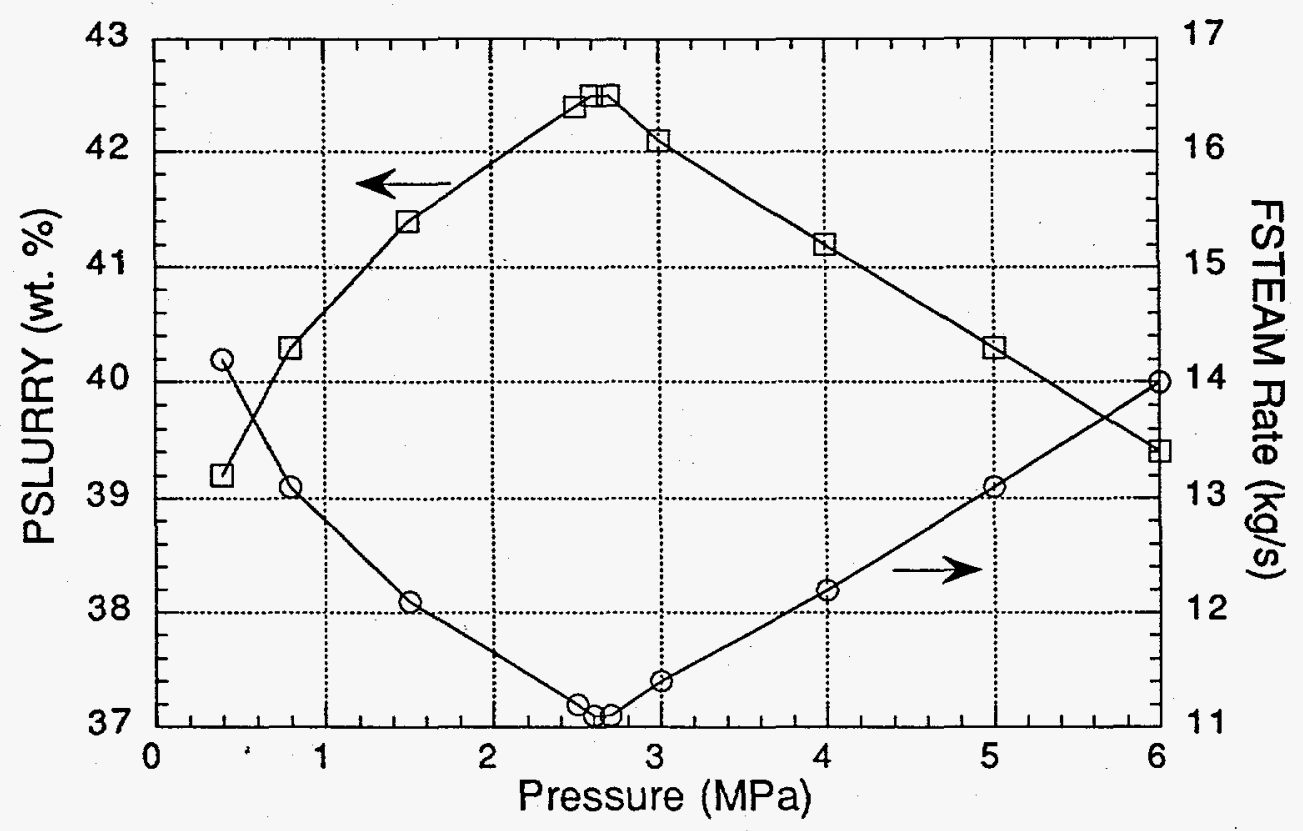

Figure 11. Computed product slurry solids content and required steam injection rate as a function of the second preheat bed pressure for a two preheat bed system.

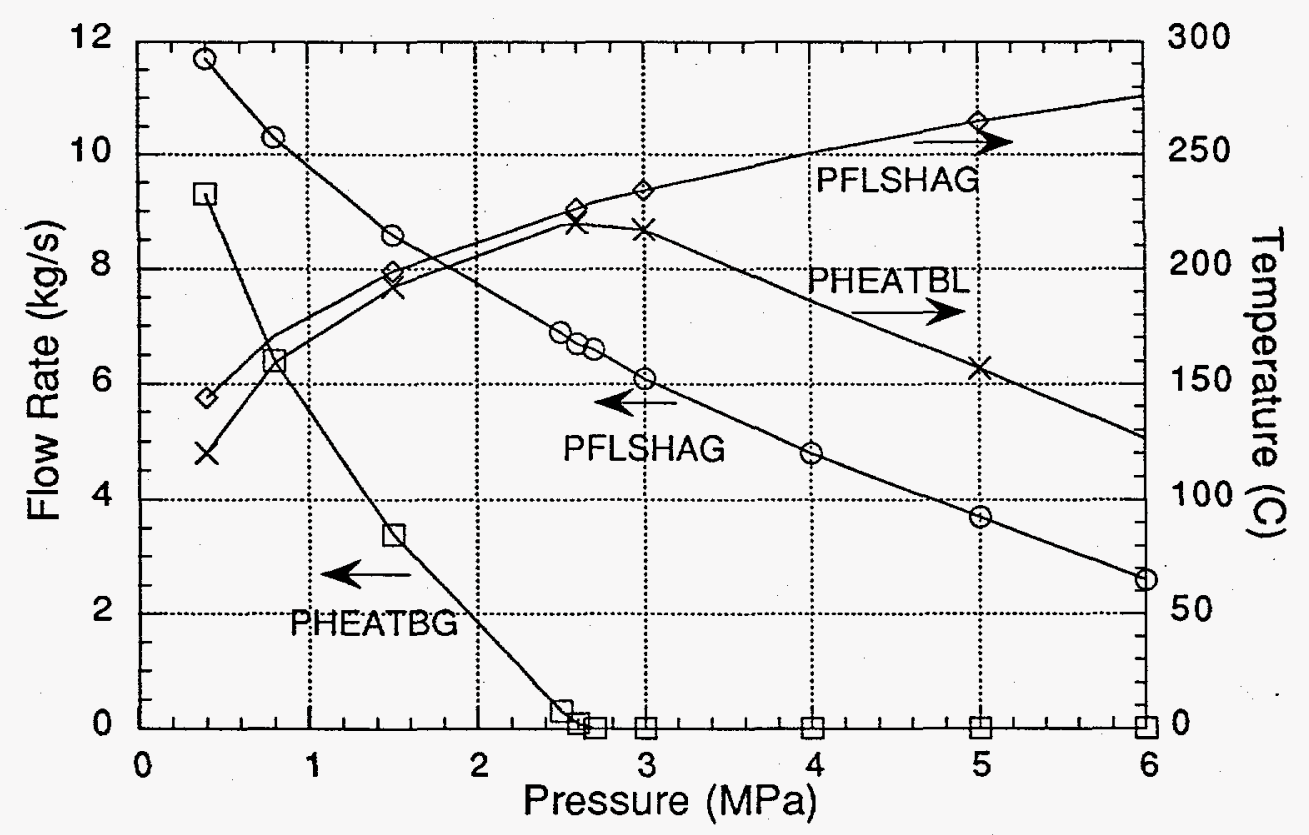

Figure 12. Computed flow rates and temperatures of gas streams exiting the preheat and flash beds as a function of the second preheat bed pressure for a two preheat bed system. 


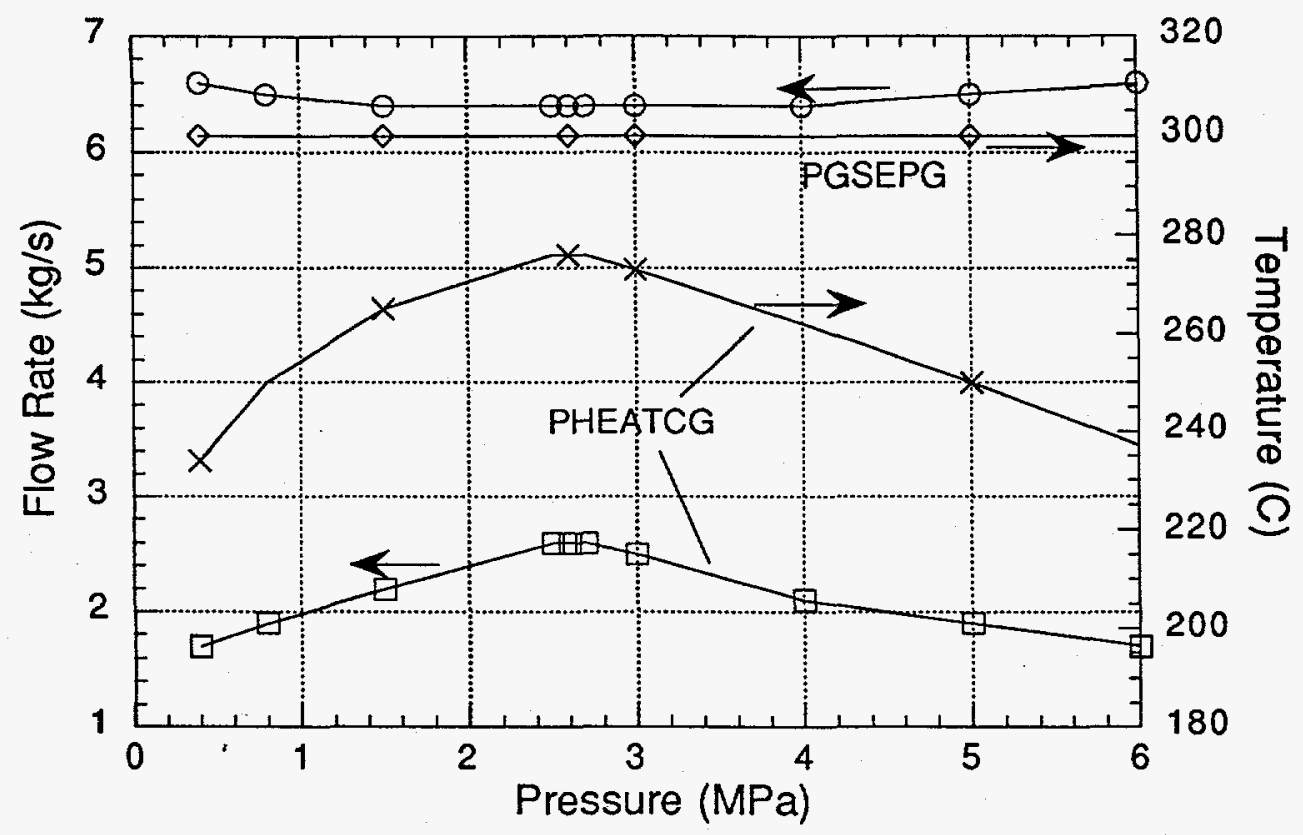

Figure 13 Computed flow rates and temperatures of gas streams exiting the high pressure preheat bed and the reactor bed as a function of the second preheat bed pressure for a two preheat bed system.

A complete set of computed results for the optimum case, pressure equal to 2.6 $\mathrm{MPa}$, is given in Fig. 14. This optimum case shows considerable improvement in process performance compared to the optimum one preheat bed case. The injection steam flow is $11.1 \mathrm{~kg} / \mathrm{s}$ compared to $16.4 \mathrm{~kg} / \mathrm{s}$, the solid content is 42.5 wt.\% compared to $37.2 \mathrm{wt} . \%$ and the required cooling is $18.7 \mathrm{MW}$ compared to $31.6 \mathrm{MW}$.

To explore the change in efficiency as a function of the pressure differences between preheat beds and source beds, a series of runs was performed in which the optimum intermediate pressure was found for each choice of pressure differentials. Selected results from these calculations are shown in Table 7, where pressure difference 1 is associated with stage 2 preheat bed and pressure difference 2 is associated with the stage 3 preheat bed. Again it is seen, as was the case with the single preheat bed, that the exact level of the pressure difference used does not have a large influence on the process performance until the pressure differences get very large. In addition, the table indicates that the computed optimum pressure is also a very weak function of the pressure differences. 


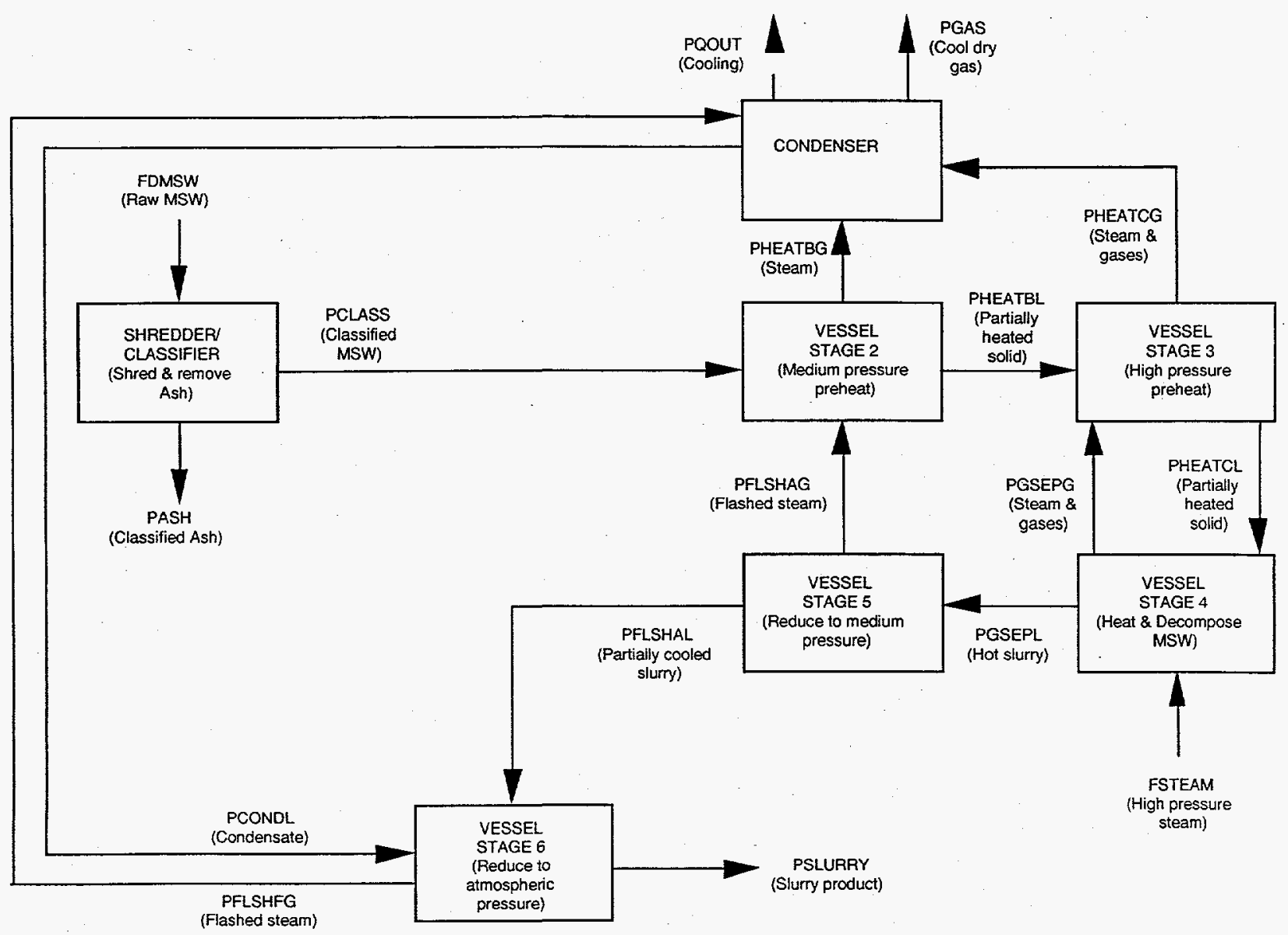

\begin{tabular}{|c|c|c|c|c|c|c|c|c|}
\hline Stream & FDMSW & FSTEAM & PASH & PSLURRY & PGAS & PCLASS & PHEATBG & PHEA \\
\hline Total Flow $(\mathrm{kg} / \mathrm{s})$ & 30 & 11.2 & 2.72 & 37.1 & 1.34 & 27.3 & 0.14 & 33 \\
\hline Pressure (MPa) & 0.1 & 11.2 & 0.1 & 0.1 & 0.1 & 0.1 & 2.4 & 2 \\
\hline Temperature (C) & 25 & 320 & 25 & 100 & 40 & 25 & 220 & $\overline{22}$ \\
\hline \multicolumn{9}{|l|}{ Conventional } \\
\hline Flow $(\mathrm{kg} / \mathrm{s})$ & 7.5 & 11.2 & & 21.4 & 1.34 & 7.5 & 0.14 & 14 \\
\hline Vapor fraction & 0 & 1 & & 0 & 1 & 0 & 1 & \\
\hline Flow $(\mathrm{kmol} / \mathrm{s})$ & 0.416 & 0.62 & & 1.19 & 0.037 & 0.416 & 0.0075 & 0.7 \\
\hline H2 (mol \%) & 0 & 0 & & 0 & 6.5 & 0 & 0.33 & \\
\hline $\mathrm{CO}(\mathrm{mol} \%)$ & 0 & 0 & & 0 & 3.7 & 0 & 0.09 & \\
\hline $\mathrm{CO} 2(\mathrm{~mol} \%)$ & 0 & 0 & & 0 & 74.0 & 0 & 3.2 & \\
\hline $\mathrm{H} 2 \mathrm{O}(\mathrm{mol} \%)$ & 100 & 100 & & 100 & 7.5 & 100 & 96.24 & 99 \\
\hline $\mathrm{CH} 4(\mathrm{~mol} \%)$ & 0 & 0 & & 0 & 8.3 & 0 & 0.15 & \\
\hline \multicolumn{9}{|l|}{ Nonconventional } \\
\hline Flow $(\mathrm{kg} / \mathrm{s})$ & 22.5 & & 2.72 & 15.74 & & 19.8 & & 78 \\
\hline ASH (wt \%) & 24.1 & & 100 & 17.2 & & 13.7 & & 13 \\
\hline ORG (wt \%) & 64.8 & & 0 & 0 & & 73.7 & & 79 \\
\hline GORG (wt \%) & 0 & & 0 & 66.9 & & 0 & & \\
\hline PLS (wt \%) & 11.1 & & 0 & 15.8 & & 12.6 & & $\overline{12}$ \\
\hline Stream & PQOUT & & & & & & & \\
\hline Energy flow (MW) & 18.7 & & & & & & & \\
\hline
\end{tabular}

Figure 14. Computed results for two preheat beds. 


\begin{tabular}{|c|c|c|c|c|c|c|c|c|}
\hline BL & PHEATCG & PHEATCL & PGSEPG & PGSEPL & PFLSHAG & PFLSHAL & PFLSHFG & PCONDL \\
\hline & 2.64 & 37.6 & 6.37 & -42.4 & 6.72 & 35.7 & 5.79 & 7.24 \\
\hline & 9.8 & 9.8 & 10.0 & 10.0 & 2.6 & 2.6 & 0.1 & 0.1 \\
\hline & 276 & 276 & 300 & 300 & 226 & 226 & 100 & 40 \\
\hline & & & & & & & & \\
\hline & 2.64 & 17.8 & 6.37 & 26.6 & 6.72 & 19.9 & 5.79 & 7.24 \\
\hline & 1 & 0 & 1 & 0 & 1 & 0 & 1 & 0 \\
\hline & 0.109 & 0.99 & 0.316 & 1.48 & 0.373 & 1.11 & 0.321 & 0.402 \\
\hline & 2.15 & 0 & 0.76 & 0 & 0.01 & 0 & 0 & 0 \\
\hline & 1.24 & 0 & 0.43 & 0 & 0 & 0 & 0 & 0 \\
\hline & 24.65 & 0.07 & 8.75 & 0.02 & 0.07 & 0 & 0.04 & 0.03 \\
\hline & 69.16 & 99.92 & 89.08 & 99.97 & 99.91 & 100 & 99.96 & 99.96 \\
\hline & 2.79 & 0 & 0.97 & 0 & 0 & 0 & 0 & 0 \\
\hline & & & & & & & & \\
\hline & & 19.8 & & 15.7 & & 15.7 & & \\
\hline & & 13.7 & & 17.2 & & 17.2 & & \\
\hline & & 73.7 & & 0 & & 0 & & \\
\hline & & 0 & & 66.9 & & 66.9 & & \\
\hline & & 12.6 & & 15.8 & & 15.8 & & \\
\hline & & & & & & & & \\
\hline & & & & & & & & \\
\hline
\end{tabular}


Table 7. Computed results for the two preheat bed case for the optimum choice of the intermediate bed letdown pressure as a function of the pressure differences between preheat beds and source beds. Pressure difference 1 is associated with the first preheat bed, stage 2, and pressure difference 2 is associated with the second preheat bed, stage 3.

\begin{tabular}{|c|c|c|c|c|c|}
\hline $\begin{array}{c}\text { Pressure } \\
\text { Difference } \\
1 \\
\text { (MPa) }\end{array}$ & $\begin{array}{c}\text { Pressure } \\
\text { Difference } \\
2 \\
\text { (MPa) }\end{array}$ & $\begin{array}{c}\text { Flash } \\
\text { Pressure } \\
\text { (MPa) }\end{array}$ & $\begin{array}{c}\text { FSTEAM } \\
\text { Rate } \\
(\mathrm{kg} / \mathrm{s})\end{array}$ & $\begin{array}{l}\text { PSLURRY } \\
\text { Solids } \\
\text { (wt. \%) }\end{array}$ & $\begin{array}{l}\text { PQOUT } \\
\text { (MW) }\end{array}$ \\
\hline 0.2 & 0.2 & 2.6 & 11.1 & 42.5 & 18.7 \\
\hline 0.4 & 0.2 & 2.7 & 11.2 & 42.3 & 18.9 \\
\hline 1.0 & 1.0 & 3.0 & 11.6 & 41.9 & 19.8 \\
\hline 0.2 & 1.0 & 2.6 & 11.3 & 42.3 & 19.1 \\
\hline 1.0 & 0.2 & 3.0 & 11.5 & 42.1 & 19.5 \\
\hline 0.2 & 3.0 & 2.6 & 11.9 & 41.6 & 20.5 \\
\hline 0.2 & 6.0 & 2.6 & 13.6 & 39.8 & 24.7 \\
\hline 0.2 & 6.0 & 2.6 & 14.8 & 38.7 & 27.6 \\
\hline
\end{tabular}

\section{Computed Results for Three Preheat Beds}

Even more heat recovery can be obtained by adding additional heat recovery beds. Adding a third preheat bed and its associated pressure letdown stage adds two additional parameters to the system, the pressure of the pressure letdown stage and the pressure difference between the letdown stage and the preheat bed. A process with three preheat beds is shown in Fig. 5. In this system there are five process parameters dealing with the manner in which the intermediate pressure letdown stages, stages 5 \& 6 , and the preheat stages, stages $2-4$, operate. These are the two flash pressures used in stages $5 \& 6$ and the three pressure differentials between the three preheat beds and their source beds.

A series of runs was performed for the three preheat bed system in which the optimum flash pressures for the letdown stages were determined as a function of pressure differences between preheat beds and their source beds. Selected results from these runs are listed in Table 8. Again, it is found that the exact level of the pressure differences does not play a crucial role in determining the system performance.

In Fig. 14, the computed solids content of the slurry and steam flow rate are plotted for the cases where the pressure differences between preheat and letdown beds are all assumed equal. For these cases the change in slurry composition and steam flow are essentially a linear function of the pressure difference. Note, however, that the variation is over only a limited range for each variable. 
Table 8. Computed results for the three preheat bed case for the optimum choice of the intermediate bed letdown pressures as a function of the pressure differences between preheat beds and source beds. Pressure difference 1 is associated with the first preheat bed, stage 2, pressure difference 2 is associated with the second preheat bed, stage 3 , and pressure difference 3 is associated with the third preheat bed, stage 4 .

\begin{tabular}{|c|c|c|c|c|c|c|c|}
\hline $\begin{array}{c}\text { Pressure } \\
\text { Difference } \\
1 \\
\text { (MPa) }\end{array}$ & $\begin{array}{c}\text { Pressure } \\
\text { Difference } \\
2 \\
\text { (MPa) } \\
\end{array}$ & $\begin{array}{c}\text { Pressure } \\
\text { Difference } \\
3 \\
(\mathrm{MPa})\end{array}$ & $\begin{array}{c}\text { Flash } \\
\text { Pressure } \\
1 \\
\text { (MPa) }\end{array}$ & $\begin{array}{c}\text { Flash } \\
\text { Pressure } \\
2 \\
(\mathrm{MPa})\end{array}$ & $\begin{array}{c}\text { FSTEAM } \\
\text { Rate } \\
\text { (kg/s) }\end{array}$ & $\begin{array}{l}\text { PSLURRY } \\
\text { Solids } \\
\text { (wt. \%) }\end{array}$ & $\begin{array}{l}\text { PCOUT } \\
\text { (MW) }\end{array}$ \\
\hline 0.2 & 0.2 & 0.2 & 4.6 & 1.2 & 10.1 & 43.7 & 16.0 \\
\hline 0.6 & 0.6 & 0.6 & 4.5 & 1.4 & 10.3 & 43.4 & 16.7 \\
\hline 1.0 & 1.0 & 1.0 & 4.6 & 1.7 & 10.7 & 43.0 & 17.5 \\
\hline 1.5 & 1.5 & 1.5 & 4.4 & 1.9 & 11.1 & 42.5 & 18.6 \\
\hline 2.0 & 2.0 & 2.0 & 4.5 & 2.3 & 11.5 & 42.1 & 19.5 \\
\hline 3.0 & 3.0 & 3.0 & 5.2 & 3.2 & 12.2 & 41.3 & 21.2 \\
\hline 4.0 & 4.0 & 4.0 & 4.2 & 5.5 & 13.1 & 40.3 & 23.5 \\
\hline 0.2 & 0.5 & 0.9 & 3.7 & 1.4 & 10.8 & 42.9 & 17.7 \\
\hline 1.0 & 1.0 & 0.2 & 4.0 & 1.5 & 10.7 & 42.9 & 17.6 \\
\hline 0.2 & 0.2 & 1.0 & 3.6 & 1.3 & 10.7 & 42.9 & 17.6 \\
\hline 0.2 & 1.0 & 0.2 & 4.3 & 1.4 & 10.6 & 43.1 & 17.2 \\
\hline
\end{tabular}

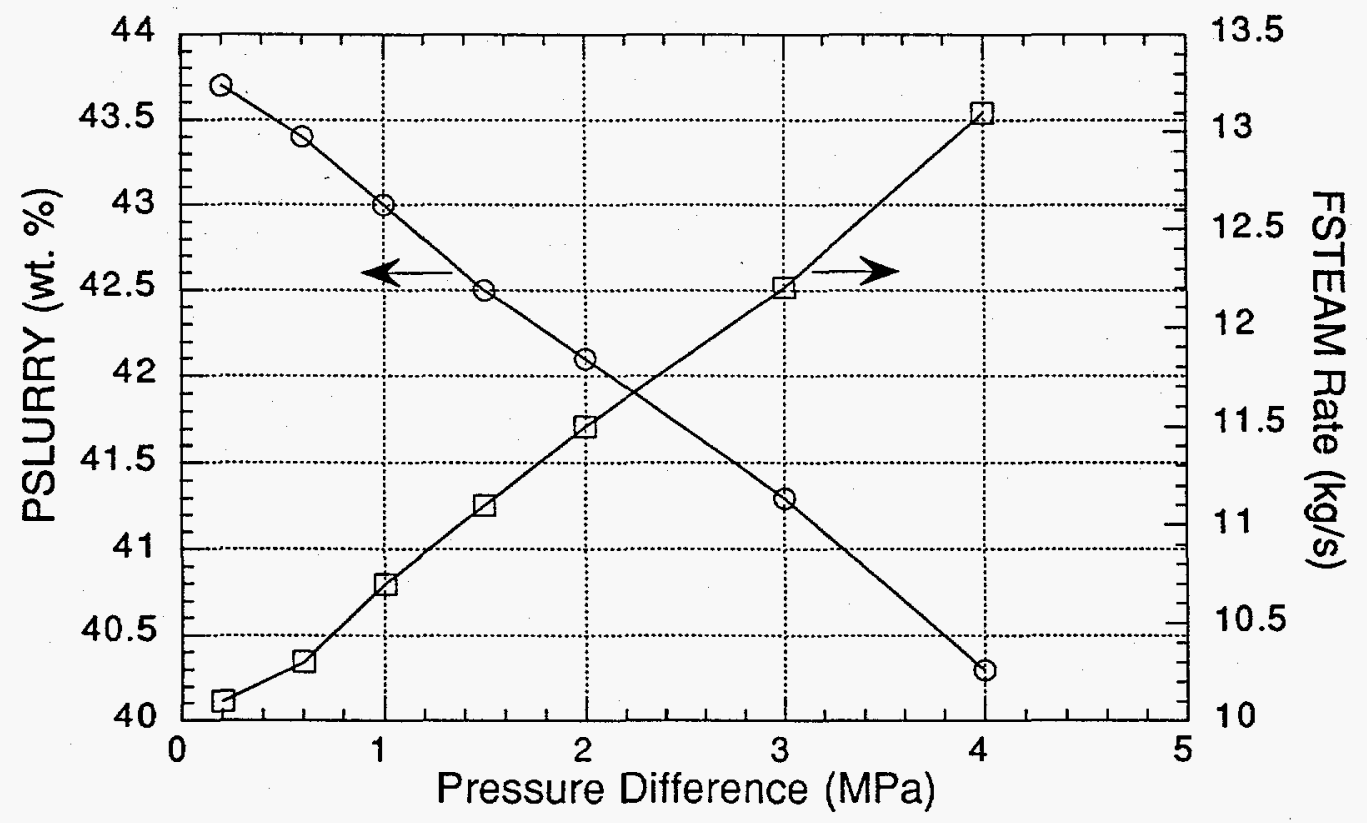

Figure 15 Computed product slurry solids content and steam injection rate as a function of the pressure difference between beds for a three preheat bed system.

A complete set of computed results for a three preheat bed operation in which the pressure difference is $0.2 \mathrm{MPa}$ between preheat and source beds is given in Fig. 16. For this case the final slurry has a solid content of $43 \mathrm{wt} . \%$ and the intermediate flash pressures are $4.6 \mathrm{MPa}$ and $1.2 \mathrm{MPa}$ for optimum performance. The reactor stage is operating at $10 \mathrm{MPa}$ and reaches a temperature of $300 \mathrm{C}$. 


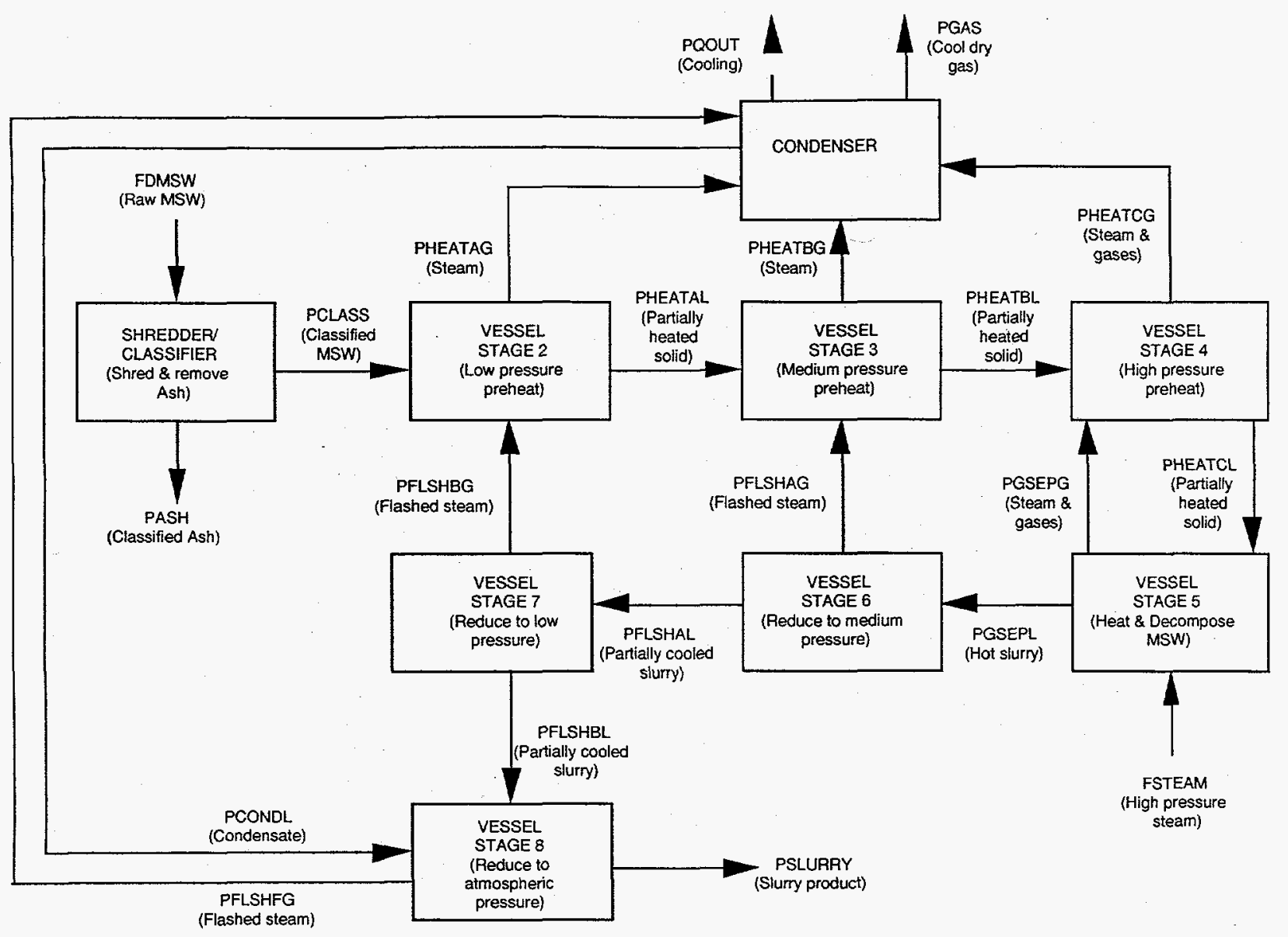

\begin{tabular}{|c|c|c|c|c|c|c|c|c|c|}
\hline Stream & FDMSW & FSTEAM & PASH & PSLURRY & PGAS & PCLASS & PHEATAG & PHEATAL & PHEATBC \\
\hline Total Flow $(\mathrm{kg} / \mathrm{s})$ & 30 & 10.1 & 2.72 & 36 & 1.34 & 27.3 & 0.2 & 32 & 0.14 \\
\hline Pressure (MPa) & 0.1 & 11.2 & 0.1 & 0.1 & 0.1 & 0.1 & 1.0 & 0.1 & 4.4 \\
\hline Temperature (C) & 25 & 320 & 25 & 100 & 40 & 25 & 180 & 180 & 254 \\
\hline Flow $(\mathrm{kg} / \mathrm{s})$ & 7.5 & 10.1 & & 20.3 & 1.34 & 7.5 & 0.2 & 12.23 & 0.14 \\
\hline Vapor fraction & 0 & 1 & & 0 & 1 & 0 & 1 & 0 & 1 \\
\hline Flow (kmol/s) & 0.416 & 0.558 & & 1.13 & 0.037 & 0.416 & 0.011 & 0.679 & 0.0076 \\
\hline $\mathrm{CO} 2(\mathrm{~mol} \%)$ & 0 & 0 & & 0 & 74.0 & 0 & 0.02 & 0 & 3 \\
\hline $\mathrm{H} 2 \mathrm{O}(\mathrm{mol} \%)$ & 100 & 100 & & 100 & 7.5 & 100 & 99.97 & 100 & 96.47 \\
\hline $\mathrm{CH} 4(\mathrm{~mol} \%)$ & 0 & 0 & & 0 & 8.3 & 0 & 0 & 0 & 0.14 \\
\hline \multicolumn{10}{|l|}{ Nonconventional } \\
\hline Flow $(\mathrm{kg} / \mathrm{s})$ & 22.5 & & 2.72 & 15.74 & & 19.8 & & 19.8 & \\
\hline ASH (wt \%) & 24.1 & & 100 & 17.2 & & 13.7 & & 13.7 & \\
\hline
\end{tabular}

Figure 16. Computed results for three preheat bed. 


\begin{tabular}{|c|c|c|c|c|c|c|c|c|c|c|}
\hline PHEATBL & PHEATCG & PHEATCL & PGSEPG & PGSEPL & PFLSHAG & PFLSHAL & PFLSHBG & PFLSHBL & PFLSHFG & PCONDL \\
\hline 36 & 3.63 & 38.7 & 6.32 & 42.5 & 4.16 & 38.3 & 4.94 & 33.4 & 3.43 & 6.07 \\
\hline 4.4 & 9.8 & 9.8 & 10.0 & 10.0 & 4.6 & 4.6 & 1.2 & 1.2 & 0.1 & 0.1 \\
\hline 254 & 288 & 288 & 300 & 300 & 259 & 259 & 188 & 188 & 100 & 40 \\
\hline & & & & & & & & & & \\
\hline 12.23 & 3.63 & 18.9 & 6.32 & 26.7 & 4.16 & 22.6 & 4.94 & 17.6 & 3.43 & 6.07 \\
\hline 0 & 1 & 0 & 1 & 0 & 1 & 0 & 1 & 0 & 1 & 0 \\
\hline 0.679 & 0.164 & 1.05 & 0.313 & 1.48 & 0.231 & 1.25 & 0.274 & 0.978 & 0.19 & 0.334 \\
\hline 0 & 1.44 & 0 & 0.76 & 0 & 0.01 & 0 & 0 & 0 & 0 & 0 \\
\hline 0 & 0.82 & 0 & 0.44 & 0 & 0 & 0 & 0 & 0 & 0 & 0 \\
\hline 0.01 & 16.43 & 0.04 & 8.73 & 0.02 & 0.12 & 0 & 0 & 0 & 0.05 & 0.03 \\
\hline 99.99 & 79.45 & 99.95 & 89.08 & 99.97 & 99.86 & 100 & 100 & 100 & 99.94 & 99.96 \\
\hline 0 & 1.86 & 0 & 0.98 & 0 & 0 & 0 & 0 & 0 & 0 & 0 \\
\hline & & & & & & & & & & \\
\hline 19.8 & & 19.8 & & 15.7 & & 15.7 & & 15.7 & & \\
\hline 13.7 & & 13.7 & & 17.2 & & 17.2 & & 17.2 & & \\
\hline 73.7 & & 73.7 & & 0 & & 0 & & 0 & & \\
\hline 0 & & 0 & & 66.9 & & 66.9 & & 66.9 & & \\
\hline 12.6 & & 12.6 & & 15.8 & & 15.8 & & 15.8 & & \\
\hline & & & & & & & & & & \\
\hline & & & & & & & & & & \\
\hline
\end{tabular}


Again, the results indicate that the addition of another preheat bed improves the process efficiency. The change in steam flow, process cooling and final solids content of slurry are summarized in Table 9 and Fig. 17 for each of process options considered (0-3 preheat beds). The results shown are the optimized results assuming a maximum reactor stage pressure of $10 \mathrm{MPa}$ and a $0.2 \mathrm{MPa}$ pressure difference between each preheat and source bed. The results indicate that amount of improvement in efficiency moving from two preheat beds to three is much less than moving from zero to one or one to two. Although the final choice of the number of preheat beds would require a more detailed design, based on the results presented here the two preheat bed system would appear to be the choice from an economic/efficiency standpoint.

Table 9. Comparison of direct steam heat process parameters as a function of the number of preheat beds.

\begin{tabular}{|cccc|}
\hline $\begin{array}{c}\text { Number of } \\
\text { Preheat } \\
\text { Beds }\end{array}$ & $\begin{array}{c}\text { FSTEAM } \\
\text { Rate } \\
(\mathrm{kg} / \mathrm{s})\end{array}$ & $\begin{array}{c}\text { PSLURRY } \\
\text { Solids } \\
(\mathrm{wt} . \%)\end{array}$ & $\begin{array}{c}\text { Cooling } \\
\text { PQOUT } \\
\text { (MW) }\end{array}$ \\
\hline 0 & 21.2 & 33.4 & 43.6 \\
1 & 16.4 & 37.2 & 31.6 \\
2 & 11.1 & 42.5 & 18.7 \\
3 & 10.1 & 43.7 & 16.0 \\
\hline
\end{tabular}

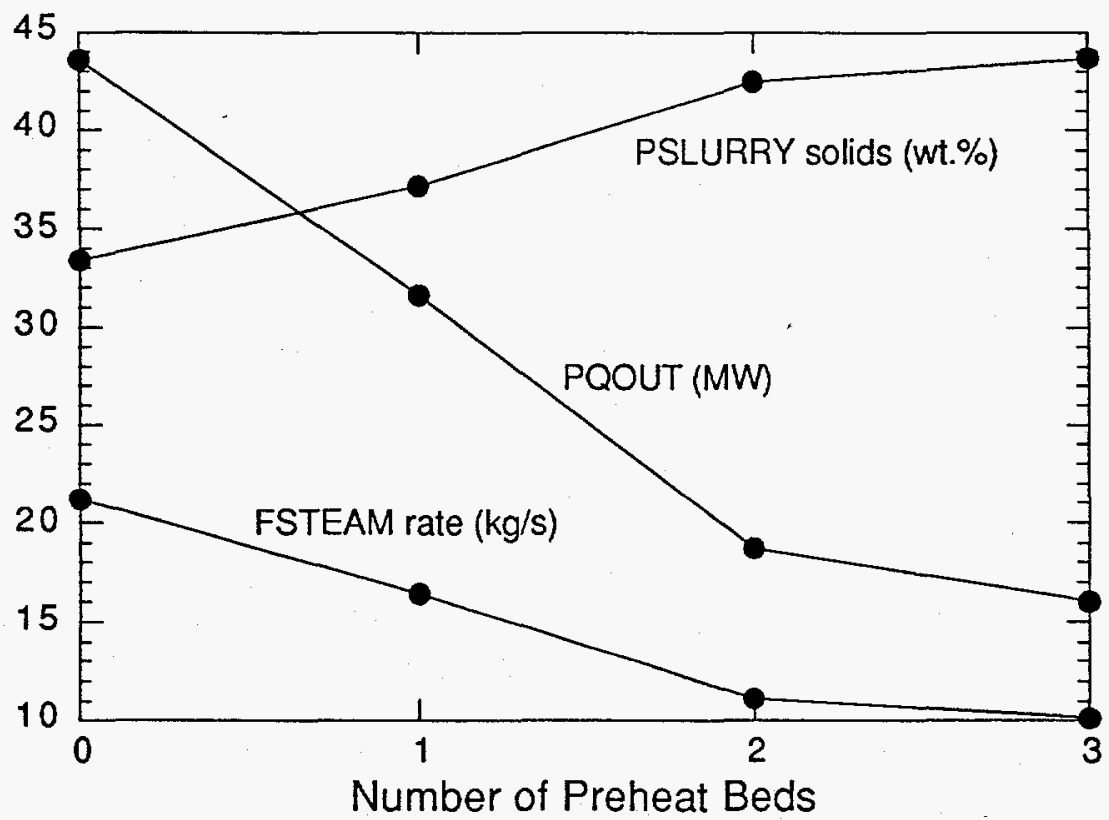

Figure 17 Computed results for optimized systems operating with a maximum pressure of $10 \mathrm{MPa}$ and pressure differential between preheat beds and source beds of $0.2 \mathrm{MPa}$. 


\section{ADDITIONAL TWO BED RESULTS}

In the above the primary focus has been on the performance of the process as a function of the number of preheat beds. In this section a number of other variables are examined. In these calculations the two preheat bed process has been used. The MSW feed rate of $30 \mathrm{~kg} / \mathrm{s}$ has been maintained and the desired reactor stage temperature of $300 \mathrm{C}$ and $10 \mathrm{MPa}$ is used except where noted. The calculations assume a $0.2 \mathrm{MPa}$ difference in pressure between preheat and source beds.

\section{MSW Water Content}

The water content of the raw MSW may vary with time of year or location. Since the water is a primary factor in the heat balance of the process, and can directly influence the water content of the final slurry, a series of runs was done with varying amounts of water in the feed. In these runs the amount of dry MSW was kept constant at $22.5 \mathrm{~kg} / \mathrm{s}$ ( $75 \%$ of the base case $30 \mathrm{~kg} / \mathrm{s}$ of raw feed).

Selected results are listed in Table 10 for water contents ranging from 15 to $35 \mathrm{wt} . \%$. The water content is computed to effect the final slurry solid content more than it effects the required steam flow or the required cooling. For a doubling of water content the slurry solid content drops by a factor of about $25 \%$. The final slurry product drops from a $48.4 \mathrm{wt} . \%$ level for MSW containing only a $15 \mathrm{wt} . \%$ water, to $36.3 \mathrm{wt}$.\% for a MSW water content of $35 \mathrm{wt} . \%$. The table also lists the range of water content of a final slurry product if the condensed water is not added to the final product. This shows that a slurry product with as high as a $60 \mathrm{wt}$.\% solids content could be produced without any need for thickening. Even for the wettest MSW the final product could have a $45 \mathrm{wt} . \%$ solid content.

Table 10. Selected computed results for a two preheat bed process as a function of water content of the MSW feed. The dry MSW feed rate is held constant at $22.5 \mathrm{~kg} / \mathrm{s}$.

\begin{tabular}{|lccccc|}
\hline & \multicolumn{5}{c|}{ Base } \\
\cline { 2 - 6 } MSW water (wt.\%) & 15 & 20 & 25 & 30 & 35 \\
FSTEAM (kg/s) & 10.1 & 10.6 & 11.1 & 11.9 & 12.9 \\
PSLURRY (kg/s) & 32.5 & 34.6 & 37.1 & 40.0 & 43.4 \\
PSLURRY Solids (wt.\%) & 48.4 & 45.5 & 42.4 & 39.3 & 36.3 \\
PCONDL (kg/s) & 6.6 & 6.9 & 7.2 & 7.7 & 8.4 \\
PSLURRY-PCONDL (kg/s) & 25.9 & 27.7 & 29.9 & 32.3 & 35.0 \\
PSLURRY-PCONDL Solids (wt.\%) & 60.7 & 56.8 & 52.6 & 48.7 & 45.0 \\
PQOUT & 17.2 & 17.8 & 18.7 & 19.9 & 21.5 \\
\hline
\end{tabular}

The solids content of the two possible slurry products are shown graphically in Fig. 17. Over the range studied the change in solid content is essentially linear with water content of the MSW feed. 


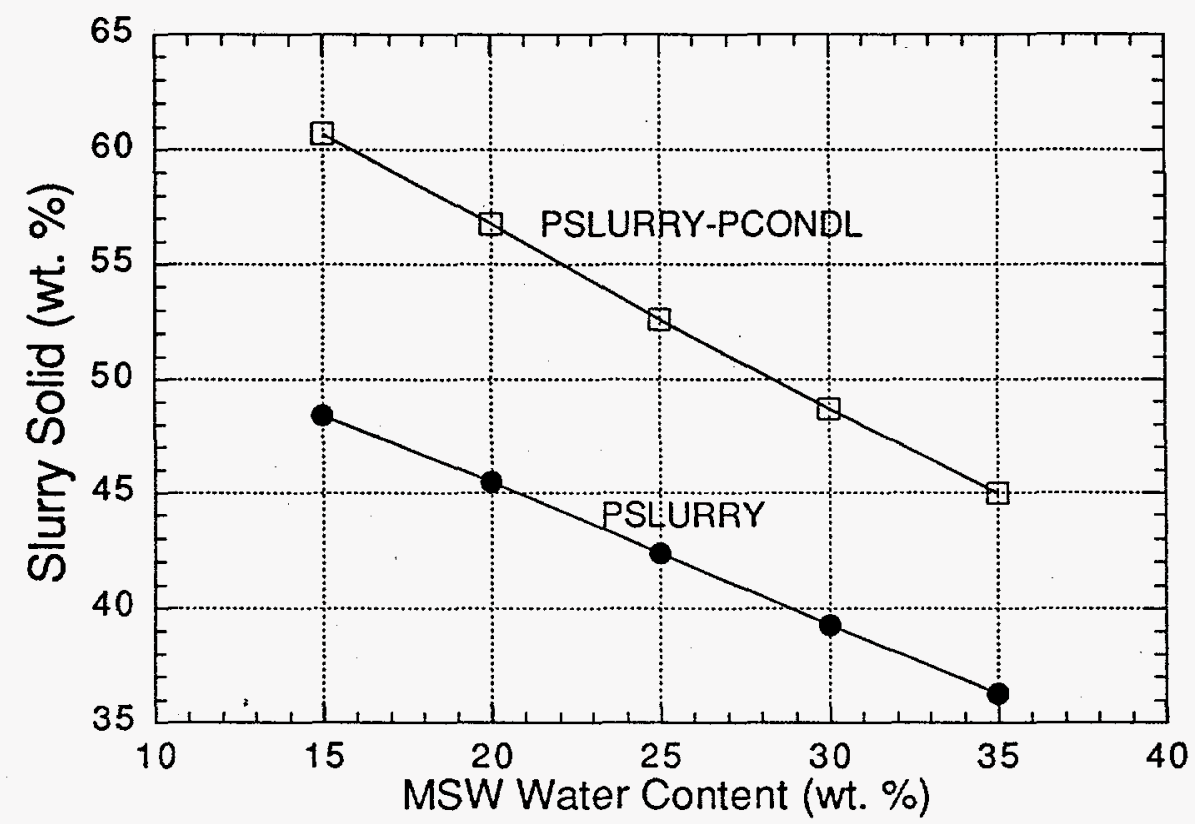

Figure 17. Computed product slurry solids content as a function of initial water content for a two preheat bed system.

Additional calculations were done to see if the optimum pressure for the intermediate pressure letdown stage was a function of the feed composition. Over this range of water content the optimum pressure was $2.6 \mathrm{MPa}$ for each case.

\section{Change in Heat of Reaction}

No actual measurements are known to be available for the heats of reaction for the MSW decomposition reactions. The value which has been used, $0.26 \mathrm{MJ} / \mathrm{kg}$ at $25 \mathrm{C}$, was obtained from heat of combustion data for newspaper and computed heats of combustion of the solid product ${ }^{1}$. The value is relatively small when compared to heats of combustion, but it is significant in relation to the heating, and maintaining the temperature, of the reacting slurry.

Since there is considerable uncertainty as to the true value, a case was run in which the heat of reaction was set to zero. This has been done by altering the heat of formation of solid product, ORG. Selected results are shown in Table 11.

This change in heat of reaction has a fairly large effect on required steam flow since the change in assumed heat of reaction is on the same order as the energy needed to heat the raw MSW. Changes in other important operating parameters are proportionately less than that for the steam flow. 
Table 11. Two preheat bed results for two different values of the decomposition heat of reaction.

\begin{tabular}{|lcc|}
\hline & & Zero Heat of \\
\cline { 2 - 3 } Heat of Reaction (MJ/kg-ORG) & 0.26 & Reaction \\
\cline { 2 - 3 } FSTEAM (kg/s) & 11.1 & 0 \\
PSLURRY (kg/s) & 37.1 & 8.8 \\
PSLURRY Solids (wt.\%) & 42.4 & 34.7 \\
PCONDL (kg/s) & 7.2 & 45.3 \\
PSLURRY-PCONDL (kg/s) & 29.9 & 6.5 \\
PSLURRY-PCONDL Solids (wt.\%) & 52.6 & 28.2 \\
PQOUT & 18.7 & 55.8 \\
\hline
\end{tabular}

\section{Ash Removal}

Raw MSW contains a fairly large fraction of nonorganic material, referred to here as $\mathrm{ASH}$. In the modeling it was assumed that the ASH component in the raw MSW could be reduced by one half as a result of upstream sorting and classification. In Table 12 results are shown for a case in which the ASH removal is increased to $75 \%$. Most of the process variables change very little. The largest, and most important change, is the increase in the organic, PLS+GORG, content of the slurry. This represents about a $4 \%$ increase in heating value.

Table 12. Two preheat bed results for two different ash removal efficiencies.

\begin{tabular}{|lcc|}
\hline & Base & \\
\cline { 2 - 3 } ASH Removal (\%) & 50 & 75 \\
FSTEAM (kg/s) & 11.1 & 11.1 \\
PSLURRY (kg/s) & 37.1 & 35.7 \\
PSLURRY Solids (wt.\%) & 42.4 & 40.3 \\
PSLURRY PLS+GORG (wt.\%) & 35.1 & 36.5 \\
PCONDL (kg/s) & 7.2 & 7.2 \\
PSLURRY-PCONDL (kg/s) & 29.9 & 28.5 \\
PSLURRY-PCONDL Solids (wt.\%) & 52.6 & 50.5 \\
PSLURRY-PCONDL PLS+GORG (wt.\%) & 43.5 & 45.7 \\
PQOUT & 18.7 & 18.5 \\
\hline
\end{tabular}

\section{Reaction Temperature}

The necessary reaction temperature for the hydrothermal process step has not been firmly established. To determine the influence of operating at other than the $300 \mathrm{C}$, cases were run using $270 \mathrm{C}$ and $330 \mathrm{C}$ for the desired reaction temperature. The reaction pressure was kept $1.5 \mathrm{MPa}$ above the water vapor pressure at the temperature of interest. The injected steam temperature was maintained $20 \mathrm{C}$ above the reaction temperature. In each calculation the same decomposition reaction was assumed and all the ORG component was assumed to have decomposed. 
Selected results of the calculations are shown in Table 13. In this case the optimum intermediate letdown pressure did change from case to case and is listed in the table as the "Flash Pressure". The results indicate that the required reaction pressure has a considerable influence on the efficiency of the process. As the temperature increases the efficiency decreases. These results indicate that there may be considerable incentive to tradeoff reaction temperature with residence time in the final process design.

Table 13. Two preheat bed results for three different reaction temperatures.

\begin{tabular}{|lccc|}
\hline & \multicolumn{3}{c|}{ Base } \\
\cline { 2 - 4 } Reaction Temperature (C) & 270 & 300 & 330 \\
Reaction Pressure (MPa) & 7.0 & 10.0 & 14.4 \\
Flash Pressure (MPa) & 1.5 & 2.6 & 4.7 \\
FSTEAM (kg/s) & 8.6 & 11.1 & 15.8 \\
PSLURRY (kg/s) & 34.5 & 37.1 & 41.7 \\
PSLURRY Solids (wt.\%) & 45.6 & 42.4 & 37.7 \\
PCONDL (kg/s) & 8.6 & 7.2 & 11.3 \\
PSLURRY-PCONDL (kg/s) & 25.9 & 29.9 & 30.4 \\
PSLURRY-PCONDL Solids (wt.\%) & 53.1 & 52.6 & 51.7 \\
PQOUT & 12.5 & 18.7 & 29.1 \\
\hline
\end{tabular}

\section{Reaction Pressure}

The influence of the reaction stage pressure was examined in a previous section for a system with no preheat beds. Here, this process parameter is varied over a range of 9-14 MPa for the two preheat bed case. In each run, the reaction stage temperature is held constant at $300 \mathrm{C}$, but the injected steam temperature is increased in to keep it above the saturation temperature. The intermediate letdown pressure was varied to determine the optimum level. The optimum level was found not to be a function of the operating pressure. In Table 14 selected results for the runs are listed, all at the computed optimum intermediate letdown pressure of $2.6 \mathrm{MPa}$.

As found earlier with the zero preheat bed results, the system efficiency is a strong function of the operating pressure near the vapor pressure of water at the reactor operating temperature of $300 \mathrm{C}$. As the operating pressure is increased above about 10 $\mathrm{MPa}$ the improvement in process performance is relatively small with each increment of pressure. The choice of an operating pressure of $10 \mathrm{MPa}$ seems to be reasonably based on these results. 
Table 14. Two preheat bed results as a function of reaction pressure.

\begin{tabular}{|lcccccc|}
\hline & \multicolumn{7}{c|}{ Base } \\
\cline { 2 - 7 } Reaction Pressure (MPa) & 9 & 10 & 11 & 12 & 13 & 14 \\
FSTEAM (kg/s) & 18.7 & 11.1 & 10.5 & 10.5 & 10.4 & 10.4 \\
FSTEAM Temperature (C) & 320 & 320 & 320 & 340 & 340 & 340 \\
PSLURRY (kg/s) & 44.7 & 37.1 & 36.4 & 36.5 & 36.4 & 36.3 \\
PSLURRY Solids (wt.\%) & 35.2 & 42.4 & 43.2 & 43.2 & 43.3 & 43.4 \\
PCONDL (kg/s) & 14.0 & 7.2 & 6.6 & 6.5 & 6.5 & 6.4 \\
PSLURRY-PCONDL (kg/s) & 30.7 & 29.9 & 29.8 & 30.0 & 29.9 & 29.9 \\
PSLURRY-PCONDL Solids (wt.\%) & 51.3 & 52.6 & 52.8 & 52.6 & 52.7 & 52.6 \\
PQOUT & 37.5 & 18.7 & 17.0 & 16.2 & 16.5 & 16.3 \\
\hline
\end{tabular}

\section{WALL INFLUENCE}

In all the above calculations it has been assumed that the operations in each stage of the process occur adiabatically from the standpoint of the MSW and slurry. In reality the pressure vessels needed to contain the pressures used in the process would be quite thick and may represent a heat reservoir which could influence the overall process. To get an idea of the magnitude of the influence, the basic process model was modified to simulate the heating and cooling of the vessel walls.

Since it is assumed that a single vessel passes through each stage, the vessel walls would heat up as the vessel moved from the feed stage to the reactor stage. Then as it moved from the reactor stage to the final pressure letdown stage, the vessel walls would tend to release stored heat into the system. This type of heat flow can be simulated in the ASPEN PLUS process model by coupling a heat transfer fluid between the stages which carries the equivalent of the heat stored in the walls between stages. The size of this coolant flow stream is dictated by the estimated weight and heat capacity of the vessel walls, the amount of MSW processed in each vessel and the required processing time. In carrying out the simulation, the model was set up so that the vessel walls would be at the same final temperature as that reached in each of the stages.

A series of calculations has been done which simulate the $0-3$ preheat bed cases assuming heat flows between vessel contents and walls. In these calculations it is assumed that the vessels have a volume of $100 \mathrm{~m}^{3}$. This allows for about a 30 minute residence time for the $30 \mathrm{~kg} / \mathrm{s}$ MSW feed rate. The wall thickness is estimated to be about 0.15 meters. Based on an aspect ratio of the vessels of about $2.3 / 1$, the diameter needs to be $4.2 \mathrm{~m}$. Using a metal density of $8000 \mathrm{~kg} / \mathrm{m}^{3}$, an empty vessel weight of $1.9 \times 10^{5} \mathrm{~kg}$ is computed. A metal heat capacity of $420 \mathrm{~J} / \mathrm{kg}-\mathrm{K}$ was used for the vessel walls in computing the required coolant flow to simulated the wall heating and cooling.

Selected results from these calculations are compared to the adiabatic results in Table 14. A complete set of results for each preheat bed case is given in Figs 18-21. In each case, the results are for the case in which the intermediate letdown pressures have been optimized. 
The results in Table 14 indicate that the thermal coupling of the vessel wall to the interior results in poorer process efficiency in each case. For the two preheat bed case the steam flow rate requirement is increased by about $40 \%$ and solid content of the final slurry product is reduced by about $10 \%$. Interestingly the required cooling changes only slightly in the two preheat bed case.

The results shown in Table 14 represents the limit of behavior between complete adiabatic operation and complete coupling between vessel wall and contents. The actual operation would depend on the actual magnitude of effective heat transfer coefficients between vessel walls and contents. These effective coefficients may well be different for heating and cooling cycles. In addition, the operation could be modified by active external heating and cooling of the vessel walls or by internal insulation. A final design would need to consider each of these factors and how they would impact the overall economics. Such a study is beyond the scope of the current work.

Table 14. Wall influence

\begin{tabular}{|c|c|c|c|c|c|c|c|c|}
\hline & \multicolumn{2}{|c|}{3 Preheat Beds } & \multicolumn{2}{|c|}{2 Preheat Beds } & \multicolumn{2}{|c|}{ 1 Preheat Bed } & \multicolumn{2}{|c|}{ O Preheat Beds } \\
\hline & Adiabatic & Nonadiabatid & Adiabatic & Nonadiabatic & Adiabatic & Nonadiabatic & Adiabatic & Nonadiabatic \\
\hline FSTEAM $(\mathrm{kg} / \mathrm{s})$ & 10.1 & 13.4 & 11.2 & 15.7 & 16.3 & 23.1 & 21.2 & 28.1 \\
\hline $\begin{array}{l}\text { PCONDL (kg/s) } \\
\text { PSLURRY solid (wt. \%) }\end{array}$ & $\begin{array}{c}6.1 \\
43.6\end{array}$ & $\begin{array}{r}5.4 \\
40.1\end{array}$ & $\begin{array}{r}7.2 \\
42.3\end{array}$ & $\begin{array}{r}7.7 \\
37.9\end{array}$ & $\begin{array}{l}12.5 \\
37.1\end{array}$ & $\begin{array}{l}15.1 \\
32.2\end{array}$ & $\begin{array}{l}16.9 \\
33.5\end{array}$ & $\begin{array}{l}19.5 \\
29.2\end{array}$ \\
\hline PQOUT (MW) & 16.0 & 14.1 & 18.7 & 19.7 & 31.6 & 38.0 & 43.6 & 50.3 \\
\hline PHEATAL Temp (C) & 180 & 171 & & & & & & \\
\hline PHEATBL Temp (C) & 254 & 234 & 220 & 202 & & & & \\
\hline PHEATCL Temp (C) & 288 & 270 & 276 & 252 & 197 & 167 & & \\
\hline PGSEPL Temp (C) & 300 & 300 & 300 & 300 & 300 & 300 & 300 & 300 \\
\hline PFLSHAL Temp (C) & 259 & 259 & 226 & 226 & & & & \\
\hline PFLSHBL Temp (C) & 188 & 188 & & & & & & \\
\hline
\end{tabular}

\section{GAS VELOCITIES}

One concern in operating the actual process would be the gas velocities present in the vessels during each stage of operation. These velocities must be low enough to lead to only modest pressure drops within the vessel and minimize the possibility of unwanted entrainment of solids and liquids in the gas exiting the vessels.

Results computed for the two preheat bed system can be used to gain an idea of the gas velocities within the vessels at each process stage. Estimates of superficial gas velocities within each stage in the process were made by assuming the computed gas flow rate exiting a vessel is a reasonable estimate of the gas flows within a vessel. For the reaction stage the inject steam rate was also used as an alternate estimate. It was assumed that the vessels had a cross sectional diameter of $4.2 \mathrm{~m}$ (consistent with vessels having a volume of $100 \mathrm{~m}^{3}$ ). Computed results for each of the vessel stages are given in Table 15. 


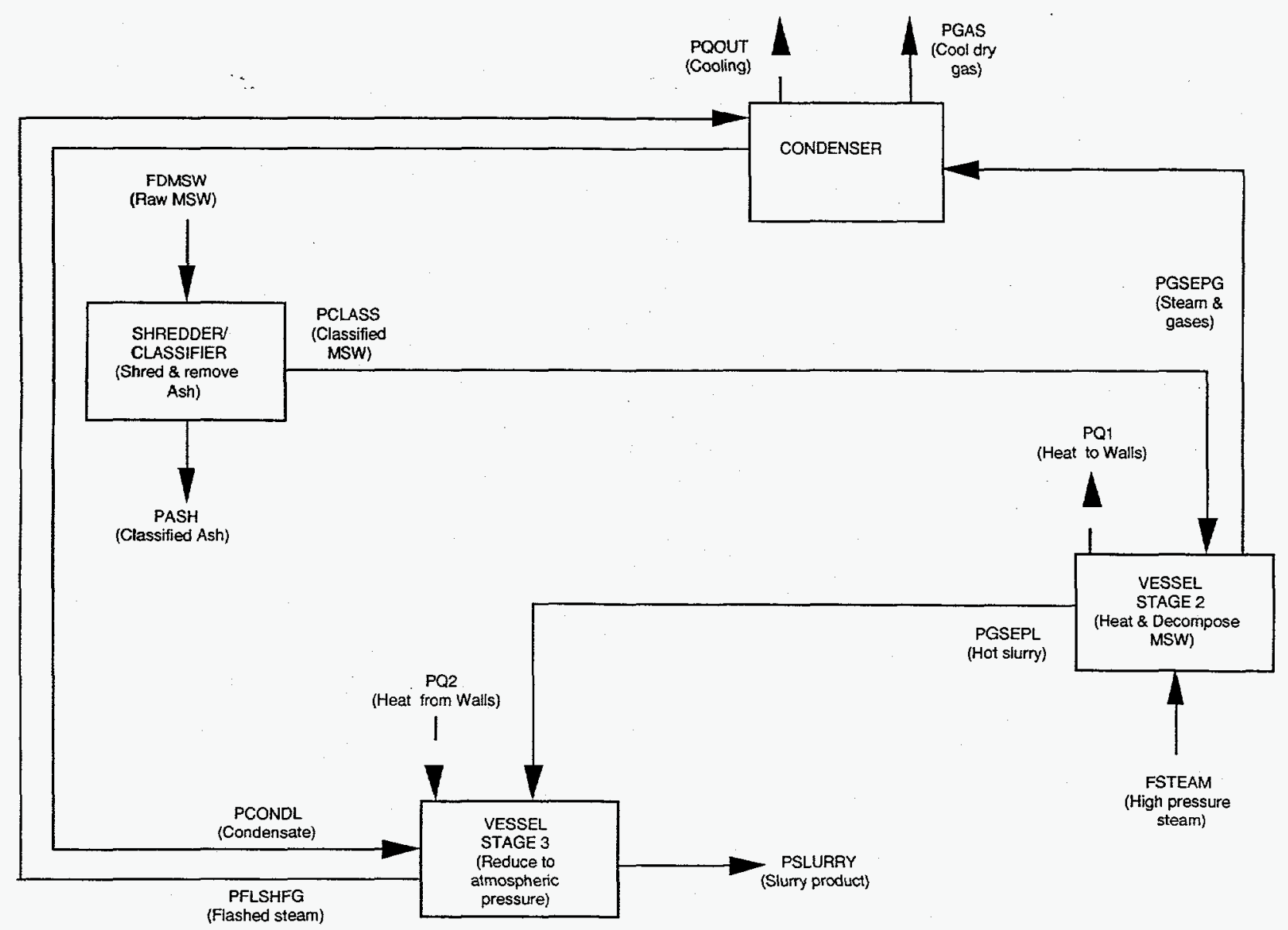

\begin{tabular}{|l|c|c|c|c|c|c|c|c|}
\hline Stream & FDMSW & FSTEAM & PASH & PSLURRY & PGAS & PCLASS & PGSEPG & PGS \\
\hline Total Flow (kg/s) & 30 & 28.1 & 2.72 & 54.1 & 1.34 & 27.3 & 6.22 & 49 \\
\hline Pressure (MPa) & 0.1 & 11.2 & 0.1 & 0.1 & 0.1 & 0.1 & 10.0 & 10 \\
\hline Temperature (C) & 25 & 320 & 25 & 100 & 40 & 25 & 300 & 3 \\
\hline Conventional & & & & & & & & \\
\hline Flow (kg/s) & 7.5 & 28.1 & & 38.3 & 1.34 & 7.5 & 6.22 & 33 \\
\hline Vapor fraction & 0 & 1 & & 0 & 1 & 0 & 1 & \\
\hline Flow (kmol/s) & 0.416 & 1.56 & & 2.12 & 0.037 & 0.416 & 0.308 & 1 \\
\hline H2 (mol \%) & 0 & 0 & & 0 & 6.5 & 0 & 0.76 & \\
\hline CO (mol \%) & 0 & 0 & & 0 & 3.7 & 0 & 0.44 & \\
\hline CO2 (mol \%) & 0 & 0 & & 0 & 74.0 & 0 & 8.72 & 0. \\
\hline H2O (mol \%) & 100 & 100 & & 100 & 7.5 & 100 & 89.08 & 99 \\
\hline CH4 (mol \%) & 0 & 0 & & 0 & 8.3 & 0 & 0.99 & \\
\hline Nonconventional & & & & & & & & \\
\hline Flow (kg/s) & 22.5 & & 2.72 & 15.74 & & 19.8 & & 15 \\
\hline ASH (wt \%) & 24.1 & & 100 & 17.2 & & 13.7 & & 17 \\
\hline ORG (wt \%) & 64.8 & & 0 & 0 & & 73.7 & & \\
\hline GORG (wt \%) & 0 & & 0 & 66.9 & & 0 & & 66 \\
\hline PLS (wt \%) & 11.1 & & 0 & 15.8 & & 12.6 & & 15 \\
\hline Stream & PQOUT & PQ1 & PQ2 & & & & & \\
\hline Energy flow (MW) & 50.3 & 10.3 & 10.3 & & & & & \\
\hline
\end{tabular}

Figure 18. Computed results with full thermal coupling of vessel contents to vessel walls. 
\begin{tabular}{|l|l|l|}
\hline PL & PFLSHFG & PCONDL \\
\hline
\end{tabular}

\begin{tabular}{|c|c|c|}
\hline PL & PFLSHFG & PCONDL \\
\hline & 14.7 & 19.5 \\
\hline & 0.1 & 0.1 \\
\hline & 100 & 40 \\
\hline & & \\
\hline & 14.7 & 19.5 \\
\hline & 1 & 0 \\
\hline & 0.812 & 1.08 \\
\hline & 0 & 0 \\
\hline & 0 & 0 \\
\hline & 0.08 & 0.03 \\
\hline & 99.9 & 99.96 \\
\hline & 0 & 0 \\
\hline & & \\
\hline & & \\
\hline & & \\
\hline & & \\
\hline & & \\
\hline & & \\
\hline & & \\
\hline & & \\
\hline
\end{tabular}




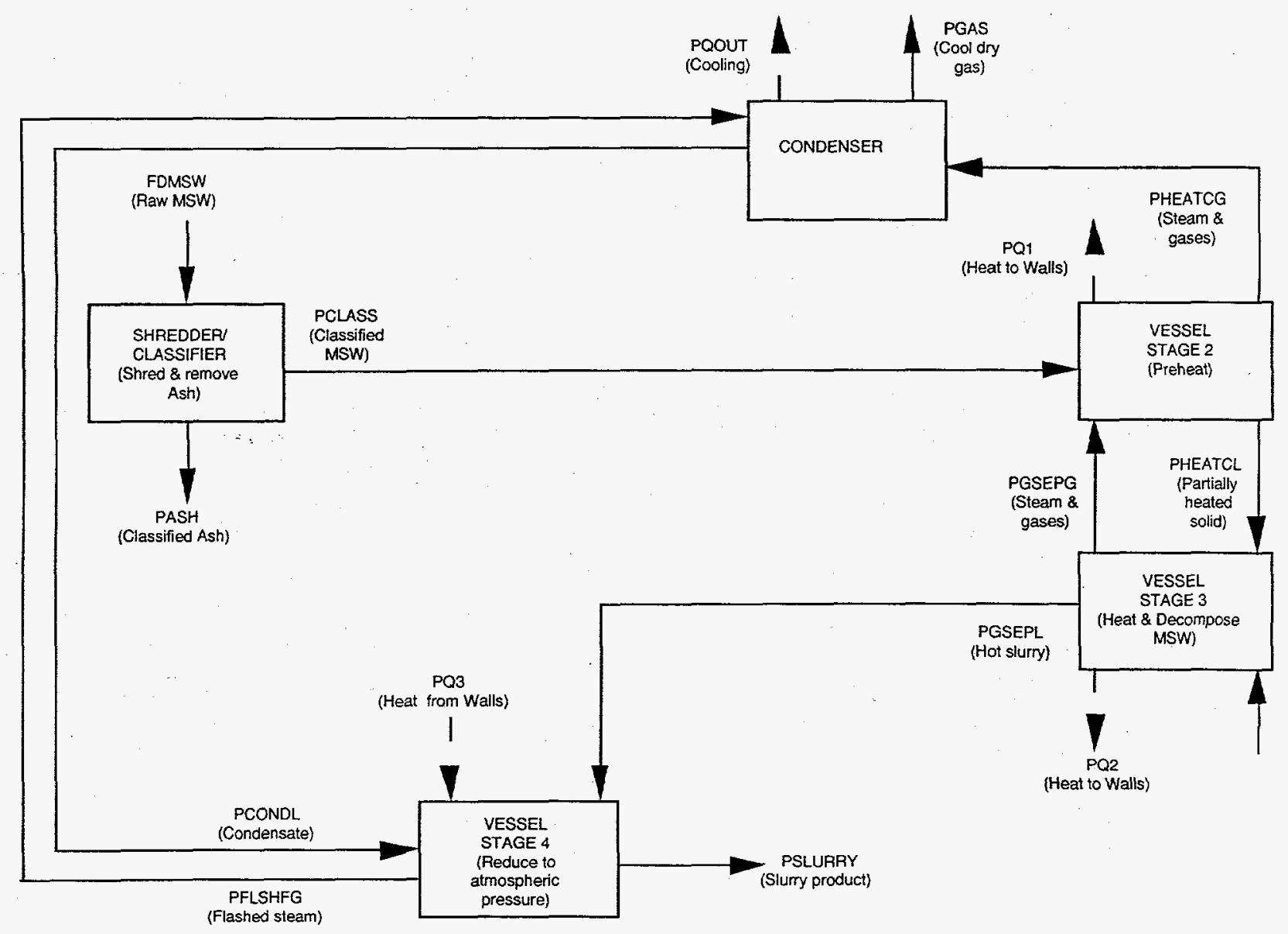

\begin{tabular}{|c|c|c|c|c|c|c|c|c|}
\hline Stream & FDMSW & FSTEAM & PASH & PSLURRY & PGAS & PCLASS & PHEATCG & PHEA \\
\hline Total Flow $(\mathrm{kg} / \mathrm{s})$ & 30 & 23.1 & 2.72 & 49.1 & 1.34 & 27.3 & 1.35 & 32 \\
\hline Pressure (MPa) & 0.1 & 11.2 & 0.1 & 0.1 & 0.1 & 0.1 & 9.8 & 9. \\
\hline Temperature (C) & 25 & 320 & 25 & 100 & 40 & 25 & 167 & $\overline{16}$ \\
\hline \multicolumn{9}{|l|}{ Conventional } \\
\hline Flow (kg/s) & 7.5 & 23.1 & & 33.3 & 1.34 & 7.5 & 1.35 & 13 \\
\hline Vapor fraction & 0 & 1 & & 0 & 1 & 0 & 1 & \\
\hline Flow (kmol/s) & 0.416 & 1.28 & & 1.85 & 0.037 & 0.416 & 0.038 & 0.7 \\
\hline $\mathrm{H} 2(\mathrm{~mol} \%)$ & 0 & 0 & & 0 & 6.5 & 0 & 6.2 & 0.8 \\
\hline $\mathrm{CO}(\mathrm{mol} \%)$ & 0 & 0 & & 0 & 3.7 & 0 & 3.6 & \\
\hline $\mathrm{CO} 2(\mathrm{~mol} \%)$ & 0 & 0 & & 0 & 74.0 & 0 & 70.7 & 0.5 \\
\hline $\mathrm{H} 2 \mathrm{O}(\mathrm{mol} \%)$ & 100 & 100 & & 100 & 7.5 & 100 & 11.5 & 99. \\
\hline $\mathrm{CH} 4(\mathrm{~mol} \%)$ & 0 & 0 & & 0 & 8.3 & 0 & 8 & 0.0 \\
\hline \multicolumn{9}{|l|}{ Nonconventional } \\
\hline Flow (kg/s) & 22.5 & & 2.72 & 15.74 & & 19.8 & & 19 \\
\hline ASH (wt \%) & 24.1 & & 100 & 17.2 & & 13.7 & & $\overline{13}$ \\
\hline ORG (wt \%) & 64.8 & & 0 & 0 & & 73.7 & & $\overline{73}$ \\
\hline GORG (wt \%) & 0 & & 0 & 66.9 & & 0 & & \\
\hline PLS (wt \%) & 11.1 & & 0 & 15.8 & & 12.6 & & 12 \\
\hline Stream & PQOUT & PQ1 & PQ2 & PQ3 & & & & \\
\hline Energy flow (MW) & 38 & 3.2 & 7.1 & 10.3 & & & & \\
\hline
\end{tabular}

Figure 19. Computed results for one preheat bed with full thermal coupling of vessel contents to 


\begin{tabular}{|c|c|c|c|c|}
\hline CL & PGSEPG & PGSEPL & PFLSHFG & PCONDL \\
\hline & 6.99 & 49 & 15.1 & 15.1 \\
\hline & 10.0 & 10.0 & 0.1 & 0.1 \\
\hline & 300 & 300 & 100 & 40 \\
\hline & & & & \\
\hline & 6.99 & 33.3 & 15.1 & 15.1 \\
\hline & 1 & 0 & 1 & 0 \\
\hline & 0.345 & 1.85 & 0.836 & 0.838 \\
\hline & 0.7 & 0 & 0 & 0 \\
\hline & 0.4 & 0 & 0 & 0 \\
\hline & 8.9 & 0.02 & 0.07 & 0.03 \\
\hline & 89.09 & 99.97 & 99.92 & 99.96 \\
\hline & 0.9 & 0 & 0 & 0 \\
\hline & & & & \\
\hline & & 15.7 & & \\
\hline & & 17.2 & & \\
\hline & & 0 & & \\
\hline & & 66.9 & & \\
\hline & & 15.8 & & \\
\hline & & & & \\
\hline & & & & \\
\hline
\end{tabular}

tessel walls. 


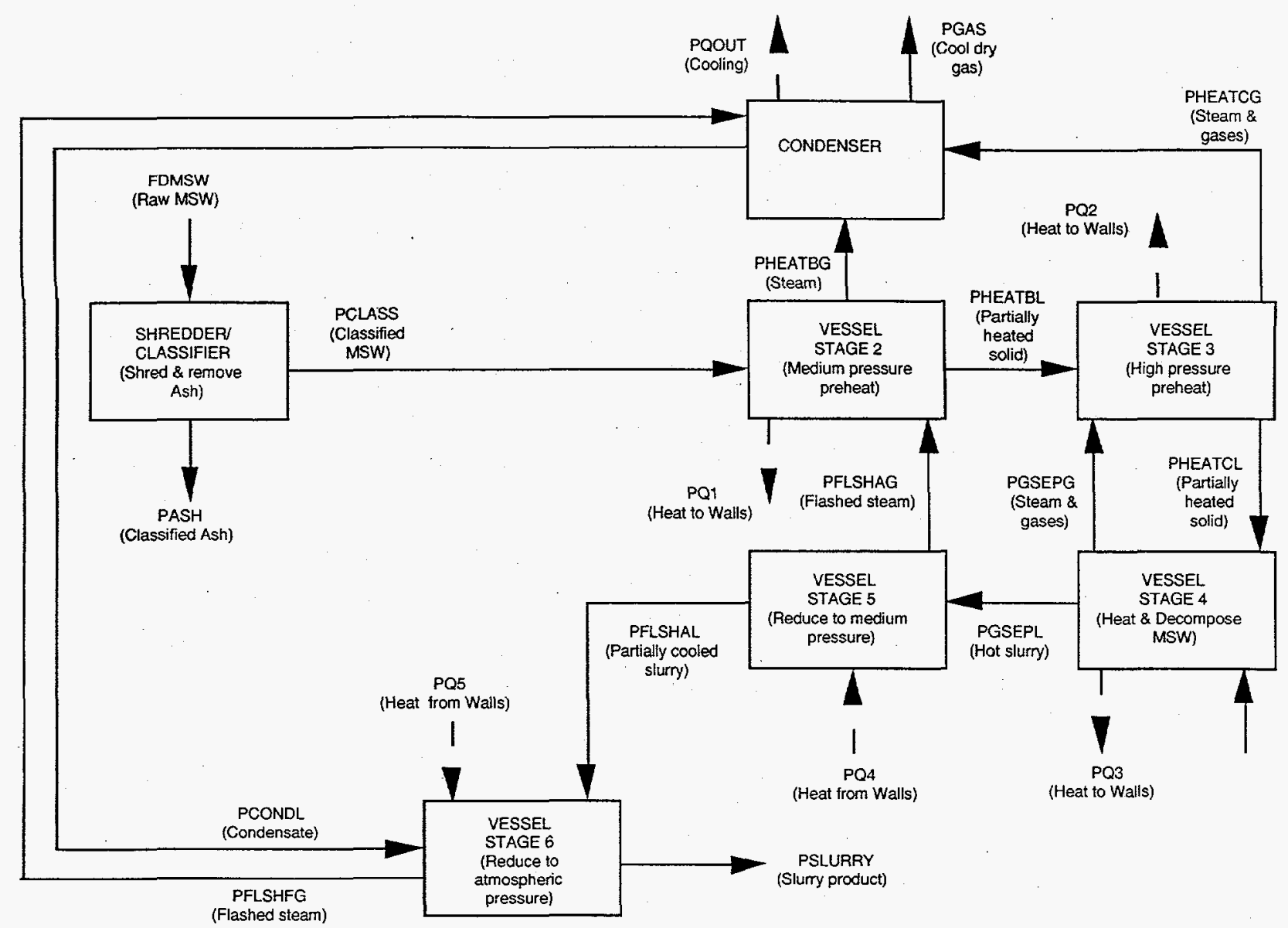

\begin{tabular}{|c|c|c|c|c|c|c|c|c|}
\hline Stream & FDMSW & FSTEAM & PASH & PSLURRY & PGAS & PCLASS & PHEATBG & PHE \\
\hline Total Flow $(\mathrm{kg} / \mathrm{s})$ & 30 & 15.7 & 2.72 & 41.7 & 1.34 & 27.3 & 0.01 & 35 \\
\hline Pressure (MPa) & 0.1 & 11.2 & 0.1 & 0.1 & 0.1 & 0.1 & 2.4 & 2 \\
\hline Temperature (C) & 25 & 320 & 25 & 100 & 40 & 25 & 202 & $\overline{21}$ \\
\hline \multicolumn{9}{|l|}{ Conventional } \\
\hline Flow $(\mathrm{kg} / \mathrm{s})$ & 7.5 & 15.7 & & 25.9 & 1.34 & 7.5 & 0.006 & 15 \\
\hline Vapor fraction & 0 & 1 & & 0 & 1 & 0 & 1 & \\
\hline Flow $(\mathrm{kmol} / \mathrm{s})$ & 0.416 & 0.87 & & 1.44 & 0.037 & 0.416 & 0.0003 & 0.8 \\
\hline $\mathrm{H} 2(\mathrm{~mol} \%)$ & 0 & 0 & & 0 & 6.5 & 0 & 5.0 & \\
\hline $\mathrm{CO}(\mathrm{mol} \%)$ & 0 & 0 & & 0 & 3.7 & 0 & 1.6 & \\
\hline $\mathrm{CO} 2(\mathrm{~mol} \%)$ & 0 & 0 & & 0 & 74.0 & 0 & 21.0 & 0.1 \\
\hline $\mathrm{H} 2 \mathrm{O}(\mathrm{mol} \%)$ & 100 & 100 & & 100 & 7.5 & 100 & 69.5 & 99. \\
\hline CH4 (mol \%) & 0 & 0 & & 0 & 8.3 & 0 & 2.3 & \\
\hline \multicolumn{9}{|l|}{ Nonconventional } \\
\hline Flow $(\mathrm{kg} / \mathrm{s})$ & 22.5 & & 2.72 & 15.74 & & 19.8 & & 19 \\
\hline ASH (wt \%) & 24.1 & & 100 & 17.2 & & 13.7 & & $\overline{13}$ \\
\hline ORG (wt \%) & 64.8 & & 0 & 0 & & 73.7 & & 73 \\
\hline GORG (wt \%) & 0 & & 0 & 66.9 & & 0 & & \\
\hline PLS (wt \%) & 11.1 & & 0 & 15.8 & & 12.6 & & 12 \\
\hline Stream & PQOUT & PQ1 & PQ2 & PQ3 & PQ4 & PQ5 & & \\
\hline Energy flow (MW) & 19.7 & 4.9 & 2.6 & 2.8 & 4.1 & 6.2 & & \\
\hline
\end{tabular}

Figure 20. Computed results for two preheat beds with full thermal coupling of vessel contents $t$ 


\begin{tabular}{|c|c|c|c|c|c|c|c|c|}
\hline BL & PHEATCG & PHEATCL & PGSEPG & PGSEPL & PFLSHAG & PFLSHAL & PFLSHFG & PCONDL \\
\hline & 1.9 & 40.1 & 6.54 & -49.3 & 8.16 & 41.1 & 7.15 & 7.72 \\
\hline & 9.8 & 9.8 & 10.0 & 10.0 & 2.6 & 2.6 & 0.1 & 0.1 \\
\hline & 252 & 252 & 300 & 300 & 226 & 226 & 100 & 40 \\
\hline & & & & & & & & \\
\hline & 1.9 & 20.3 & 6.54 & 33.5 & 8.16 & 25.4 & 7.15 & 7.72 \\
\hline & 1 & 0 & 1 & 0 & 1 & 0 & 1 & 0 \\
\hline & 0.068 & 1.12 & 0.324 & 1.86 & 0.452 & 1.41 & 0.397 & 0.428 \\
\hline & 3.5 & 0.01 & 0.75 & 0 & 0.01 & 0 & 0 & 0 \\
\hline & 2.0 & 0 & 0.43 & 0 & 0 & 0 & 0 & 0 \\
\hline & 39.8 & 0.13 & 8.78 & 0.02 & 0.08 & 0 & 0.03 & 0.03 \\
\hline & 50.2 & 99.85 & 89.08 & 99.97 & 99.91 & 100 & 99.96 & 99.96 \\
\hline & 4.5 & 0 & 0.96 & 0 & 0 & 0 & 0 & 0 \\
\hline & & & & & & & & \\
\hline & & 19.8 & & 15.7 & & 15.7 & & \\
\hline & & 13.7 & & 17.2 & & 17.2 & & \\
\hline & & 73.7 & & 0 & & 0 & & \\
\hline & & 0 & & 66.9 & & 66.9 & & \\
\hline & & 12.6 & & 15.8 & & 15.8 & & \\
\hline & & & & & & & & \\
\hline & & & & & & & & \\
\hline
\end{tabular}

vessel walls. 


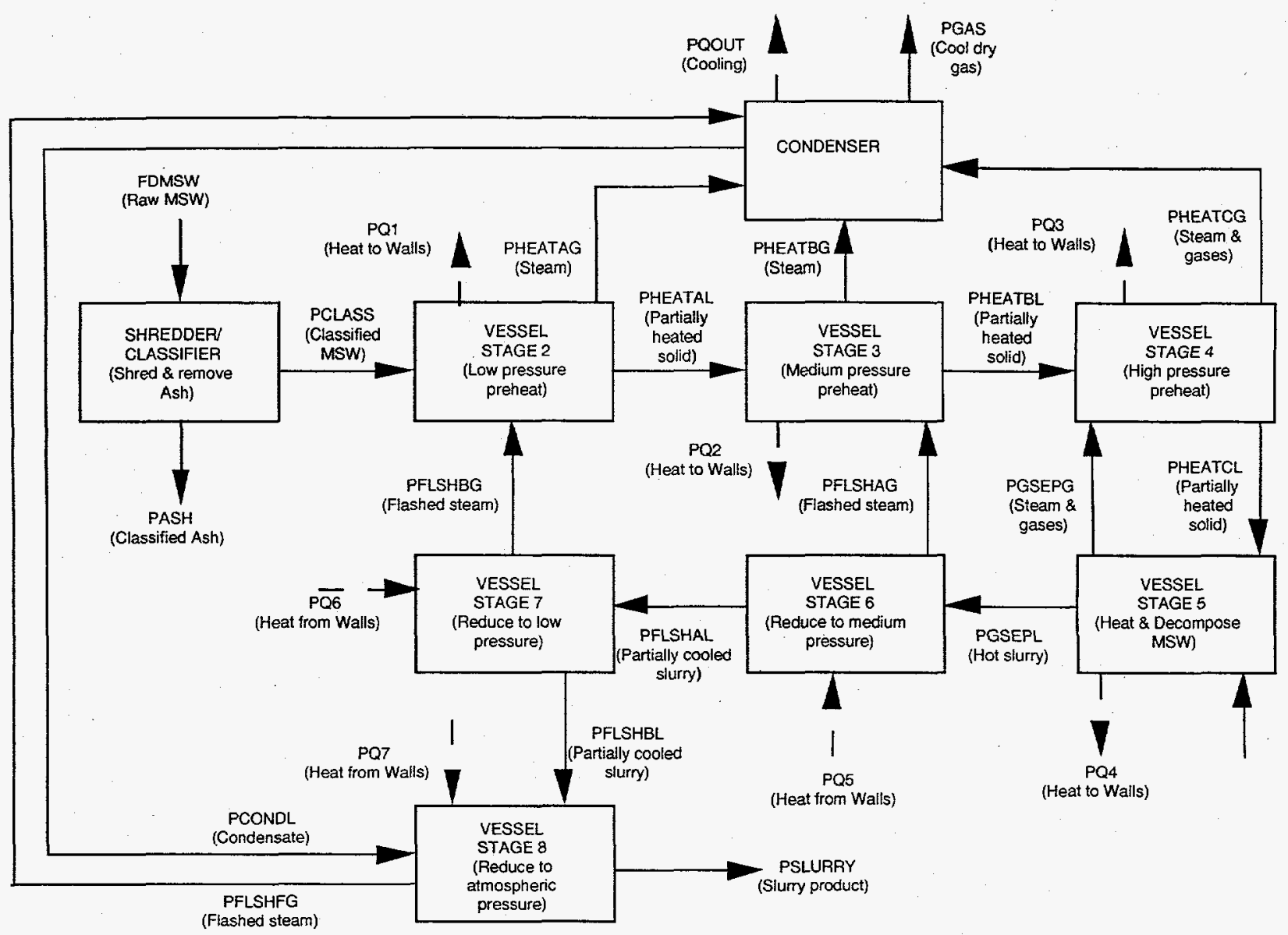

\begin{tabular}{|c|c|c|c|c|c|c|c|c|c|}
\hline Stream & FDMSW & FSTEAM & PASH & PSLURRY & PGAS & PCLASS & PHEATAG & PHEATAL & PHEATBC \\
\hline Total Flow $(\mathrm{kg} / \mathrm{s})$ & 30 & 13.44 & 2.72 & 39.4 & 1.34 & 27.3 & 0 & 33.3 & 0 \\
\hline Temperature (C) & 25 & 320 & 25 & 100 & 40 & 25 & & 171 & \\
\hline \multicolumn{10}{|l|}{ Conventional } \\
\hline Flow (kg/s) & 7.5 & 13.44 & & 23.6 & 1.34 & 7.5 & & 13.5 & \\
\hline Vapor fraction & 0 & 1 & & 0 & 1 & 0 & & 0 & \\
\hline Flow $(\mathrm{kmol} / \mathrm{s})$ & 0.416 & 0.746 & & 1.31 & 0.037 & 0.416 & & 0.749 & \\
\hline $\mathrm{CO} 2(\mathrm{~mol} \%)$ & 0 & 0 & & 0 & 74.0 & 0 & & 0 & \\
\hline $\mathrm{H} 2 \mathrm{O}(\mathrm{mol} \%)$ & 100 & 100 & & 100 & 7.5 & 100 & & 100 & \\
\hline $\mathrm{CH} 4(\mathrm{~mol} \%)$ & 0 & 0 & & 0 & 8.3 & 0 & & 0 & \\
\hline \multicolumn{10}{|l|}{ Nonconventional } \\
\hline Flow $(\mathrm{kg} / \mathrm{s})$ & 22.5 & & 2.72 & 15.74 & & 79.8 & & 19.8 & \\
\hline ASH (wt \%) & 24.1 & & 100 & 17.2 & & 13.7 & & 13.7 & \\
\hline Energy flow (MW) & 14.1 & 3.4 & 3.2 & 2 & 1.8 & 2.4 & 3.7 & 4.3 & \\
\hline
\end{tabular}

Figure 21. Compute results for three preheat beds with full thermal coupling of vessel contents $t$ 


\begin{tabular}{|c|c|c|c|c|c|c|c|c|c|c|}
\hline PHEATBL & PHEATCG & PHEATCL & PGSEPG & PGSEPL & PFLSHAG & PFLSHAL & PFLSHBG & PFLSHBL & PFLSHFG & PCONDL \\
\hline 38.3 & 2.39 & 42.4 & 6.43 & 49.4 & 5.06 & 44.3 & 5.99 & 38.3 & 4.38 & 5.43 \\
\hline 4.4 & 9.8 & 9.8 & 10.0 & 10.0 & 4.6 & 4.6 & 1.2 & 1.2 & 0.1 & 0.1 \\
\hline 234 & 270 & 270 & 300 & 300 & 259 & 259 & 188 & 188 & 100 & 40 \\
\hline & & & & & & & & & & \\
\hline 18.6 & 2.39 & 22.6 & 6.43 & 33.6 & 5.06 & 28.6 & 5.99 & 22.6 & 4.38 & 5.43 \\
\hline 0 & 1 & 0 & 1 & 0 & 1 & 0 & 1 & 0 & 1 & 0 \\
\hline 1.03 & 0.095 & 1.25 & 0.319 & 1.87 & 0.28 & 1.59 & 0.333 & 1.25 & 0.243 & 0.301 \\
\hline 0 & 2.5 & 0.01 & 0.76 & 0 & 0.01 & 0 & 0 & 0 & 0 & 0 \\
\hline 0 & 1.4 & 0 & 0.43 & 0 & 0 & 0 & 0 & 0 & 0 & 0 \\
\hline 0.03 & 28.6 & 0.08 & 8.76 & 0.02 & 0.12 & 0 & 0 & 0 & 0.04 & 0.03 \\
\hline 99.96 & 64.2 & 99.91 & 89.08 & 99.97 & 99.85 & 100 & 100 & 100 & 99.96 & 99.96 \\
\hline 0 & 3.2 & 0 & 0.97 & 0 & 0 & 0 & 0 & 0 & 0 & 0 \\
\hline & & & & & & & & & & \\
\hline 19.8 & & 19.8 & & 75.7 & & 75.7 & & 75.7 & & \\
\hline 13.7 & & 13.7 & & 17.2 & & 17.2 & & 17.2 & & \\
\hline 73.7 & & 73.7 & & 0 & & 0 & & 0 & & \\
\hline 0 & & 0 & & 66.9 & & 66.9 & & 66.9 & & \\
\hline 12.6 & & 12.6 & & 15.8 & & 15.8 & & 15.8 & & \\
\hline & & & & & & & & & & \\
\hline & & & & & & & & & & \\
\hline
\end{tabular}

vessel walls. 
Table 15 Estimated gas velocities in process vessels in a two preheat bed process.

\begin{tabular}{|ccccc|}
\hline Stage & Description & $\begin{array}{c}\text { Gas Flow } \\
(\mathrm{kmol} / \mathrm{s})\end{array}$ & $\begin{array}{c}\text { Gas Flow } \\
(\mathrm{m} 3 / \mathrm{s})\end{array}$ & $\begin{array}{c}\text { Superficial } \\
\text { Velocity } \\
(\mathrm{m} / \mathrm{s})\end{array}$ \\
\hline 2 & 1st Preheat & 0.008 & 0.01 & 0.0009 \\
3 & 2nd Preheat & 0.109 & 0.04 & 0.0029 \\
4 & Reaction (exit gas) & 0.316 & 0.12 & 0.0086 \\
4 & Reaction (Steam in) & 0.620 & 0.20 & 0.0144 \\
5 & intermediate letdown & 0.373 & 0.54 & 0.0388 \\
6 & Final letdown & 0.321 & 9.90 & 0.7122 \\
\hline
\end{tabular}

The results clearly indicate that the final letdown stage, because of its low pressure, has by far the largest superficial gas velocities. One means of gauging the impact of these velocities on the process operation is to use Darcy's law to estimate the minimum bed permeability for an assumed pressure gradient within the vessel. Using a modest internal pressure drop of $0.1 \mathrm{MPa}$ from top to bottom of a vessel, and assuming it is about $10 \mathrm{~m}$ high, the required bed permeability as a function of superficial gas velocity is given by $k=v 10^{-8}$, where $k$ is the permeability in $\mathrm{m}^{2}$ and $v$ is the superficial velocity in $\mathrm{m} / \mathrm{s}$. The required minimum permeability for stage 6 would be $0.7 \times 10^{-8} \mathrm{~m}^{2}$, 7000 darcys, and for stage $50.4 \times 10^{-9} \mathrm{~m}^{2}, 400$ darcys. For comparison a bed composed of $0.1 \mathrm{~mm}$ particles has a permeability of about $10^{5}$ darcys. Consequently, all the beds except stage 6 should not have a problem with excessive internal pressure drops.

The velocity estimates presented in Table 15 are based on the flows computed by the ASPEN PLUS model. These estimates represent average flows. In reality each vessel stage is a batch process and the flows and internal pressures and temperature would vary over the time interval the vessel was in each stage. Since the final pressure letdown, stage 6, presents by far the most potential for having excessive internal gas velocities it is useful to examine what its actual operation may look like relative to gas flows and internal pressure.

A vessel in stage 6 would start out at a pressure of $2.6 \mathrm{MPa}$ and end up at a pressure of $0.1 \mathrm{MPa}$. In computing superficial velocities above, the final vessel pressure was used, and therefore the computed velocity is high. In actual operation, the pressure reduction could be scheduled over time to minimize the internal vessel velocities. This minimum would occur when the pressure reduction schedule led to a constant volumetric flow out of the vessel.

To estimate what the constant volumetric flow exiting the vessel must be, it is necessary to relate the change in vessel temperature to the volume of steam which must be released to accomplish the necessary cooling. If it is assumed that most of heat capacity of the system is in the form of hot water, then the following relations hold

$$
\frac{d W}{d T}=\frac{c_{p}}{\Delta H_{v}}
$$




$$
\frac{d V}{d T}=\frac{c_{p}}{\rho_{v} \Delta H_{v}}
$$

where $W$ is the mass of water, $T$ is the temperature, $c_{p}$ is the heat capacity of water, $\Delta H_{v}$ is the heat of evaporation of water, $V$ the volume of water vapor release per unit mass of water, and $\rho_{\nu}$ is the density of water vapor. The first equation above is a simple heat balance. The second equation, which relates the necessary gas volume per unit mass to a change in temperature, is derived from the first by simply dividing it by the density of water vapor. This factor, $\frac{d V}{d T}$, is dependent on temperature primarily through the density term. It is plotted as a function of temperature in Fig. 22 using a semi-log plot to suggest that a simple exponential function can be used to express the functionality fairly well over the temperature range of interest.

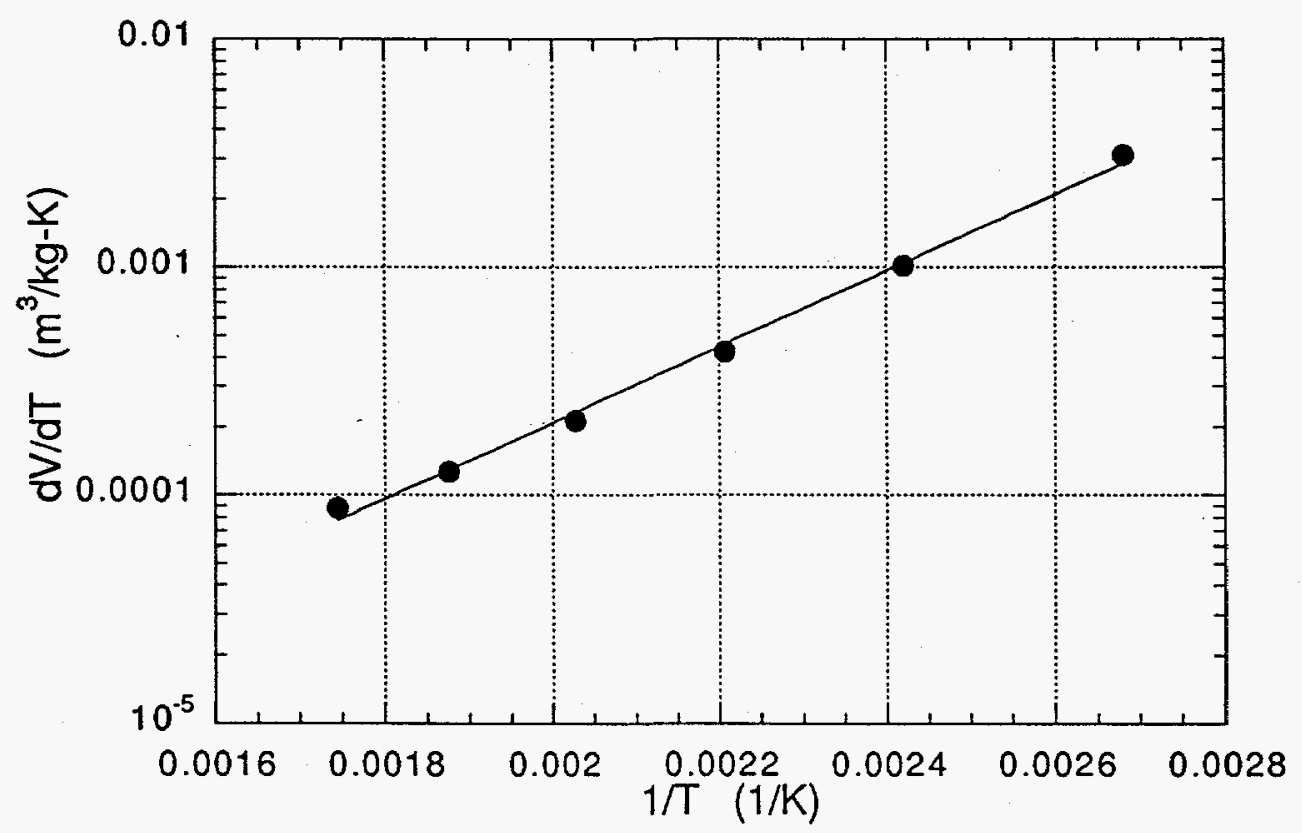

Figure 22. Steam volume per degree of temperature change as a function of temperature.

If it assumed that to a first approximation the change in the amount of water is small then the following relates the sought after constant volume flow, $\frac{d V}{d t}$, and the time rate of change of temperature

$$
\frac{d V}{d t}=\frac{d T}{d t}\left(\frac{d V}{d T}\right)=\text { constant }
$$

Substituting in the previous relation yields 


$$
\frac{d V}{d t}=f_{\nu}=\frac{d T}{d t}\left(\frac{c_{p}}{\rho_{\nu} \Delta H_{v}}\right)
$$

Integrating this equation gives the final relation for the constant volumetric flow rate per unit water mass, $f_{v}$,

$$
f_{v}=\frac{1}{\tau} \int_{T_{1}}^{T_{2}}\left(\frac{c_{p}}{\rho_{v} \Delta H_{v}}\right) d T,
$$

where $\tau$ is the time interval over which the pressure letdown occurs. The integration limits are the desired starting and ending temperatures.

Integrating the above and using the average amount of water in stage 6 leads to a computed value of $1.9 \mathrm{~m}^{3} / \mathrm{s}$ as the desired constant volumetric flow rate. This results in an internal superficial velocity of $0.14 \mathrm{~m} / \mathrm{s}$, using the same vessel area as above.

The relation developed above yields an analytic method of estimating the constant volumetric flow. However, a number of simplifying assumptions were made and it is useful to determine the desired constant voulmetric flow rate for something closer to the actual system. This can be done by using ASPEN PLUS. A number of flash stages can be put into the model to represent the overall flash of stage 6 . The exit temperature from these stages can be adjusted to obtain a near constant volumetric flow. This was done for the current case using eight intermediate temperatures. The results give an average volumetric flow of about $3 \mathrm{~m}^{3} / \mathrm{s}$, about $50 \%$ higher than the simple model. This volumetric flow corresponds to a superficial velocity of about $0.22 \mathrm{~m} / \mathrm{s}$. This is substantially lower than the original estimate given in Table 15, and under conditions outlined above would require a minimum bed permeability of only $2.2 \times 10^{-9} \mathrm{~m}^{2}, 2200$ darcys.

The computed velocity can also be used to look at the possibility of entrainment within the vessel. Since entrainment is a function of both gas velocity and density the potential entrainment of the smallest particle would occur at the highest pressure. Using the 0.22 $\mathrm{m} / \mathrm{s}$ and correlations from Kunii and Levenspeil ${ }^{2}$ a maximum droplet size for entrainment of about 100 microns is computed. It is unclear whether this would lead to operational problems.

Another estimate of the possibility for potential problems from high gas velocities comes from correlations associated with gas and liquid flows in packed beds. Since both are present in the system it is probably reasonable to be in a flow regime in which a liquid/gas packed bed could operate successfully. Using correlations from Walas 3 , estimates for successful operation at low liquid rates indicate maximum acceptable gas flows of about $0.7 \mathrm{~m} / \mathrm{s}$ at the upper temperature of operation of satge $6,226 \mathrm{C}$, and 3.4 $\mathrm{m} / \mathrm{s}$ at $100 \mathrm{C}$. These both are well above the $0.22 \mathrm{~m} / \mathrm{s}$ estimate, and would indicate acceptable performance. 


\section{PROCESSING OPTIONS}

The conceptual processing scheme described in this report assumes that the raw MSW will be loaded into a pressure vessel and then this vessel will move through the various stages of the process. Since the pressures of the various stages differ, and several stages for multi-preheat bed cases occur at modest pressure, the possibility of moving the slurry between high and low pressure vessels should be considered in any final design. Depending on the fluidity of the material at a given process stage this transfer may be able to be made by simply opening a valve, or it may require mechanical assistance. Any savings in vessel costs would of course have to be balanced against increased complexity and the need for additional hardware.

It is probable that the hydrothermally treated material would require shearing to fully realize the potential for high solids loading in an acceptably low viscosity slurry. This shearing could possibly be accomplished as part of the final pressure letdown phase. Since pressures in the final letdown are in the range of pulp/paper technology experience, $2.6 \mathrm{MPa}$ for the two preheat bed case, it is possible that conventional pulping hardware could be used to accomplish the pressure letdown and shearing. Some indirect cooling could possibly be incorporated in this process to help reduce the slurry temperature below $100 \mathrm{C}$ and thus make its downstream handling easier.

One obvious concern of the direct steam heating operation is the ability of the steam to efficiently contact all the material in a vessel. Because the heat is released by condensation and condensation by its nature results in low pressure zones, steam heating of material is much more efficient than using a hot gas. Consequently, it is possible that the steam can heat essentially the entire vessel contents by simply introducing it to the vessel. If this is not the case, it may be necessary to have some ability to gently mix the vessel contents during heating. Because of the inherent efficiency of the steam heating process the amount of mixing, if needed, should be modest. A simple internal auger which redistributes the solids once or twice during the heating maybe all that would be required.

\section{HYDROGEN PRODUCTION}

The most important property in determining the efficiency of gasification of the hydrothermally produced slurry is its heating value. The slurry heating value is directly proportional to the solid content of the slurry for a fixed composition of solid. In the processing schemes described here a variety of solid loading of the final slurry product have been found. An ASPEN PLUS model, described in a previous report ${ }^{1}$, has been used to determine the hydrogen production and other basic operating parameters of a plant producing hydrogen from hydrothermally produced slurries covering a range of solids content. These results are listed in Table 16. The solid flow rate was held constant in each case representing a process having a constant raw MSW feed rate of 2600 tonne/day. 
Table 16. Computed hydrogen production and other selected process variables for a gasification/hydrogen plant fed with hydrothermally produced MSW slurry feedstock.

\begin{tabular}{|l|c|c|c|c|}
\hline PSLURRY (solid wt. \%) & 55 & 50 & 45 & 40 \\
\hline PSLURRY (Heating Value MJ/kg) & 11.7 & 10.6 & 9.6 & 8.5 \\
\hline & & & & \\
\hline Hydrogen Product (kmol/s) & 0.66 & 0.60 & 0.53 & 0.44 \\
\hline Oxygen Input (kmol/s) & 0.45 & 0.48 & 0.51 & 0.56 \\
\hline Hydrogen/Oxygen & 1.47 & 1.25 & 1.04 & 0.79 \\
\hline PSLURRY (kg/s) & 28.6 & 31.5 & 35 & 39.4 \\
\hline Hydrogen/Feed-Heat Value (mol/MJ) & 1.97 & 1.80 & 1.58 & 1.31 \\
\hline & & & & \\
\hline Non-Hydrothermal Cooling (MW) & 141 & 160 & 185 & 216 \\
\hline Compression (MW) & 3.8 & 3.5 & 3.1 & 2.7 \\
\hline & & & & \\
\hline Fuel Gas - Available Energy (MW) & 9.8 & 8.4 & 6.9 & 4.4 \\
\hline
\end{tabular}

In the table the entry for required cooling is just for the process downstream of the hydrothermal process. This cooling is primarily for dropping water out of the product gas stream prior to the final hydrogen separation process. This required cooling increases as the water content of the input slurry increases. The compression energy requirement listed in the table is the energy required to recompress the product stream during one stage of the pressure swing adsorption (PSA) process used to separate the hydrogen from other produced gases. The fuel gas is a by-product of the PSA process and contains hydrogen, carbon monoxide and methane as the primary fuel elements. The available energy estimate is made assuming consumption of the gas in an air-blown heater with a flue-gas temperature of about $350 \mathrm{C}$.

The heating values of the slurries shown in Table 16 are below that for optimum performance of the gasification unit. When the gasifier is performing near optimum produced hydrogen (actually hydrogen + carbon monoxide) to injected oxygen ratios approaching 3 would be present. It is true that for the hydrogen to oxygen ratios shown in the table some penalty has been taken because some of the produced hydrogen, and carbon monoxide, is present in the fuel gas by-product. This amount is relatively small however. If the hydrogen production was set equal to the molar flow of all hydrogen and carbon monoxide exiting the gasifier for the 55\% slurry case the hydrogen/oxygen ratio would only increase from the 1.47 reported in the table to 1.59. This still indicates less than optimum performance.

One way to improve the overall gasification efficiency is to add some additional fuel to the gasifier. Conceivably this could be coal added to the slurry, but added coal would probably result in a need to reduce the processed MSW content to maintain suitable pumpability, consequently the increase in fuel value of the slurry may not be large. A more attractive added fuel may be a heavy oil which has a low market value but high heating value. The heavy oil could be added to the slurry directly if it improved the solid carrying characteristics of the MSW slurry, or it could be introduced separately into the gasifier. 
Calculations were done for a series of slurry/heavy oil mixtures which yielded net feedstock heating values up to $19.7 \mathrm{MJ} / \mathrm{kg}$. The results are shown in Table 17. The heavy oil was assumed to have an elemental analysis of $84.44 \%$ carbon, $10.56 \%$ hydrogen, $0.49 \%$ nitrogen, $3.38 \%$ sulfur and $1.13 \%$ oxygen, all on a weight basis. The heating value of the oil was estimated to be $44 \mathrm{MJ} / \mathrm{kg}$. Although the exact performance of the system depends not only on heating value but also atomic ratios entering the gasifier, it is seen that the produced hydrogen to injected oxygen ratio correlates very well with heating value even as the fuel mix changes, see Fig. 23. The correlation of hydrogen production with total heating value of the feedstock, Fig. 24, is not quite as good, due to changes in composition, but still shows a clear correlation of feedstock heating value and hydrogen production.

Table 17. Computed hydrogen production and other selected process variables for a gasification/hydrogen plant fed with hydrothermally produced MSW slurry feedstock augmented with heavy oil.

\begin{tabular}{|c|c|c|c|c|}
\hline PSLURRY (solid wt. \%) & 40 & 45 & 50 & 55 \\
\hline PSLURRY $(\mathrm{kg} / \mathrm{s})$ & 39.4 & 35 & 31.5 & 28.6 \\
\hline PSLURRY (Heating Value MJ/kg) & 8.5 & 9.6 & 10.6 & 11.7 \\
\hline Auxillary Fuel (kg/s) & 6.7 & 7.6 & 8.5 & 9.4 \\
\hline Total Feed Rate $(\mathrm{kg} / \mathrm{s})$ & 46.1 & 42.6 & 40 & 38 \\
\hline Effective Feed Heating Value ( $\mathrm{MJ} / \mathrm{kg}$ ) & 13.7 & 15.7 & 17.7 & 19.7 \\
\hline Hydrogen Product (kmol/s) & 1.29 & 1.48 & 1.66 & 1.81 \\
\hline Oxygen Input (kmol/s) & 0.75 & 0.73 & 0.71 & 0.71 \\
\hline Hydrogen/Oxygen & 1.72 & 2.03 & 2.34 & 2.55 \\
\hline Hydrogen/Feed-Heat Value (mol/MJ) & 2.04 & 2.21 & 2.34 & 2.42 \\
\hline Gasifier exit $\mathrm{H} 2 \mathrm{O}+\mathrm{CO} 2$ (mole \%) & 57 & 49 & 41 & 34 \\
\hline Non-Hydrothermal Cooling (MW) & 242 & 219 & 202 & 189 \\
\hline Compression (MW) & 7.1 & 8.2 & 9.3 & 10.3 \\
\hline Fuel Gas - Available Energy (MW) & 19.6 & 24.6 & 30.2 & 36.5 \\
\hline
\end{tabular}




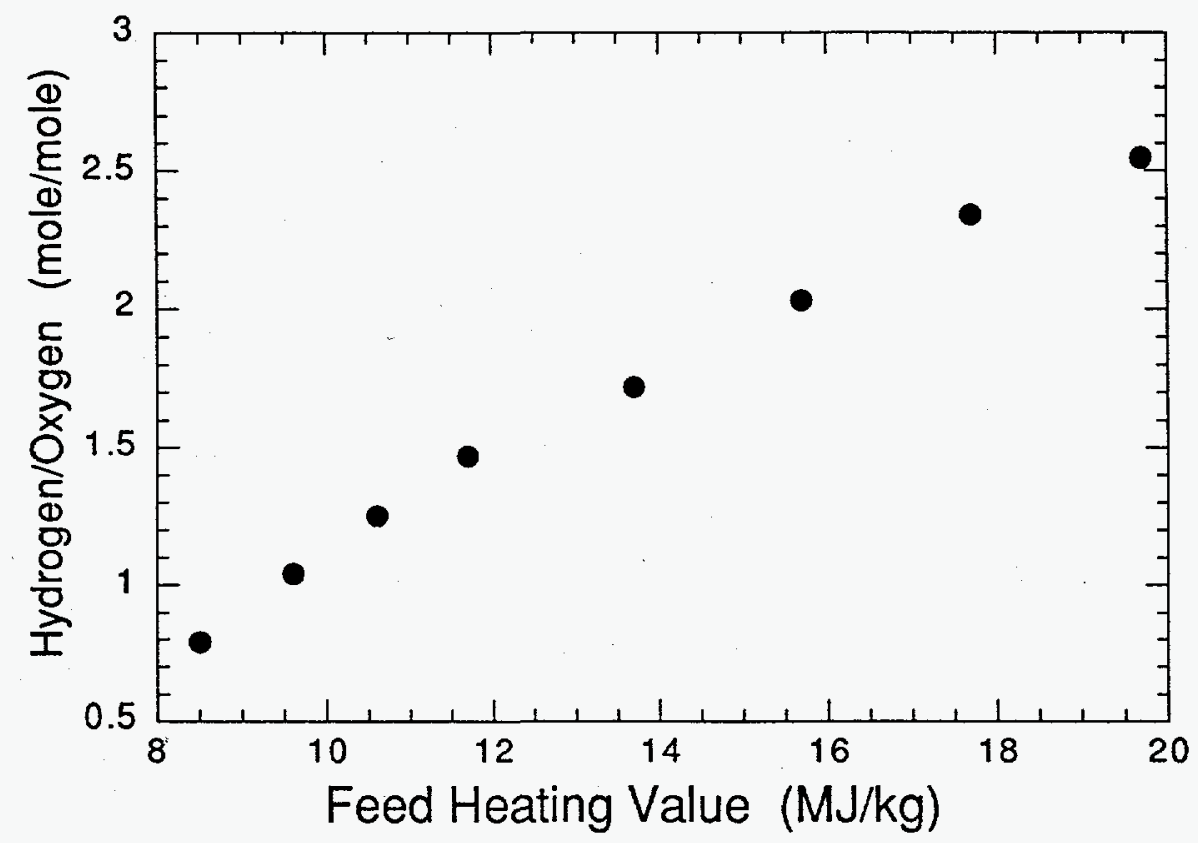

Figure 23 Computed ratio of hydrogen product to oxygen injection to the gasifier as a function of the net heating value of the gasifier feed. Results for heating values above $13 \mathrm{MJ} / \mathrm{kg}$ include heavy oil as an auxiliary feedstock.

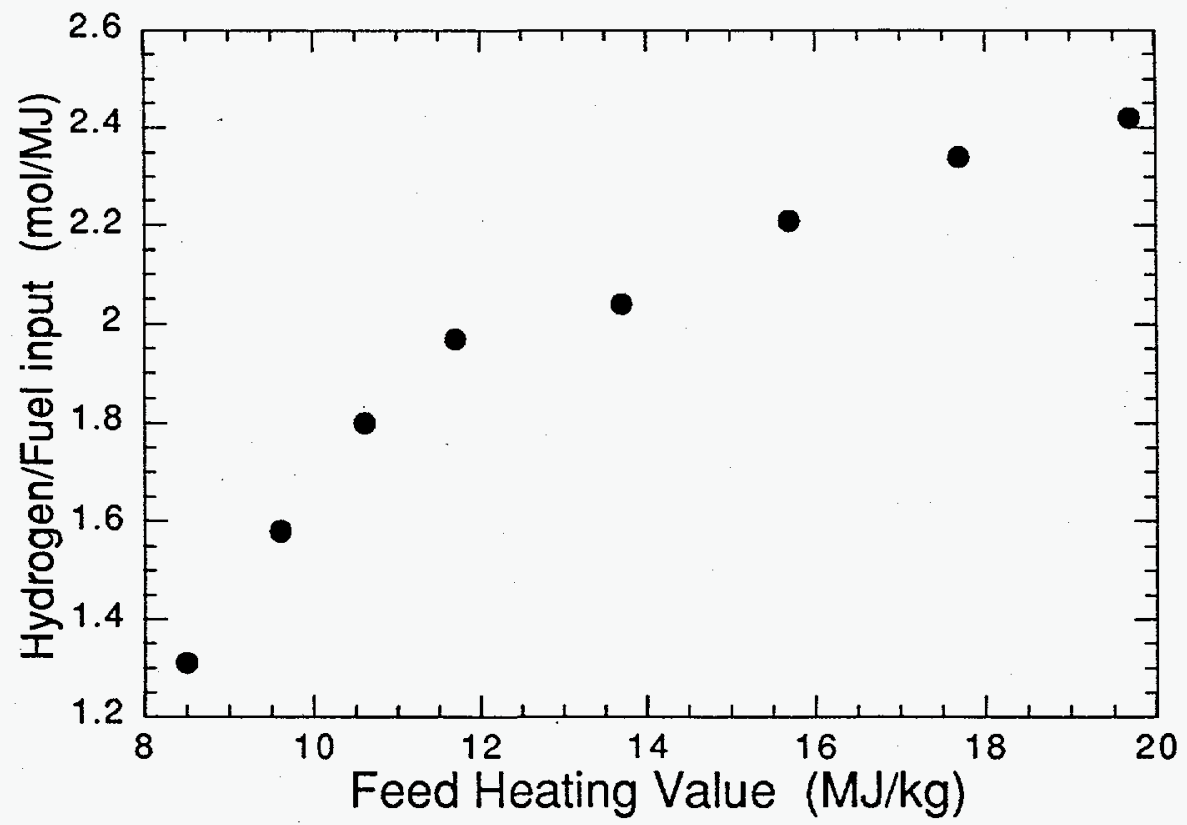

Figure 24 Computed ratio of hydrogen product to total heating value of feed entering the gasifier as a function of the net heating value of the gasifier feed. Results for heating values above $13 \mathrm{MJ} / \mathrm{kg}$ include heavy oil as an auxiliary feedstock.

The calculations indicate that fairly good gasifier performance is achieved as the net heating value approaches $20 \mathrm{MJ} / \mathrm{kg}$. At some point the addition of more fuel will cause the gasifier to operate too fuel rich or too hot. This occurs as the effluent carbon dioxide 
and steam concentrations fall towards zero. The computed result indicate that there is still plenty of these constituents left in the product even for the highest heating value feedstock used.

It is of interest to compare the energy available in the by-product fuel gas with the energy required to raise the steam used in the hydrothermal process. Results in the previous sections indicate that the 2600 tonne/day raw MSW can be hydrothermally processed using $11-16 \mathrm{~kg} / \mathrm{s}$ of high pressure steam. Assuming this is $320 \mathrm{C}$ saturated steam and is raised from $100 \mathrm{C}$ water the energy requirement is $2.3 \mathrm{MJ} / \mathrm{kg}$, and thus the total energy needed to raise the required steam flow is $25-37 \mathrm{MW}$. It appears that the by-product fuel gas could provide a substantial fraction of the energy needed to raise the steam.

Another source of energy within the process which could be tapped to raise high pressure steam is in the gasifier unit. It has been assumed in the gasification model computations that the hot gas, $1425 \mathrm{C}$, exiting the active gasification zone will be quenched by passing it through a water bath. This method of quenching is the simplest and allows operation with the widest variation in ash properties. An alternate means of cooling the gas would be to use a heat recovery heat exchanger to extract energy prior to water quenching. Assuming a working temperature of $300 \mathrm{C}$ about $60-70 \mathrm{MW}$ of energy could be extracted. This is roughly twice the energy needed to raise the steam required in the hydrothermal process unit.

\section{$\underline{\text { SUMMARY }}$}

A conceptual hydrothermal process in which direct steam heating is used to raise MSW to the required reaction temperature is capable of producing product slurries in the range of interest for gasification, 35-55 wt.\% solids. Computations indicate that slurries at the lower end of this range can be produced with no waste water cleanup since all condensate is added back to the product. At the higher end, some waste water treatment would be needed, although no net water would be produced. In this mode of operation condensate from the cooling operation could be cleaned sufficiently to supply water for the steam generator.

It appears that the use of multiple pressure vessels working together to recover waste heat would be the most efficient arrangement for direct steam heating of MSW in a hydrothermal processing scheme. Although a more complete design and accompanying economic evaluation is needed, it appears that a system in which two preheat stages are used is probably near the optimum.

For systems in which preheat beds are used to capture waste heat there is an optimum pressure for operation of the companion intermediate pressure letdown stages. For a system including two preheat bed the optimum intermediate letdown pressure is 2.6 $\mathrm{MPa}$ for the system studied. In this system the maximum system pressure was $10 \mathrm{MPa}$ in the reaction stage. 
It is advantageous to operate the reaction stage somewhat above the minimum pressure which would maintain the water phase. This reduces the steam requirements at the expense of operating at a slightly higher pressure. Operating the reaction stage 1.5-2. $\mathrm{MPa}$ above the vapor pressure of water at the desired reaction temperature appears to be a good compromise between steam savings and increased operating pressure.

The efficiency of the heat recovery using preheat beds is a very weak function of pressure difference between gas source beds and preheat beds. Consequently, the process can accommodate nearly any pressure differential needed to drive the required gas flows.

Pressure drop within vessels and potential entrainment is a concern. The most severe conditions are present in the final pressure letdown stage of the process. It is estimated that an effective bed permeability of 2200 darcy or more is required to insure that pressure drop within the vessel is not a problem. Velocities in this vessel have the potential of entraining particles 100 microns or less in size.

Interchange of heat between vessel walls and interior would reduce the efficiency of the process. For the two preheat bed case the difference between complete adiabatic operation and complete equilibration of vessel contents and wall results in an increase of steam requirements of $40 \%$. The manner in which heat would move from vessel contents to wall is fairly complicated and additional work would be needed to determine the exact impact of the vessel walls on the process efficiency.

The wetter the MSW feed the less efficient the process. For the same operating conditions increasing the MSW feed water content from 25 to $35 \mathrm{wt} . \%$ increases the steam requirement by about $15 \%$.

Using heavy oil, or other low cost fuel, as an additional feedstock to increase the efficiency of the gasification of the product slurry needs to be considered. A slurry containing $42.3 \mathrm{wt}$. \% solids can be produced assuming adiabatic operation of a two preheat bed system needing no waste water treatment. Gasifying this slurry on its own would produce $0.49 \mathrm{kmol} / \mathrm{s}$ of hydrogen from $30 \mathrm{~kg} / \mathrm{s}$ of raw MSW, with a produced hydrogen to consumed oxygen mole ratio of 0.9 . Adding $16 \mathrm{~kg} / \mathrm{s}$ of heavy oil feedstock to the gasifier along with the $37 \mathrm{~kg} / \mathrm{s}$ of slurry would result in the production of 2.6 $\mathrm{kmol} / \mathrm{s}$ of hydrogen with a hydrogen/oxygen ratio of 2.6 . 


\section{REFERENCES}

1. C.B. Thorsness, Process Modeling of Hydrogen Production from Municipal Solid Waste Lawrence Livermore National Laboratory, Livermore Calif., UCRL-ID-119231 (1994).

2 Daizo Kunii and Octave Levenspeil, Fluidization Engineering , (Robert E. Krieger Publishing Company, Hunington, New York, 1977), page 76.

3 Stanley Walas, Chemical Process Equipment Selection and Design, (ButterworthHeinemann, Boston, 1990), page 438. 


\section{APPENDIX I}

\section{VAPOR PRESSURE CURVES FOR WATER}

In Table I-1 the vapor pressure and heat of evaporation for water estimated by ASPEN PLUS's SYSOP8A property set is compare to steam table values. The steam values were also obtained from ASPEN PLUS using the SYSOP12 option.

Table I-1. ASPEN PLUS SYSOP8A steam properties compared to steam table values.

\begin{tabular}{|c|c|c|c|c|}
\hline \multirow[b]{3}{*}{$\begin{array}{l}\text { Temperature } \\
\text { (C) }\end{array}$} & \multicolumn{2}{|c|}{ Steam Table Data } & \multicolumn{2}{|c|}{ SYSOP8A Properties } \\
\hline & Vapor & Heat of & Vapor & Heat of \\
\hline & $\begin{array}{c}\text { Pressure } \\
(\mathrm{kPa})\end{array}$ & $\begin{array}{c}\text { Evaporation } \\
(\mathrm{MJ} / \mathrm{kmol})\end{array}$ & $\begin{array}{c}\text { Pressure } \\
(\mathrm{kPa})\end{array}$ & $\begin{array}{c}\text { Evaporation } \\
(\mathrm{MJ} / \mathrm{kmol})\end{array}$ \\
\hline 20 & 2.3361 & 44.041 & 2.4092 & 43.926 \\
\hline 30 & 4.2413 & 43.620 & 4.3125 & 43.537 \\
\hline 40 & 7.3754 & 43.196 & 7.4378 & 43.141 \\
\hline 50 & 12.337 & 42.768 & 12.399 & 42.736 \\
\hline 60 & 19.924 & 42.335 & 19.981 & 42.323 \\
\hline 70 & 31.169 & 41.894 & 31.208 & 41.901 \\
\hline 80 & 47.372 & 41.446 & 47.366 & 41.470 \\
\hline 90 & 70.130 & 40.988 & 70.042 & 41.028 \\
\hline 100 & 101.36 & 40.520 & 101.14 & 40.576 \\
\hline 110 & 143.31 & 40.039 & 142.92 & 40.113 \\
\hline 120 & 198.61 & 39.545 & 197.95 & 39.638 \\
\hline 130 & 270.21 & 39.035 & 269.20 & 39.150 \\
\hline 140 & 361.46 & 38.507 & 359.96 & 38.649 \\
\hline 150 & 476.13 & 37.961 & 473.91 & 38.133 \\
\hline 160 & 618.20 & 37.393 & 615.03 & 37.601 \\
\hline 170 & 792.13 & 36.802 & 787.79 & 37.053 \\
\hline 180 & 1002.7 & 36.186 & 996.73 & 36.486 \\
\hline 190 & 1255.1 & 35.542 & 1246.8 & 35.899 \\
\hline 200 & 1554.7 & 34.868 & 1543.7 & 35.290 \\
\hline 210 & 1907.3 & 34.161 & 1892.6 & 34.657 \\
\hline 220 & 2318.9 & 33.774 & 2299.7 & 33.997 \\
\hline 230 & 2796.0 & 33.459 & 2771.2 & 33.307 \\
\hline 240 & 3346.2 & 33.113 & 3313.7 & 32.583 \\
\hline 250 & 3975.4 & 32.734 & 3934.9 & 31.819 \\
\hline 260 & 4691.5 & 32.323 & 4641.5 & 31.010 \\
\hline 270 & 5502.3 & 31.878 & 5441.8 & 30.149 \\
\hline 280 & 6416.1 & 31.397 & 6344.5 & 29.225 \\
\hline 290 & 7441.3 & 30.873 & 7358.9 & 28.225 \\
\hline 300 & 8589.4 & 30.297 & 8494.9 & 27.130 \\
\hline 310 & 9867.8 & 29.654 & 9763.5 & 25.914 \\
\hline 320 & 11289. & 28.838 & 11180. & 24.537 \\
\hline 330 & 12865. & 27.900 & 12754. & 22.933 \\
\hline 340 & 14610. & 26.856 & 14502. & 20.984 \\
\hline 350 & 16527. & 25.675 & 16442. & 18.438 \\
\hline
\end{tabular}

